\title{
طرق تدريس وتقييم طلبة الدراسات العليا في القانون: نحو بناء القدرات والخبرات
}

* أ. د. فوزي بن أحمد بالكناني

| الملخص:

تسعى هذه الورقة البحثية إلى معالجة الأزمة المزمنة التي مازالت جل كليات القانون

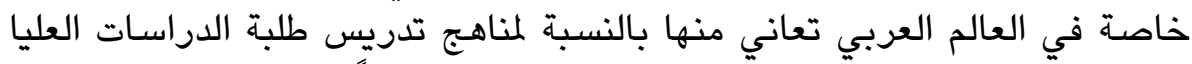

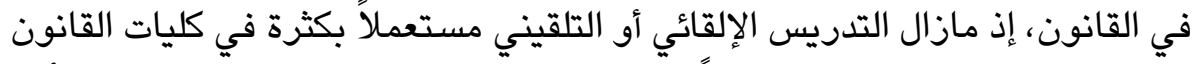

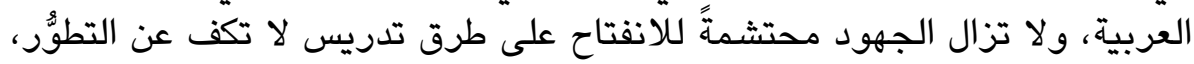

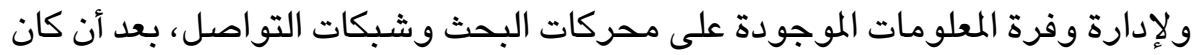

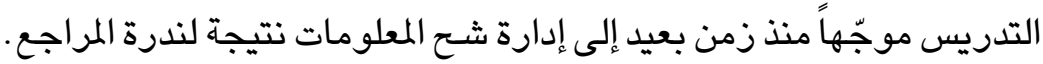

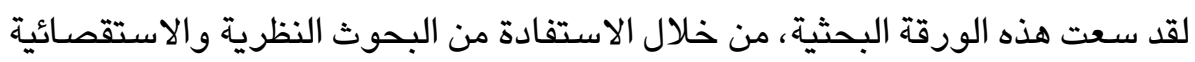

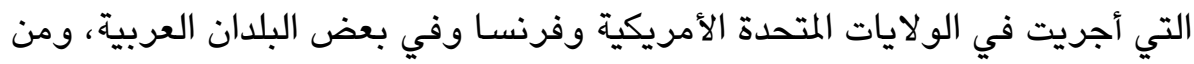

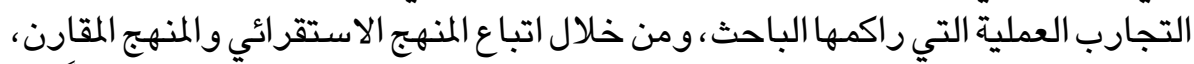

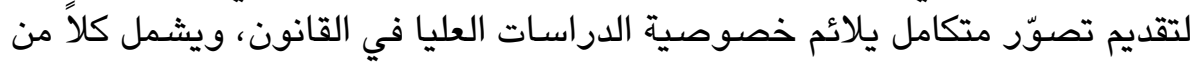

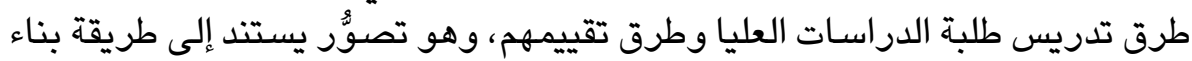

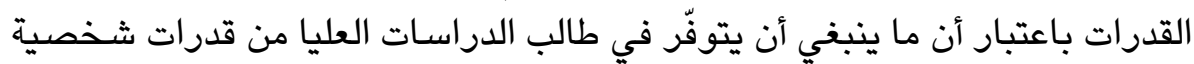

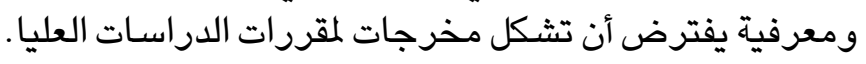

وقد توصّلت هذه الورقة البحثية إلى استخلاص آليات تدريس طلبة الدراسات العليا

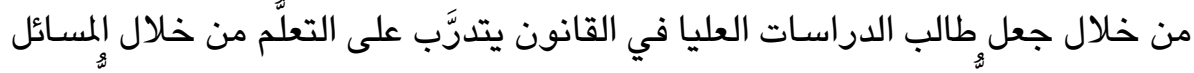

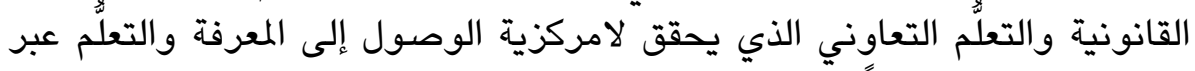

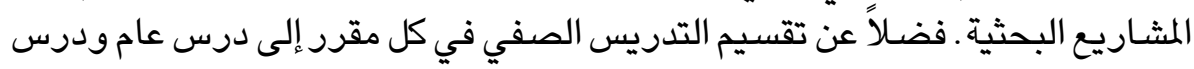

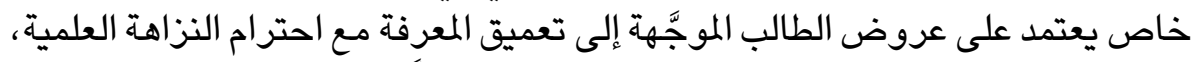

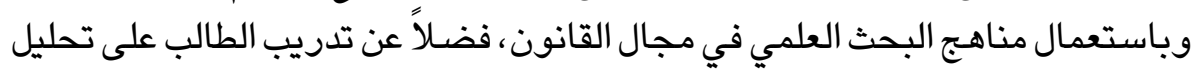
الأفكار ، وعلى النقد أي التقييم المستند إلى تبريرات التحان قانونية ومنطقية.

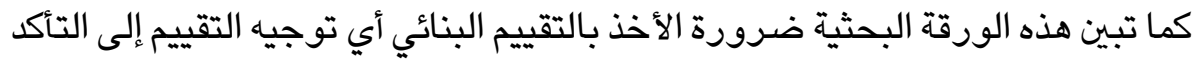
من اكتساب طلاب الدراسات العليا في القانون للقدرات المطلوبة أي إلى التقويم، التئ، باعتبار

* أستاذ القانون المدني، كلية القانون، جامعة قطر. 
التقييم أحد عناصر عملية التدريب واكتساب المهارات المعرفية والسلوكية المطلوبة،

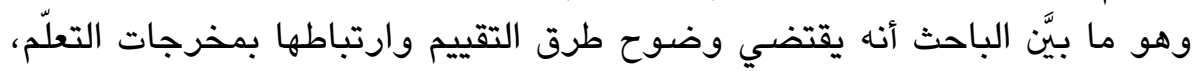
ويقتضي كذلك استعمال آليات مختلفة في كل من التكليفات والمشاريع وارئ البحثية من جهة والاختبارات من جهة أخرى.

وتسعى هذه الورقة البحثية إلى توجيه كل من تدريس وتقييم طلبة الدراسات العليا

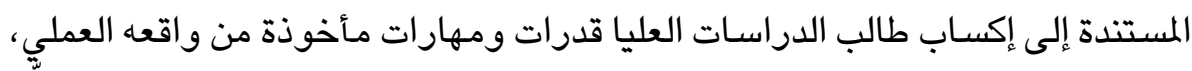

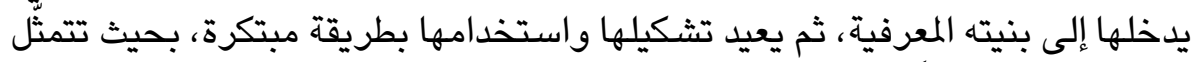

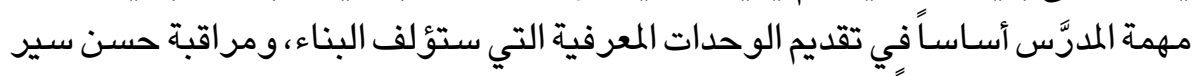

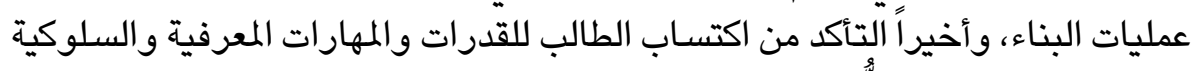

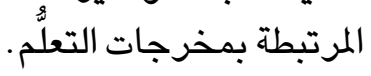
كلمات دالة: منهجية قانونية، تدريس دراسات عليا، تقييم وتقويم، بناء قدرات ومهارات، المشاريع البحثية. داله: منهية 


\section{المقدمة:}

لا تخلو كتب الأوّلين، من ذكر ما كان ينجم عن التدريس قديماً من اختلال في العلاقة

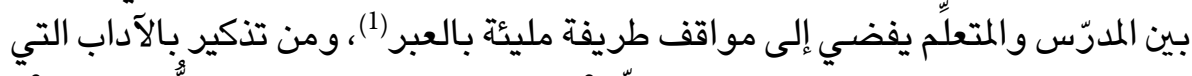

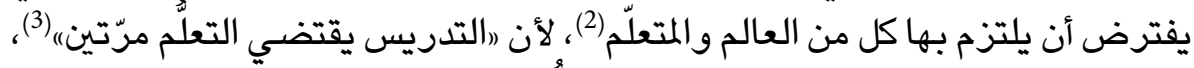

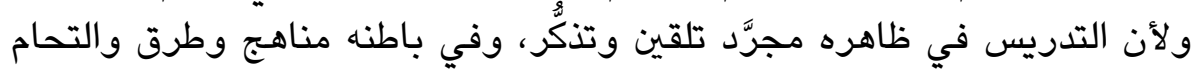
بتكنولوجيا قد لا يكون المدرّس شـبّ عليها.

ومـع ذلك يطالب المدرس، بالانفتاح على طرق تدريس لا تكف عن التطور، ويمواكبة الجديد من وسـائل التواصل، وفي التدريس للمحافظة على نجاعة أدائه التدريسي

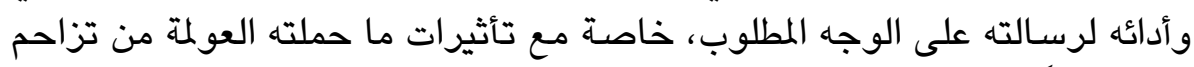

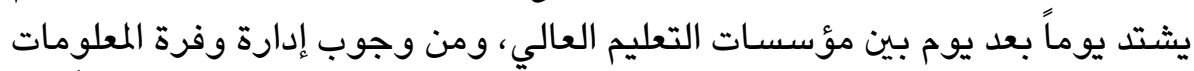

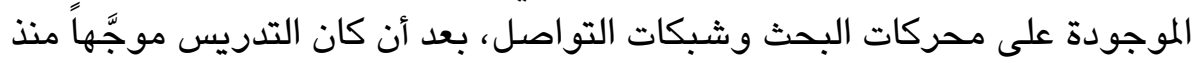
زمن بعيد إلى إدارة شَح المعلومات نتيجة لندرة المراجح(4). وفي المقابل أورد تقرير التنمية البشرية العربية لسنة 2003 أن : (انوعية التعليم المقدم في مؤسسـات التعليم الجامعي والعالي في البلدان العربية تتأثر بعوامل كثيرة من أهمها: عدم وضوح الرؤية، وغياب سياسـات واضحة تحكم العملية التعليمية، وقلة الموارد

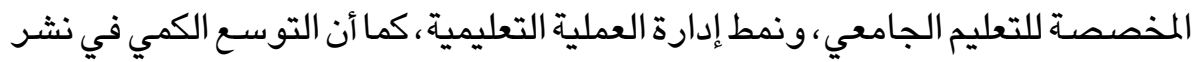
التعليم العالي جاء على حسـاب نوعيته وجودته(5)، بينما ورد في تقرير التنمية البشرية

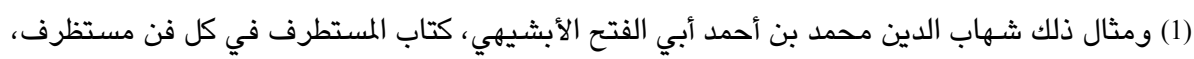

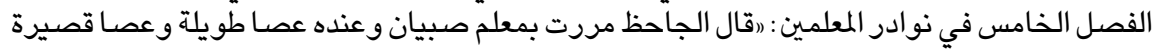

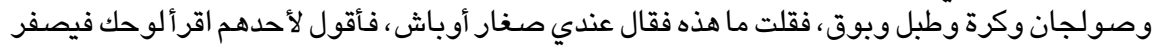

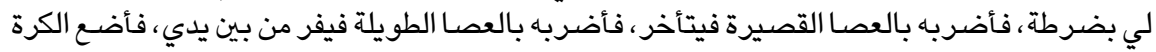

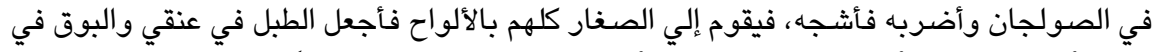

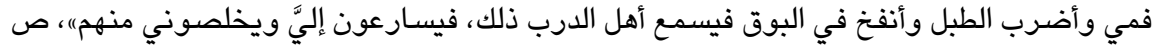

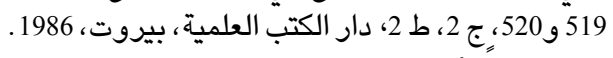

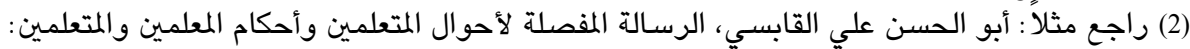

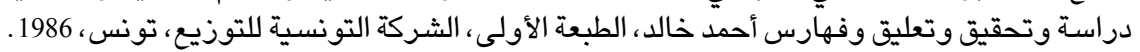

(3) Joseph Joubert: De l'éducation, LXVIII (1866), «Enseigner, c'est apprendre deux fois».

(4) Juan Campechano Covarrubias: the globalization effects on the quality of higher education, the Mexican case, national executive committee, national teachers trade union, mexico, 2004.

(5) تقرير التنمية البشرية 2003 http://hdr.undp.org/en/media/hdr03_complete.pdf ؛ علي نصار، التعليم

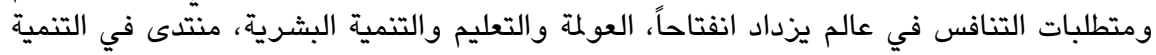

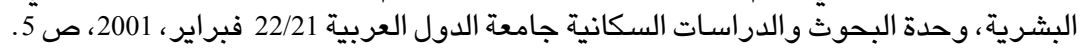


لسنة 2015 أنّ : راليوم هو زمن المهارات المتخصصـة والتعليم المناسب، لأن العاملين بهذه

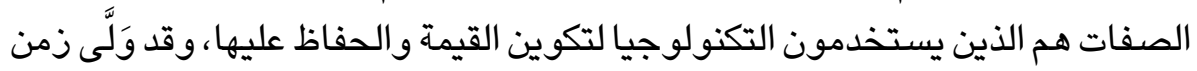

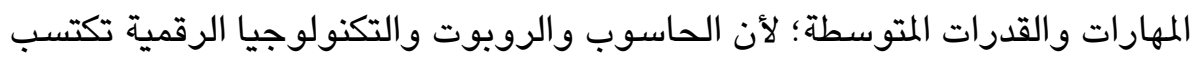
هذه المهارات والقدرات بسرعة فائقة)،(6). إن ما سبق يجعل جودة التعليم ترتبط بمدى تحقيق مخرجات البرامج التعليمية والمقررات في الخريجين من خلال إكسابهم أهم القدرات المعرفية والابتكارية التي تسـاعدهم على لى إيجاد الحلول للمسـائل التي تطرح عليهم في مجال تخصصـهم، وإكسـابهم أهم المهارات التي تسـاعدهم على التكيف في بيئات العمل المختلفة التي قد يشتغلون فيها(7)، وتلك جودة

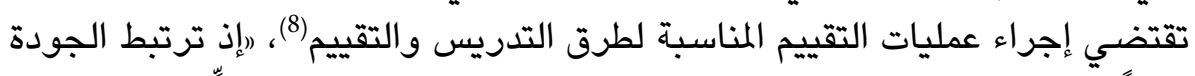

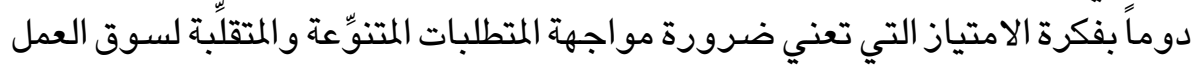

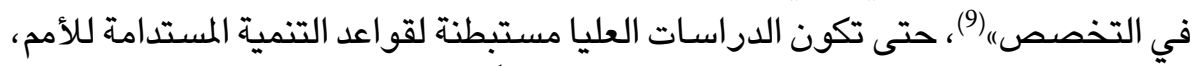
ومنتجة للقيادة العلمية والعملية للمجتمعات انطلاقاً من تراثها العلمي والعملي (10. وقد بيَّتت بعض البحوث أنَّ التدريس يقوم على إثارة الاهتمام لدى الطالب وتوجيه

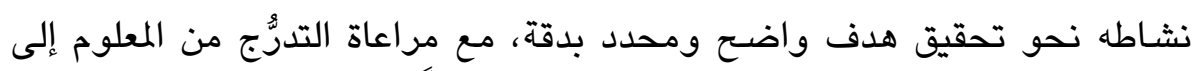

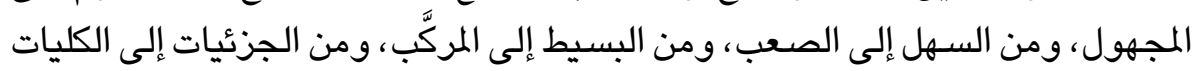

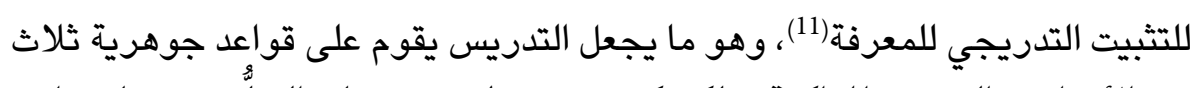

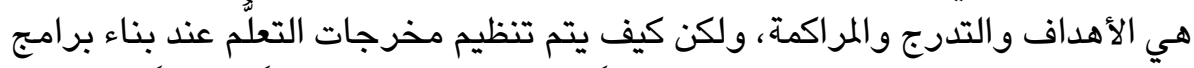

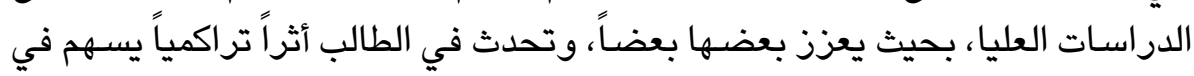
(6) يراجع: تقرير التنمية البشرية 2015، التنمية في كل عمل، لمحة عامة، ص 10، منشور على الموقع

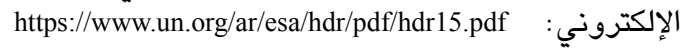

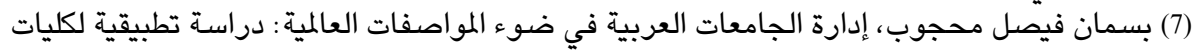

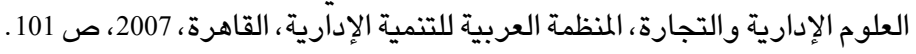

وراجع كذلك:

Dale H. Biesterfield \& others, Total Quality management, Columbus, Ohio, upper sadder River, 1999, p5; James R. Evens. \& William Lindsay, The Management and Control of Quality, South Western College, Publishing,1999, p.11.

(8) Nina Becket \& Maureen, Analyzing Quality Audits in Higher Education, Brookes journal of Learning and Teaching, Volume 1, Issue 2, 2005.

(9) Peter Jackson \& David Asheton, Achieving Besom I so 9000, India, Kagan page, 1996, p.15.

(10) Jahm Radford \& Others, Quantity and Quality in higher Education, Athenaeum press, 1997, p52.

(11) Herbert spencer, Education - Intellectual - Moral and Physical, New York, D. Appleton and Company, 1,3, and 5 Bond Street, 1891. 
تحقيق جودة التعليم(12)؟ وكيف ساهم السعي الدؤوب إلى جودة التعليم في تطوير كل

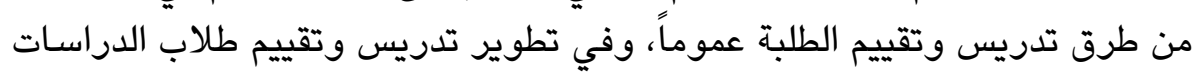

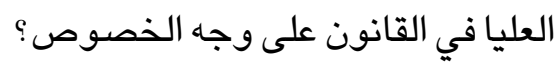

تهدف هذه الدراسة إلى الاستفادة من البحوث النظرية والاستقصائية، ومن التجارب

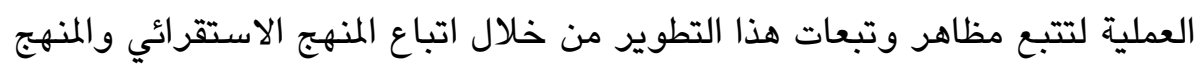

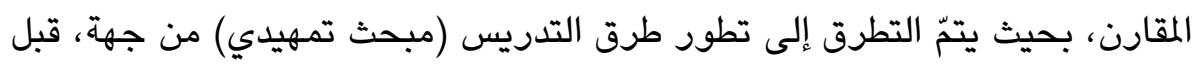

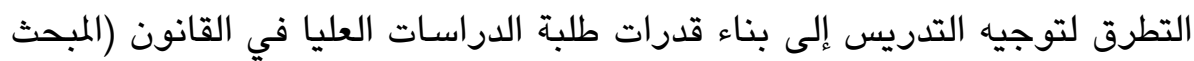

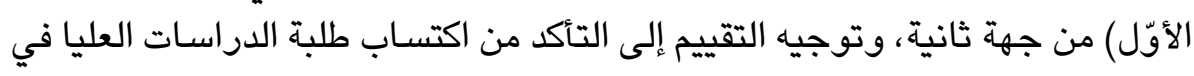
القانون للقدرات المطلوبة (المبحث الثاني) من جهة ثالثة.

(12) Irving A Taylor, A theory of Creative Trans Actualization, A Systematic Approach to Creativity with Implications for Creative Leadership (Creative Education Foundation, occasional paper, 1972, 8, pp. 103-104. 


\section{مبحث تمهيدي \\ تطوّر طرق التدريس}

يجوز الحديث عن طرق تدريس كبرى ثلاث أقدمها طريقة التدريس الإلقائي أو الإخباري أو التلقيني (المطلب الأول)، تليها الطريقة السلوكية للتدريس (المطلب الثاني)، وآخرها طريقة بناء القدرات (المطلب الثالث).

\section{المطلب الأول \\ طريقة التدريس الإلقائي أو الإخباري أو التلقيني \\ Pédagogie magistrale}

تعتمد هذه الطريقة التقليدية في التدريس على المدرّس باعتباره هو مَنْ ينقل المعرفة، معتمداً

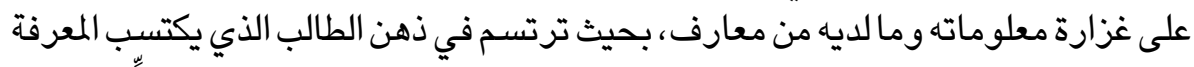

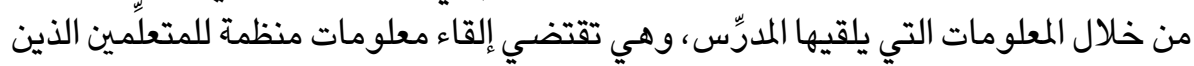

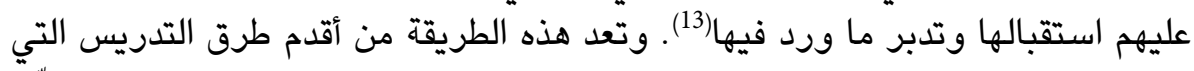

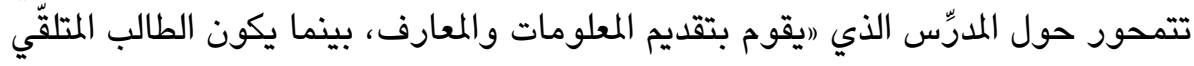

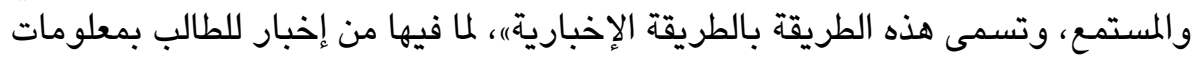

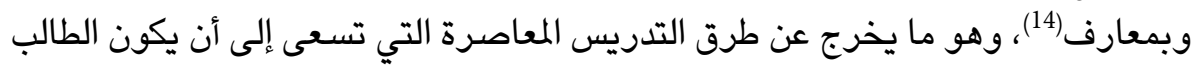

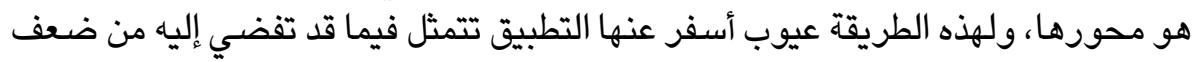

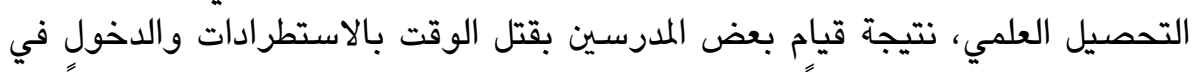

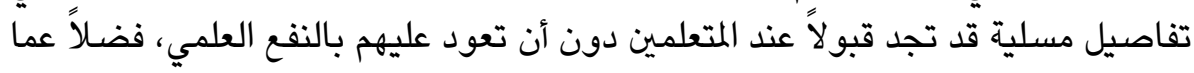

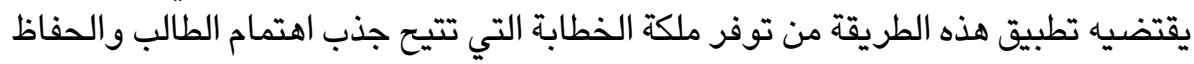

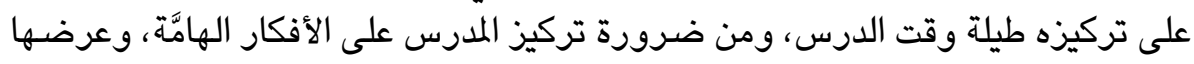

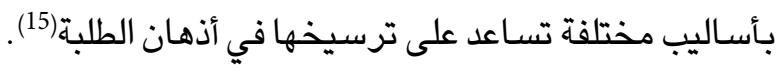

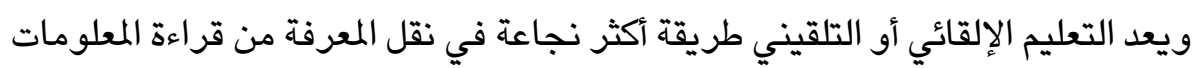

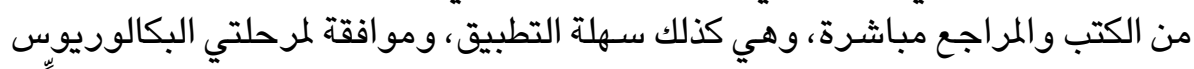

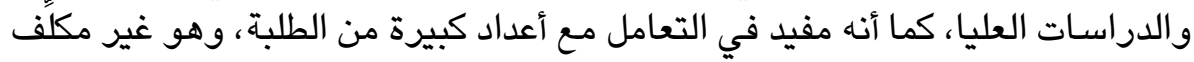

(13) Estelle Blanquet \& Éric Picholle, Démarche d'investigation, pédagogie transmissive et principe d'autorité: l'exemple du système héliocentrique, Revue recherches en éducation, №34 - Novembre 2018, pp. 62 - 74.

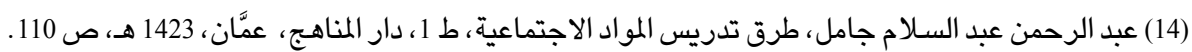

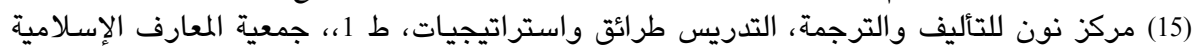

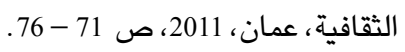


لكونه لا يحتاج إلى مواد أو وسائل تعليمية كثيرة، خلافاً لطرق التدريس الأخرى. ولكن من أهم عيوب التعليم الإلقائي صعوبة استمرار لفت انتباه جميع الطلبة إلى المدرّس؛

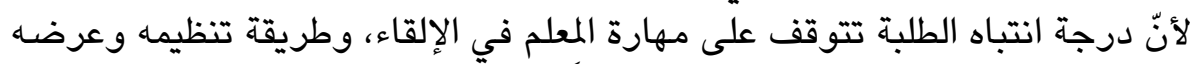

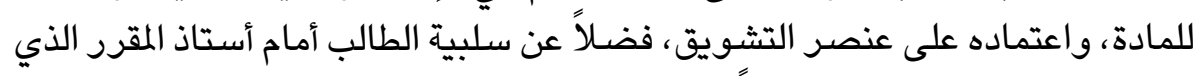

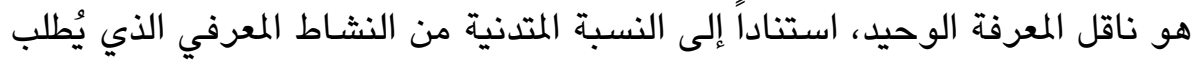
عادة منه (حسن إعادة ما قيل) أو المنهجي (تدوين رؤوس أقلام) فيما يتعلق بالكفايات

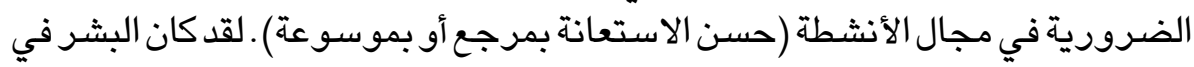

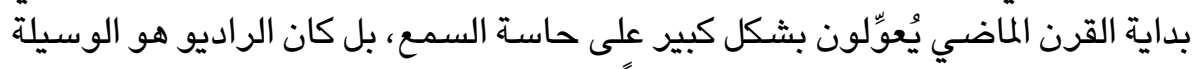

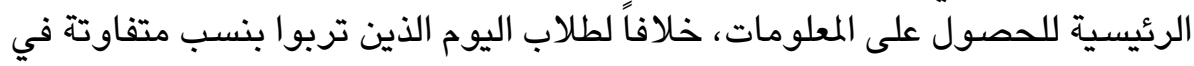

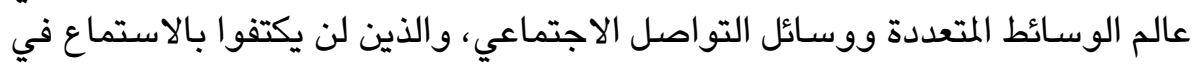

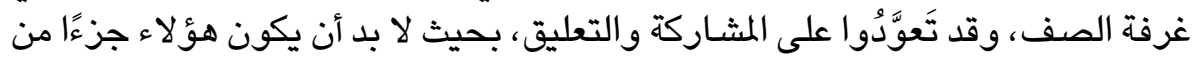

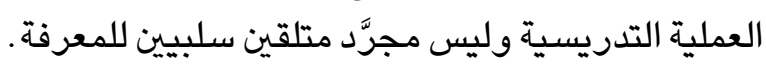
كما أنَّ الإلقاء يُهمل ما بين الطلبة من فروق فردية، و لا يُعنى فيه المدرِّس سوى بالمتوسطين

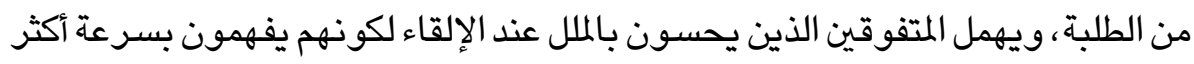

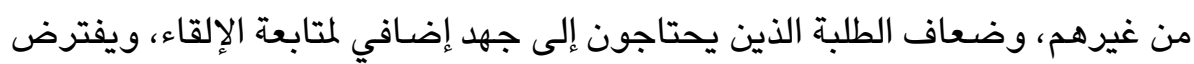

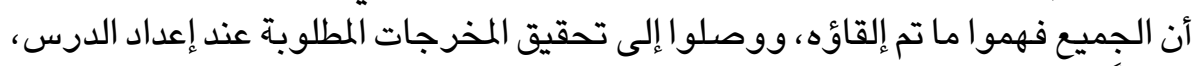

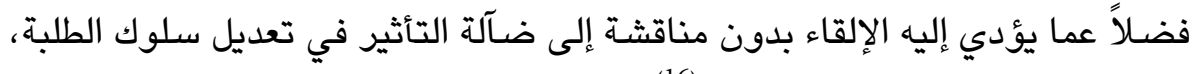
وتكوين عادة التفكير المنطقي السليم (16).

\section{المطلب الثاني}

\section{الطريقة السلوكية للتدريس الطبس}

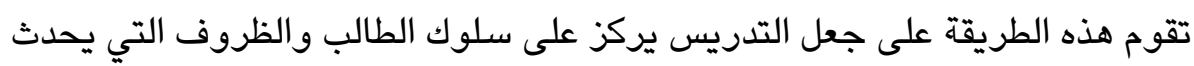

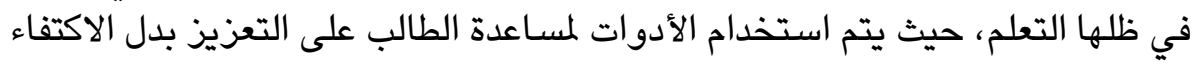
بالإلقاء، لأن الملارس غير قادر على تحقيق هذا التعزيز لوحده، وتسـاعده تقنية التعليم

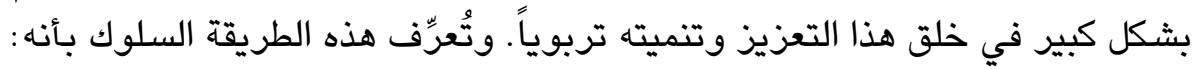

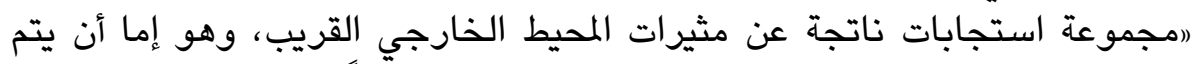

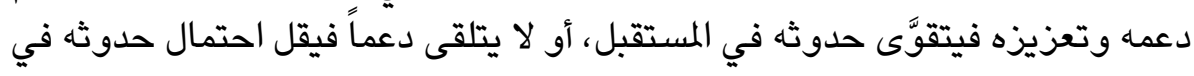

(16) أحمد محمد عبد القادر، طرق التدريس العامة، ط 8، مكتبة النهضية المصرية ، القاهرة، 1419 هـ - مكت

1999 م، ص صد 83 
المستقبل)|(17). كما ترى هذه الطريقة أن تلقي المحفِّزات والمكافآت يدعم السلوك ويثبته،

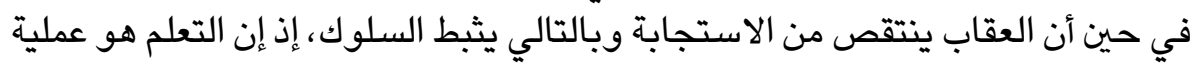

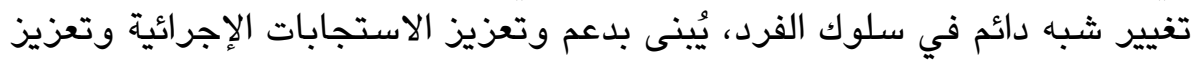

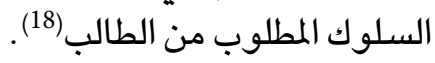

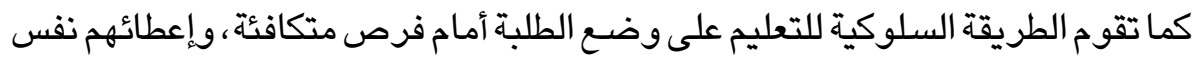

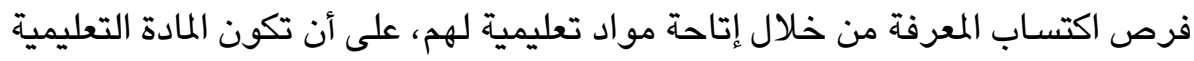

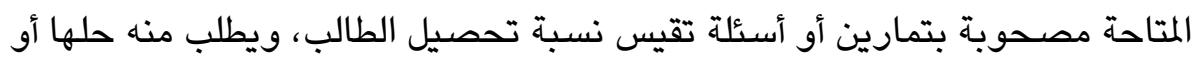

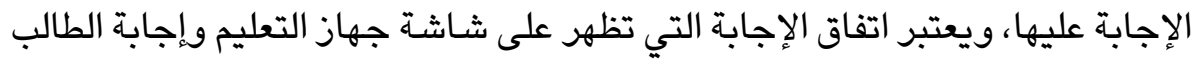

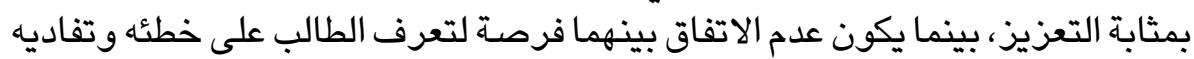

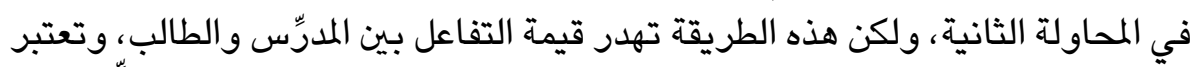

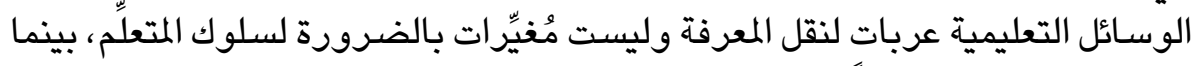

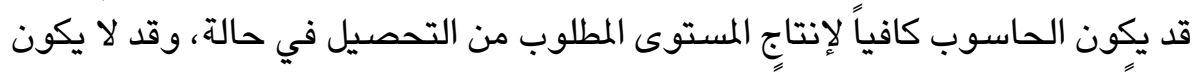

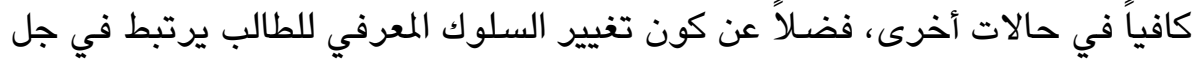

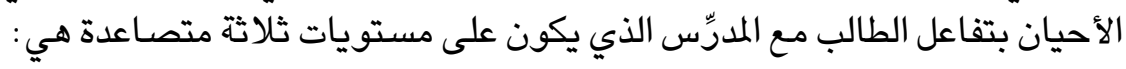

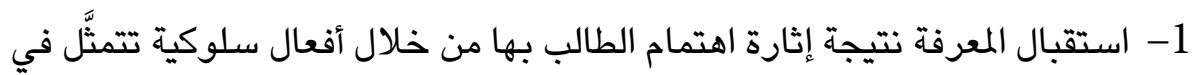
إبداء الاهتمام بالاستفسار ، والمشاركة.

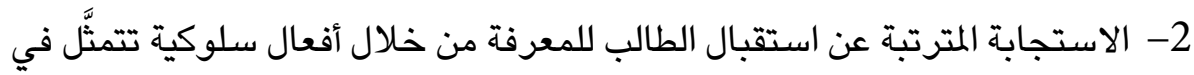

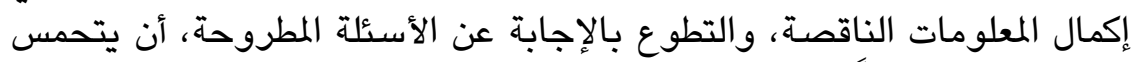

$$
\text { للقيام بتكليفات تتعلَّق بالمعرفة المقصودة التطوع بالإنات }
$$

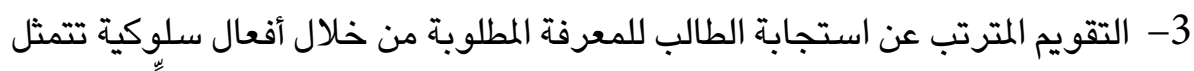

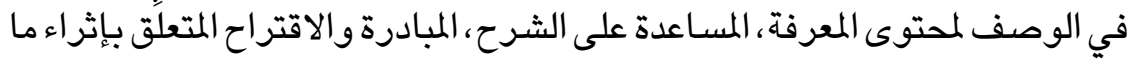

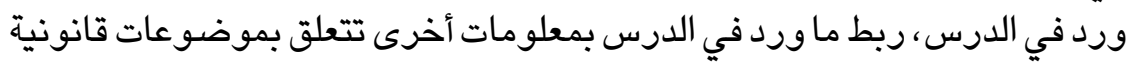

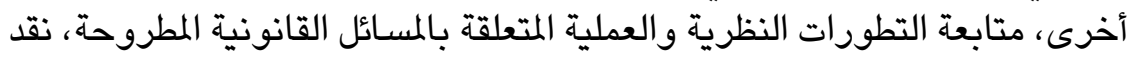

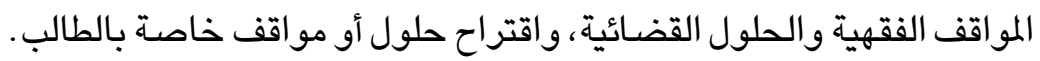

(17) Padly-al-Patani, Introduction of Psychology, Behaviorism, May 2014, https://www.academia. edu/9426444/Behaviorism.

$$
\text { (18) رشيد التلواتي ، نظريات التعلم : الملدرسـة السلوكية ، منشور على الموقع التالي : }
$$

https://www.new-educ.com/behaviorisme-et-de-sa-relation-a-leducation-de-la-technologie 


\section{المطلب الثالث}

\section{طريقة بناء القدرات Constructivism}

تكمن نقطة ارتكاز هذه الطريقة في الطالب، وهي تقوم على بناء قدراته(19) من خلال

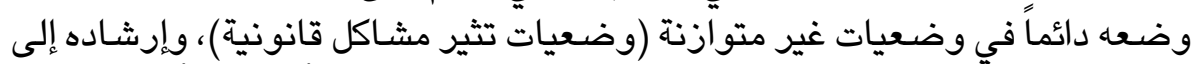

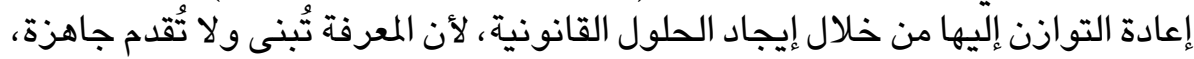
تقتضي هذه الطريقة البدء بمرحلة تنشيط المعارِف السابقة (Phase d'Activation)

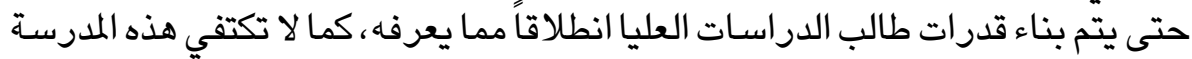

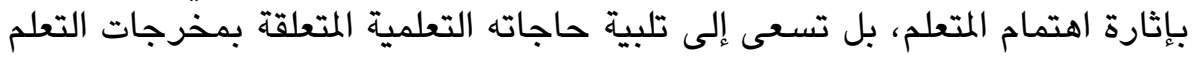
بطريقة فعالة.

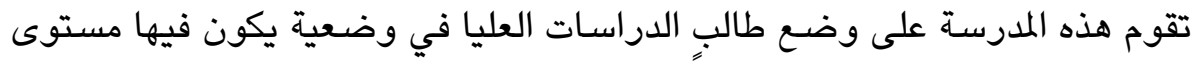

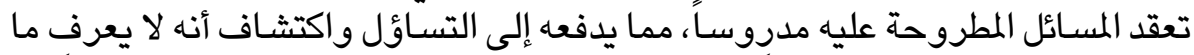

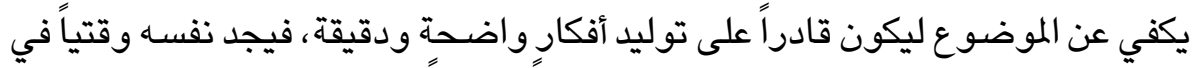

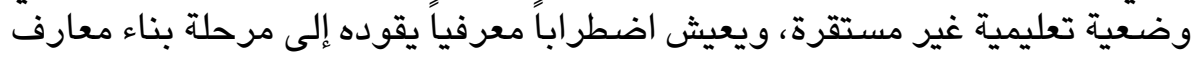

جديدة (Phase D'Élaboration).

كما تقوم هذه الطريقة على مساعدة الطالب على استخلال استراتيجيات التعلُم الشخصية وتطويرها بها فهدف بناء قدرات تسمى المعارف الإجرائية (Connaissances procédurales)

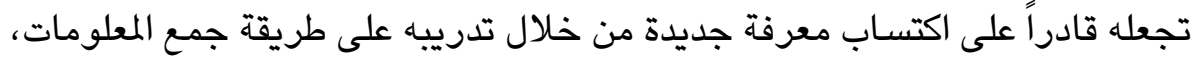

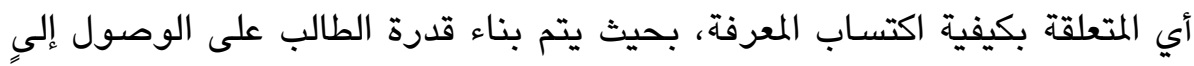

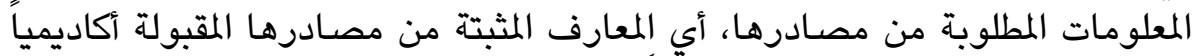
(Connaissances déclaratives)

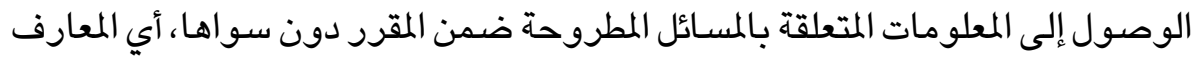
المشروطة (Connaissances Conditionnelles)

إن هذه الاستراتيجيات المتباينة تقتضي بناء قدرات ومهارات متباينة يستخدمها

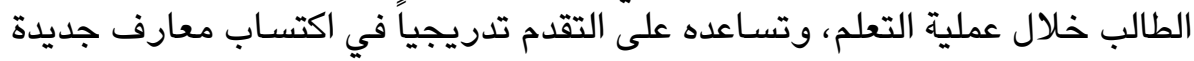

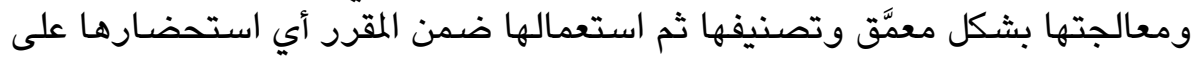

(19) Philippe Meirieu, Apprendre... oui, mais comment, ESF Éditeur, Paris, 5eme édition augmentée d'un guide méthodologique et d'un nouveau glossaire, février 1990, p. 27.

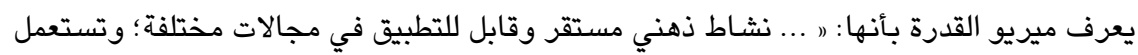

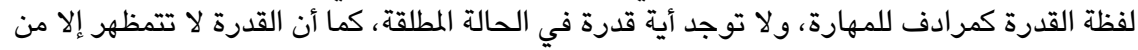

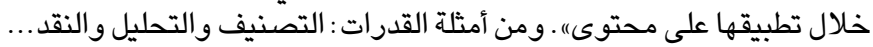

(20) Domenico Masciotra, Le Constructivisme En Termes Simples, Revue Vie pédagogique no 143 Avril et Mai 2007, pp 48 - 52. 
نحو مناسب خلال الوضعيات التعليمية(21)، بحيث تتيح للطالب بناء علاقات متينة

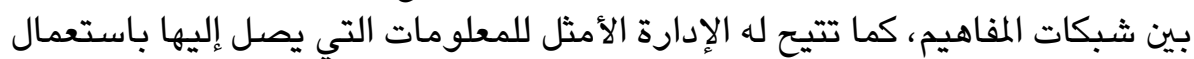

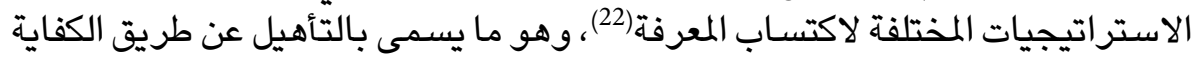
(Formation par Competences)

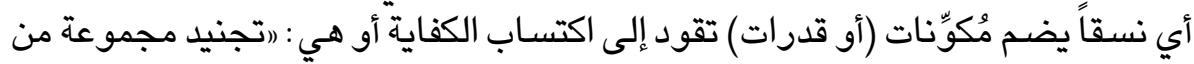

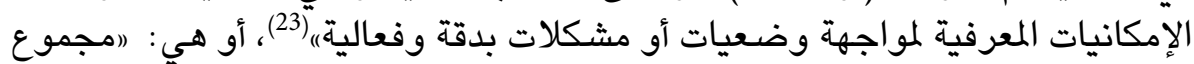

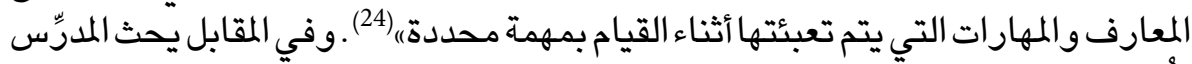

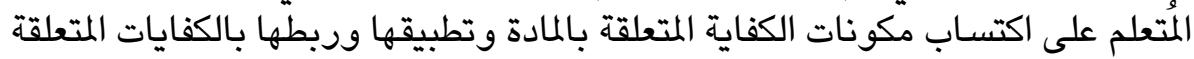

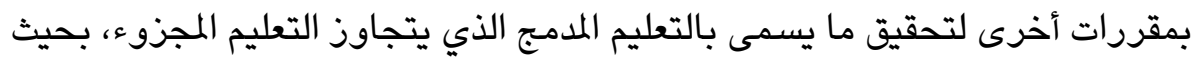

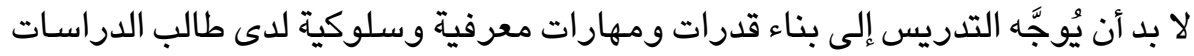

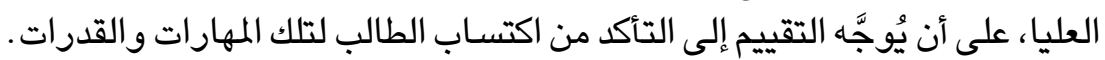
ويمكن إجمال القدرات المعرفية التي يفترض أن يكتسبها طالب الدراسـات العليا فيما يلي : 1- القدرة على التحليل القانوني الدقيق والصـارم للنصوص القانونية والأحكام

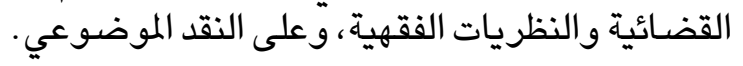

2- القدرة على تصور حل قانوني واضَح ومنطقي يستجيب للمعايير الأكاديمية،

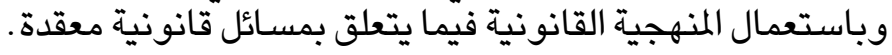

3- القدرة على التعامل مع عدم وضوح الحلول القانونية (المسـائل القانونية المفتوحة). 4- القدرة على التواصل والاقناع (عند الإلقاء، وعند الكتابة). 5- القدرة على التعلم من العمل ضـمن مجموعة.

إن تراكم المعارف والقدرات لدى الطالب الذي تدرج في اكتسـابها يتيح له القدرة على التعامل

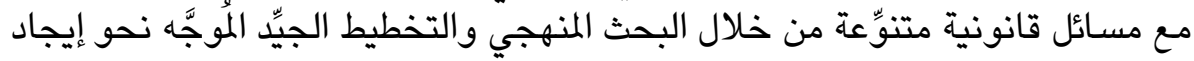

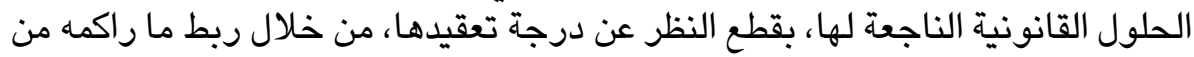

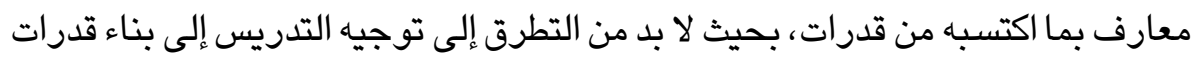

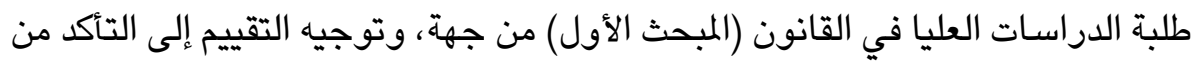
اكتساب طلبة الدراسـات العليا في القانون للقدرات المطلوبة (المبحث الثاني) من جهة مثانية ونوانية.

(21) Jacqueline Bideaud, Constructivismes, développement cognitif et apprentissages numériques, Revue Perspectives revue trimestrielle d'éducation comparée, no 118, Vol. XxX1, no 2, juin 2001, p. 205.

(22) Jean-Jacques Ducret, Constructivismes: usages et perspectives en éducation, Revue Perspectives (revue trimestrielle d'éducation comparée), no 118, Vol. XxX1, no 2, juin 2001, p .177.

(23) Philippe Perrenoud: L'université entre transmission de savoirs et développement de compétences, Texte d'une conférence au Congrès de l'enseignement universitaire et de l'innovation, Girona, Espagne, juin 2004, pp. 3 - 4.

(24) Brien, Robert: Science cognitive et formation, 3ème éd., Presses de l'Université du Québec - et sur le Web: http://www.fse.ulaval.ca/fac/ten/reveduc/html/voll/nol/scco.html. 


\section{المبحث الأول}

\section{توجيه التدريس إلى بناء قدرات طلبة الدراسات العليا في القانون}

إنَّ الإحاطة بتوجيه التدريس إلى بناء القدرات يقتضي تفصيل القول في أسس توجيه

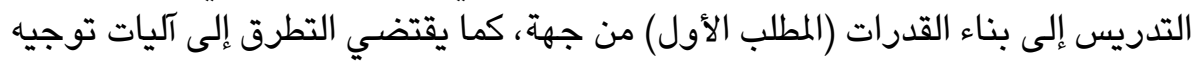
التدريس إلى بناء قدرات طلبة الدراسات العليا في القانون (المطلب الثاني) من جهة الثانية الثانية.

\section{المطلب الأول}

\section{أسس توجيه التدريس إلى بناء القدرات}

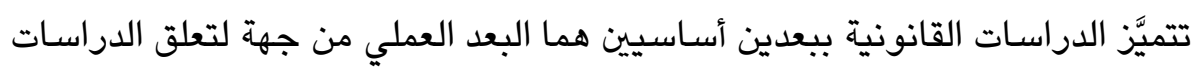

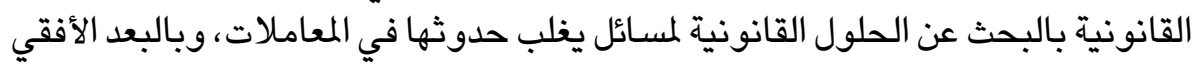

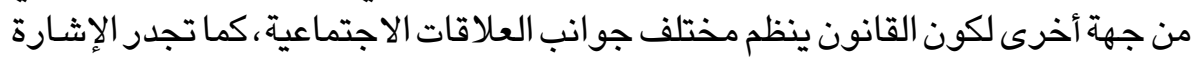

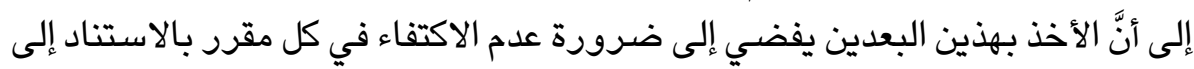

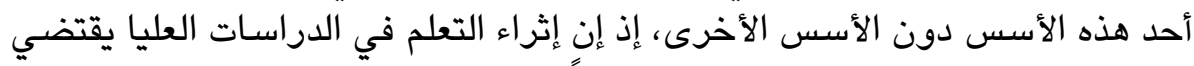

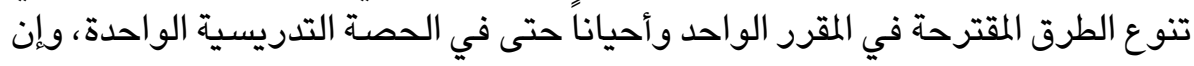

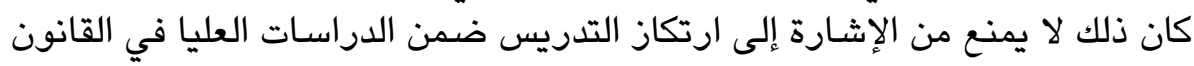

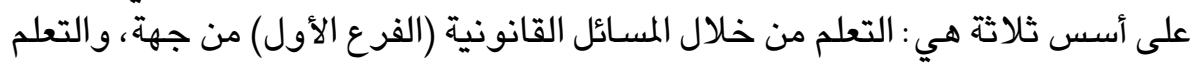

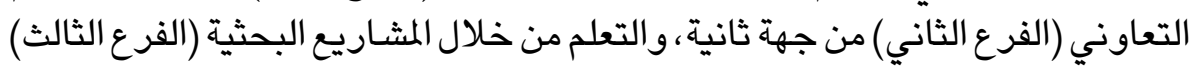
من جهة ثالثة.

\section{الغرع الأول}

\section{التعلم من خلال المسائل القانونية}

يستند هذا الأساس إلى مقومات ثلاثة هي:

1- الانطلاق من مسألة قانونية تطرح مشكلة في التطبيق، أو هي محل اختلاف فقهي أو قضائي.

2- وضـع مصادر ملائمة (وثائق، روابط، أحكام، ومقالات فقهية) في متناول الطلاب

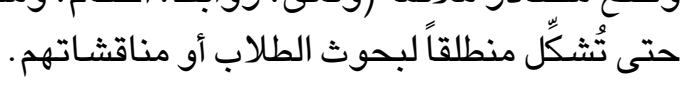

3- تكليف الطلاب بأنشطة حصر المشكل القانوني ودمج المعارف لتحليل المسألة القانونية والبحث عن حلول لها. 
كما يجب أن تستجيب المسألة المطروحة على الطلاب إلى معايير ثلاثة هي:

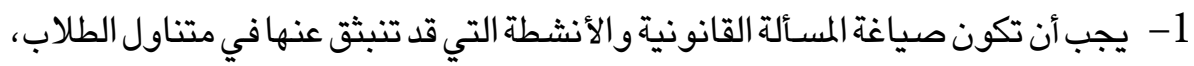

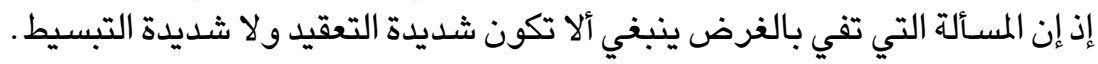

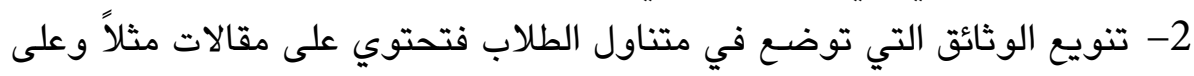

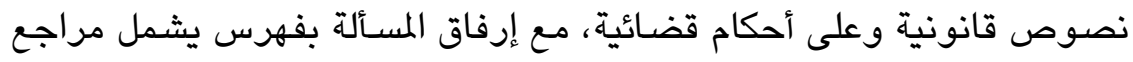
أخرى يرمي إلى تعويد الطالب على توثيق معارفها وعلى السعي إلى إلى مزيد تعميقها. 3- ضبط الخطوات المتوقعة من الطالب، مثلاً: أ. أ. فهم المشكلة القانونية.

ب. استخلاص فرضيات الحلول من المراجع والوثائق المتاحة. ج. تفسير فرضيات الحلول وتقييمها باتباع قواعد المنهجية القانونية. د. ـ صياغة الحل الأمثل وتسبيبه.

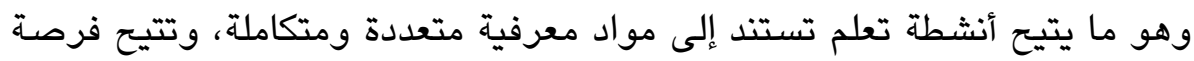

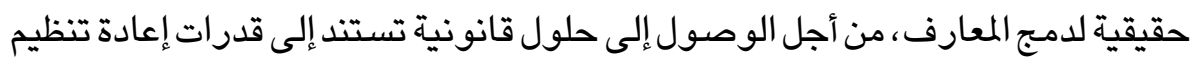

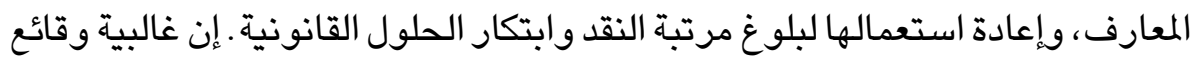

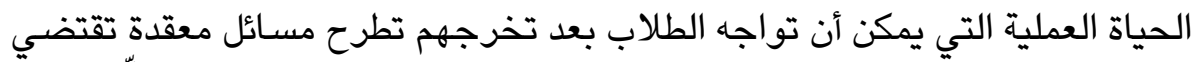

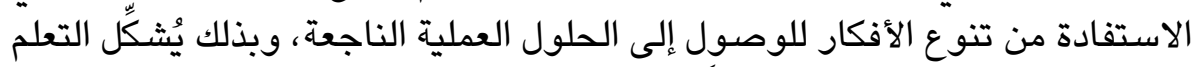

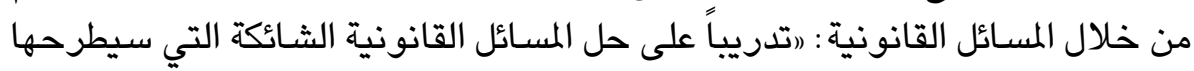
الواقع العملي (على الطالب) في المستقبل)(25 المساتل.

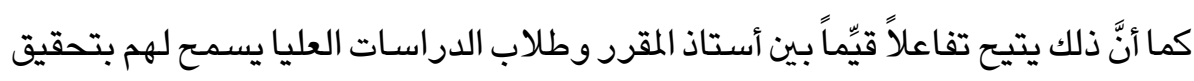
المكتسبات الإيجابية التالية:

أ. التحكم في المعارف التي يكتسبونها بحيث يمكن لهم إعادة استعمالها بطريقة مختلفة

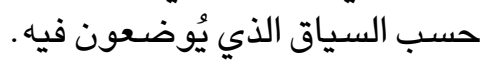

ب. اعتماد على الذات بشكل أفضل فيما يتعلَّق باكتساب المعرفة وتحليلها وإيجاد الحلول القانونية. ج. التحفيز للقيام ببحوث قانونية أطول وتحقيق إنجازات بحثية أكثر تعقيداً. د. التدريب على إدارة الوقت بشكل أفضل من خلال تخصيص وقت للتعلم ووقت للتعليم.

(25) Christian Atias, La Controverse Et L'enseignement Du Droit, Annales D'histoire des Facultés de Droit, 1985,2, p.114. 


\section{الغرع الثاني \\ التعلم التعاوني}

يغلب ألا يتعلَّم الطالب بمفرده، ولذلك يحسن بأستاذ المقرر استخدام التعلم التعاوني

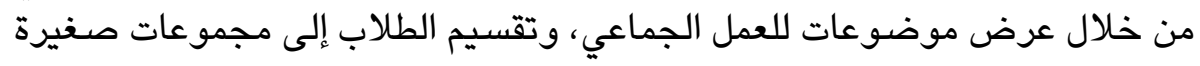

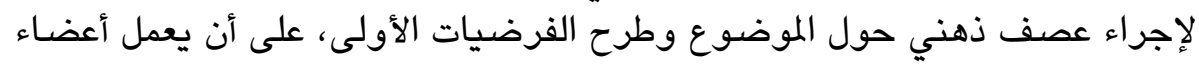

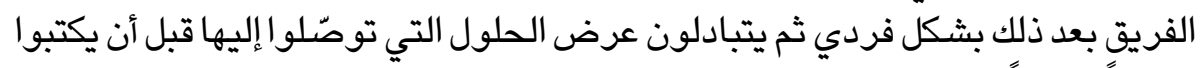

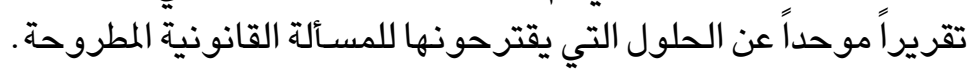

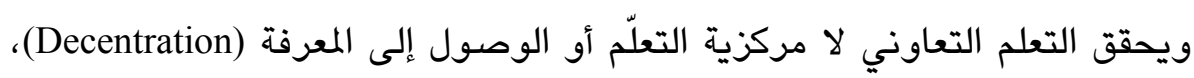

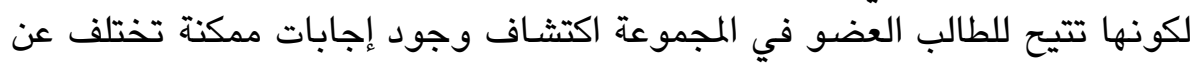

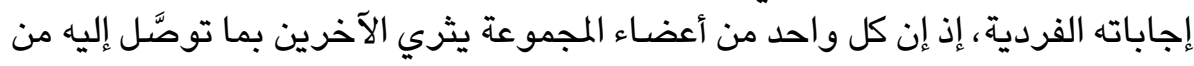

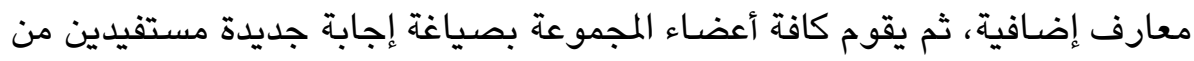
تضافر جهود كل واحد منهم مـع البقية (26).

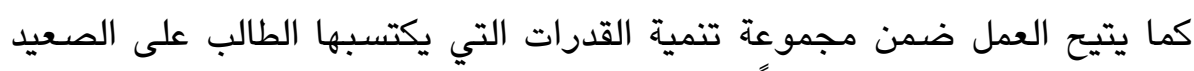

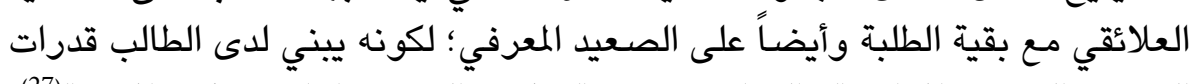

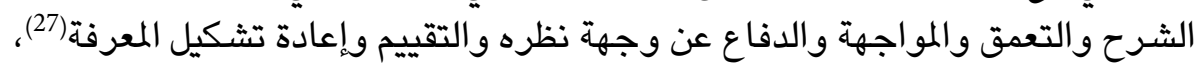
وهي قدرات مطلوبة لدى خريج الدراسات العليا.

ولكن يجب أن يخضـ تعلم الطلاب ضمن مجموعات إلى الضوابط التالية :

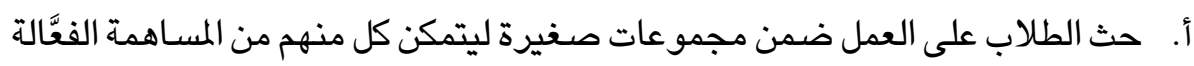
في إيجاد الحل المطلوب، ولائيُوِّل أي واحد من أفراد المجموعة على على جهد بقية الأفراد.

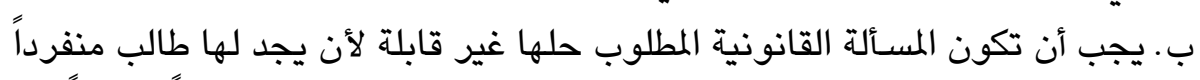

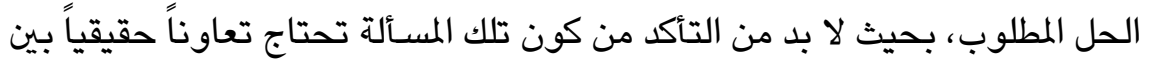

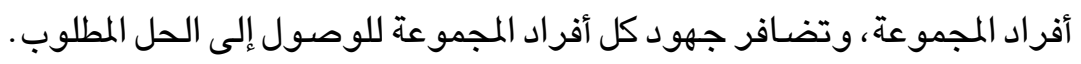

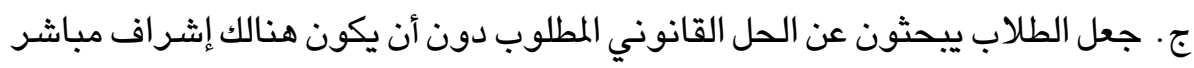
وفوري من أستاذ المقرر.

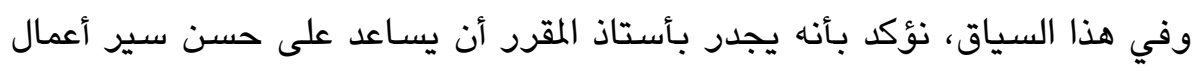

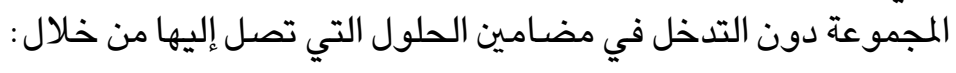

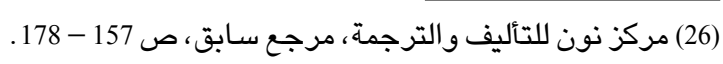

(27) عبد الفتاح خضر ، أزمة البحث العلمي في العالم العربي، الناشر الإلكتروني كتب عربية، بدون تاريخ، ص 131. 
أ. تزويد أعضاء المجموعة بالمراجع والوثائق الضرورية لإيجاد الحل حينما يعجزون عن الوصول إليها.

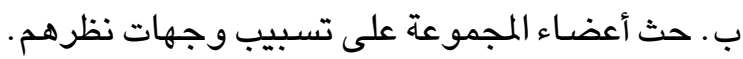

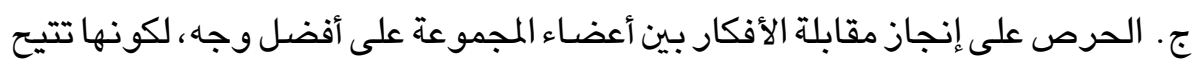
تطوير معارف كافة أعضائها.

وهو ما يترتب عنه الانعكاسات الإيجابية التالية بالنسبة للطالب: أ. إدراك كل واحد من أعضاء المجموعة لمهاراته الشخصية من خلال مقارنتها بمهارات

$$
\text { بقية أعضاء المجموعة. }
$$

ب. إمكانية ابتعاد اكتساب الطالب للقدرات عن المركز المتمثل في أستاذ المقرر. ج. إمكانية نقل القدرات الشخصية لأحد أعضـاء المجموعة إلى أعضاء آخرين عن طريق المحاكاة.

د. التدرب على التعامل مع مسائل قانونية متشعبة، والقدرة على الدخول في نقاشـات

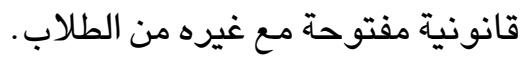
هـ. تدني نسبة الخوف من الفشل وتزايد الثقة في النفس. الفرع الثالث

\section{التعلم من خلال المشاريع البحثية}

تهدف هذه الطريقة إلى جعل الطالب يتعامل مع مشروع بحثي طويل الأمد، بحيث يدل

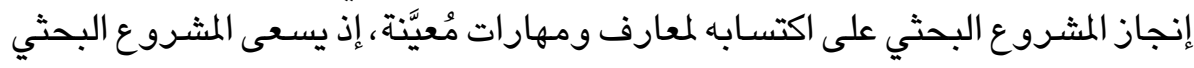

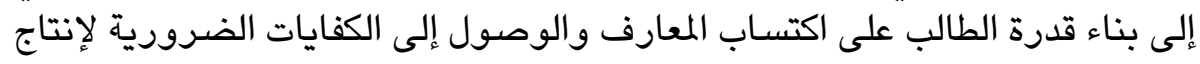

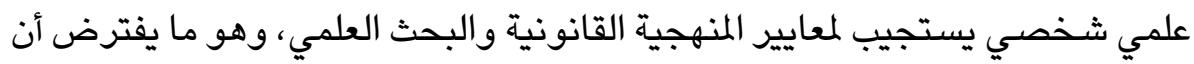

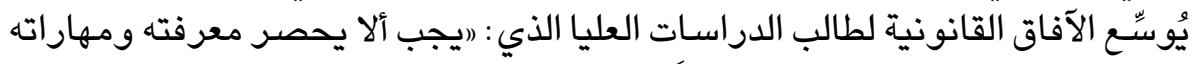

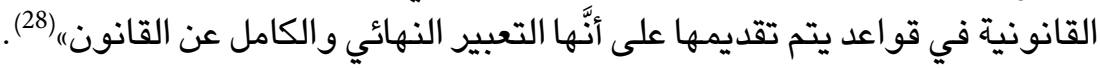

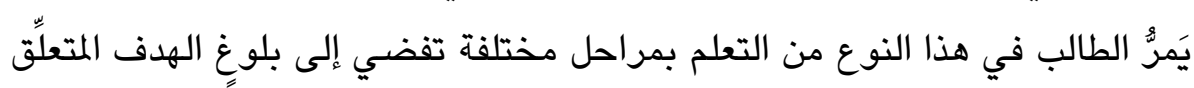

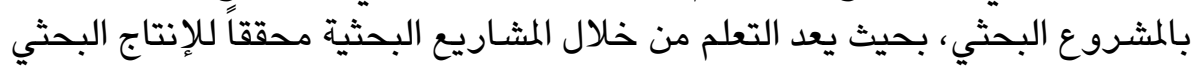

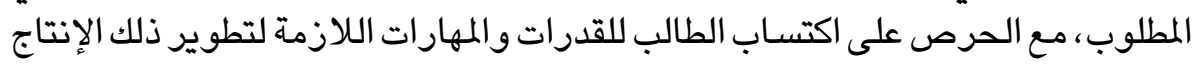
البحثي، بحيث تتيح هذه الطريقة في التعلم للطالب المرور بمختلف الخطوات العلماتية

(28) Christian Atias, Op. Cit., P .118. 


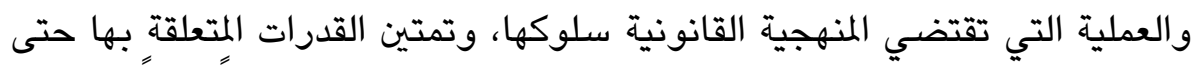

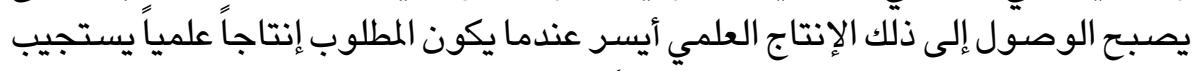

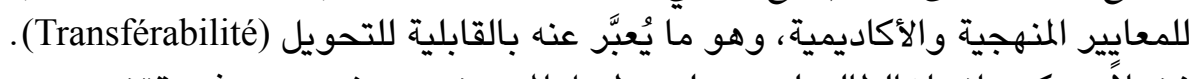

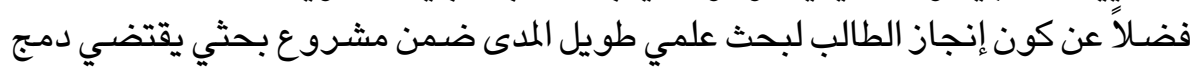

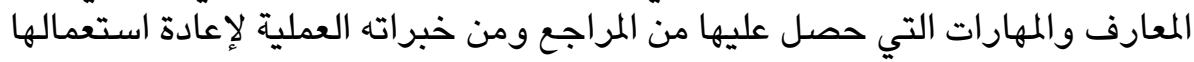

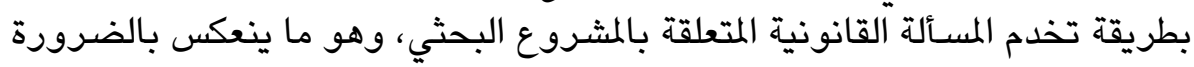

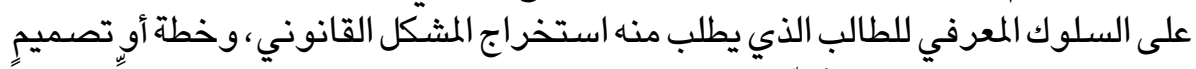

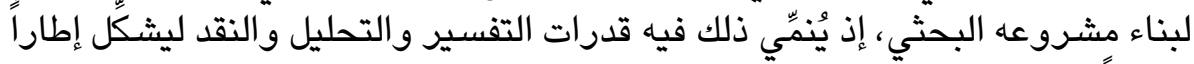

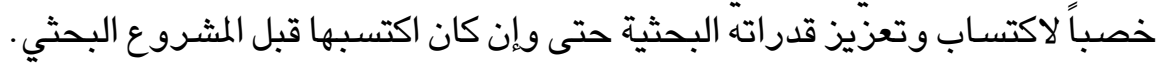

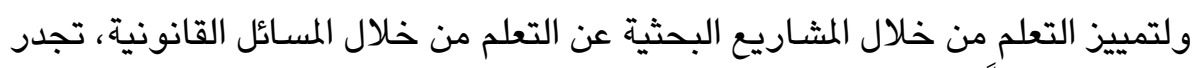

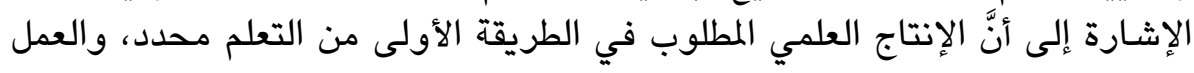

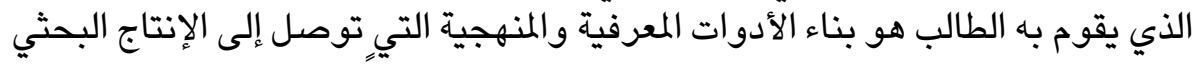

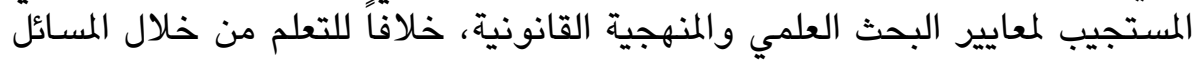

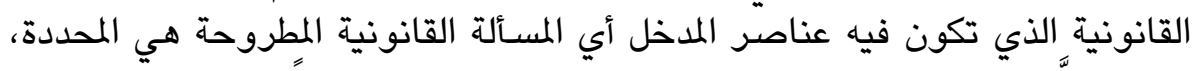

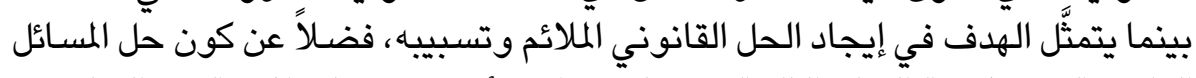

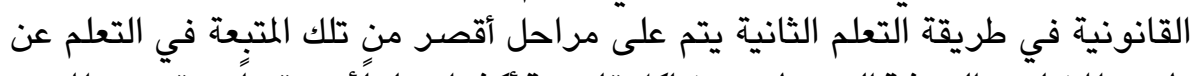

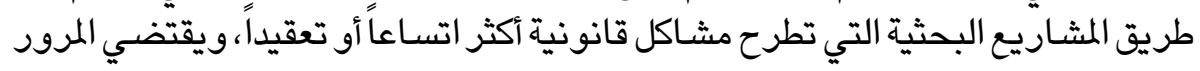
بمختلف المراحل المؤدية إلى إنجاز البحث العلمي المطلوب مدة مد قد تصل إلى إلى فصل كُامل .

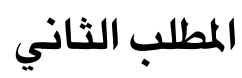

\section{آليات توجيه التدريس إلى بناء قدرات طلبة الدراسات العليا في القانون}

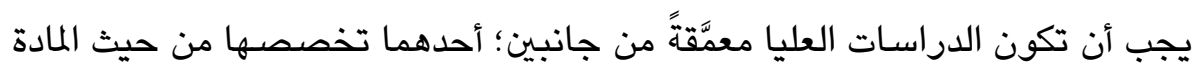

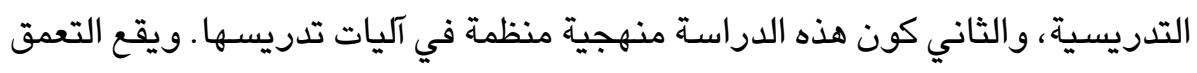

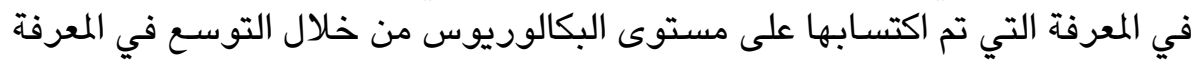

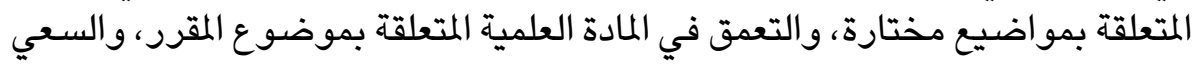

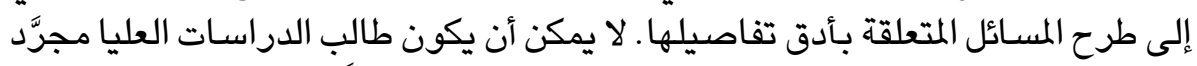

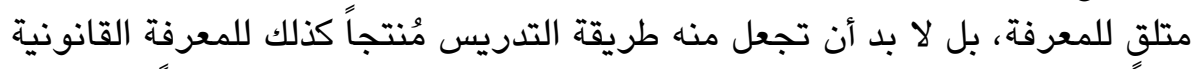

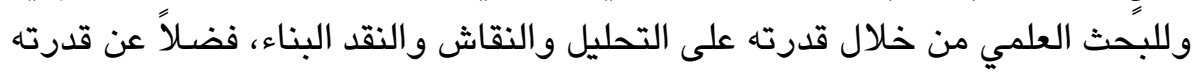

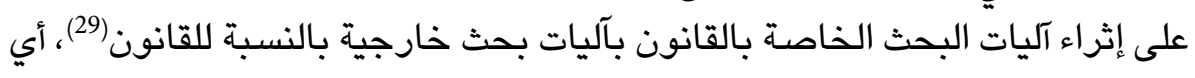

(29) François Ost, Questions méthodologiques A propos de la recherche interdisciplinaire en droit, Revue Interdisciplinaire d'études juridiques, 1981, 6, pp. 19-20. 
آليات مستلهمة من علوم أخرى كإجراء الاستبانات مع الالتزام بالضوابط الجامعية،

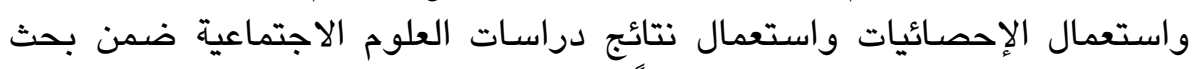

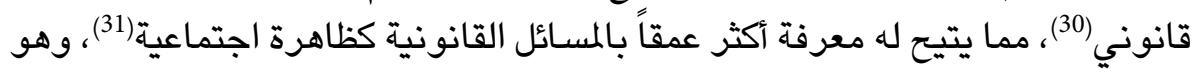

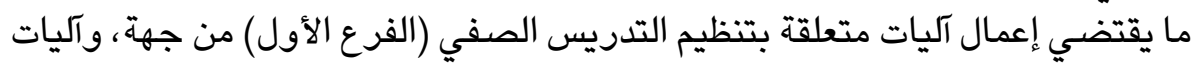

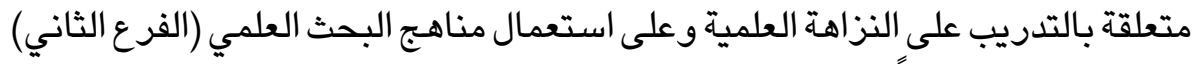

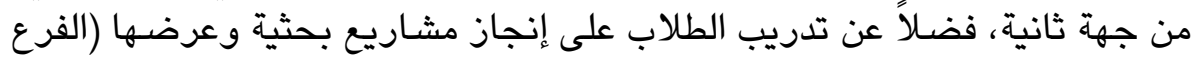

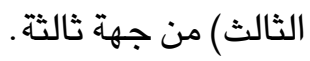

\section{الفرع الأول}

\section{الآليات المتعلقة بتظظيم التدريس الصفي}

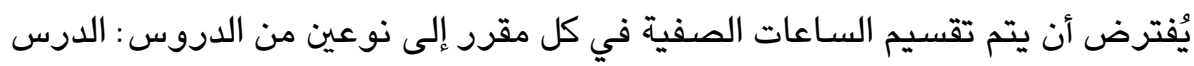

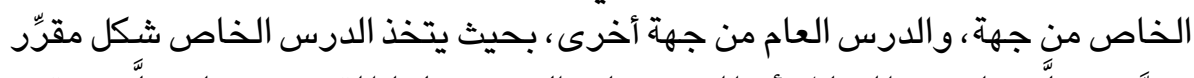

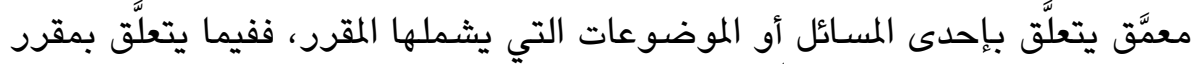

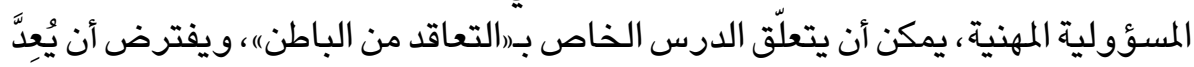

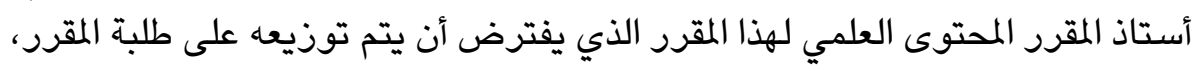

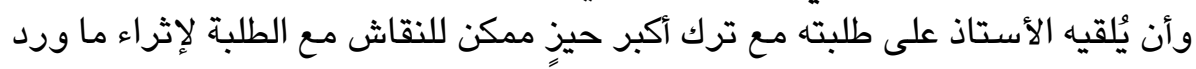

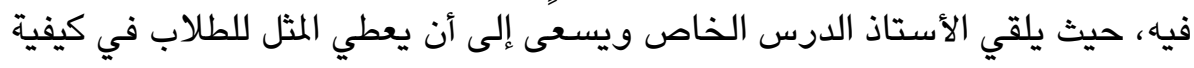

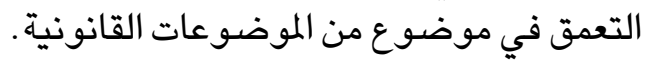

أما الدرس العام، فهو عبارة عن موضوعات قانونية قريبة من الدرس الخاص يختارهـا

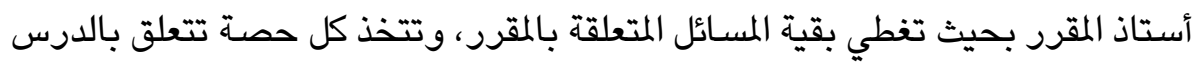

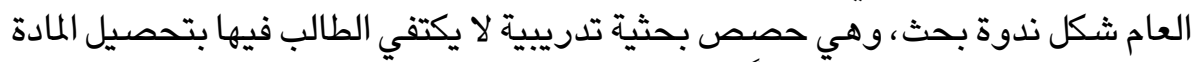

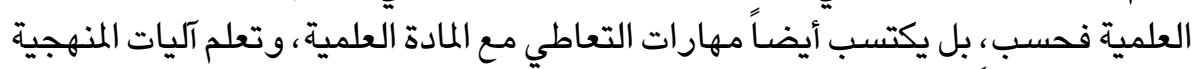

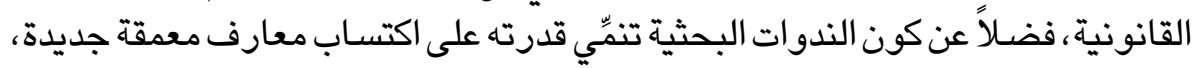

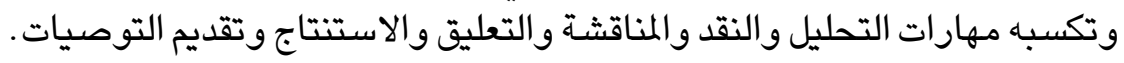
وفي المقابل فإنه يجب على بقية الطلاب حسن الاستعداد خلال كل من الدرس العام

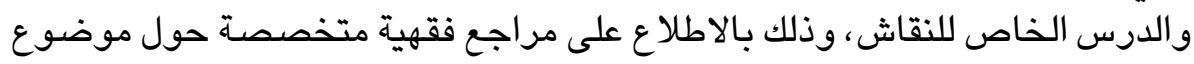

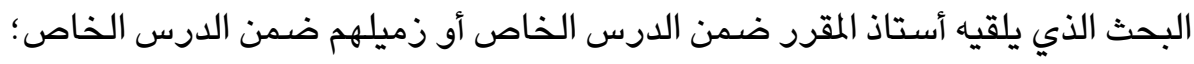

(30) M. Villey, De la dialectique comme art de dialogue et sur ses relations au droit, Archives de philosophie de droit, 1982, 27, pp. 265 - 267.

(31) Association canadienne des professeurs de droit, Bulletin (octobre 1986) aux pp. 2-3 (Document conjoint prépare par le Comité des doyens des Facultés de droit canadiennes et par l'exécutif de l'Association). 
حتى يتمكنوا من فهم ومناقشـة زملائهم ومن تقديم النقد البنَّاء للبحث المنجز، وبذلك

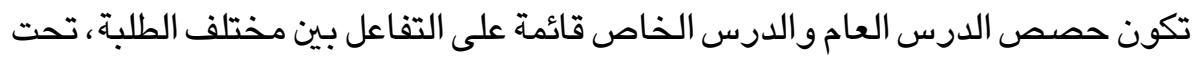

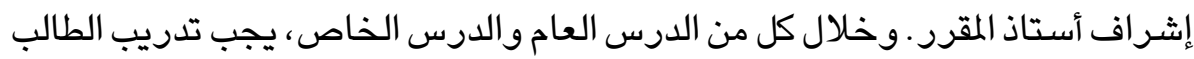

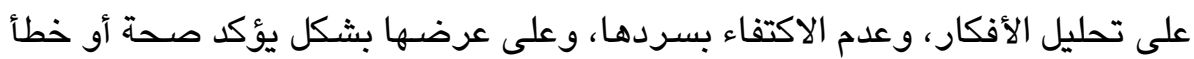
فكرة معينة مع البرهنة على ذلك من خلال اعتماد شـواهد فقهية أو قانونية أو قضـائية لتأكيد موقف الطالب أو تتسيبه. معينه كما يجب تدريب الطالب على النقد أي التقييم(32) بالرجوع إلى موقف فقهي أو فقه قضـائي

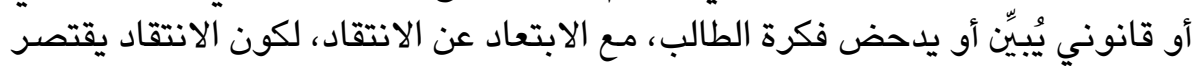
على الجانب السلبي، بينما يشـمل النقد الجانبين السلبي والإيجابي من المسـألة القانونية.

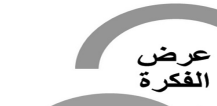

الثثر

الإثر اء

التقينيم

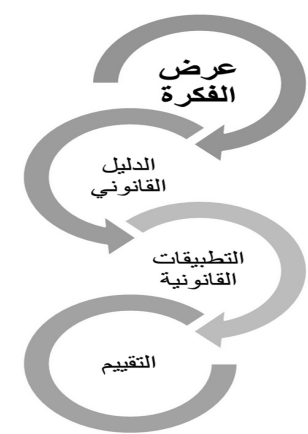

عرض نص المادة أو تسبيب الحكم

الشرح

الإثراء

الثقييم

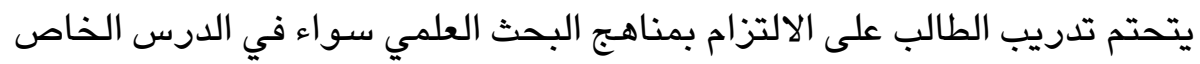

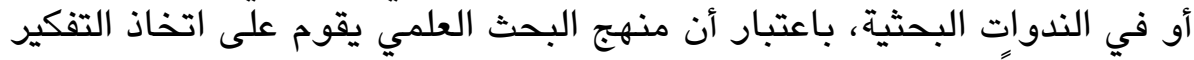

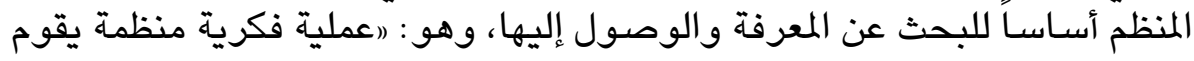

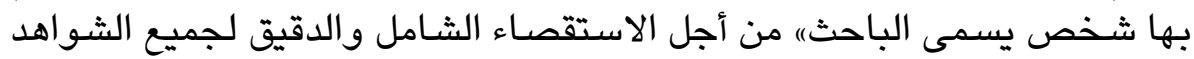

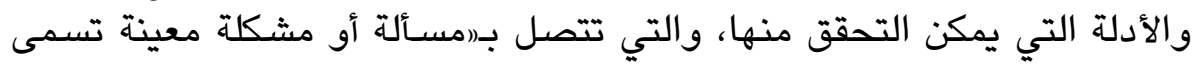

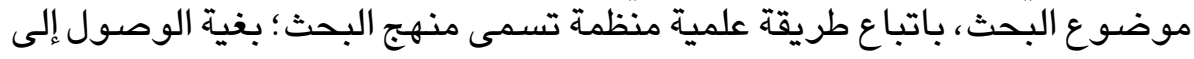

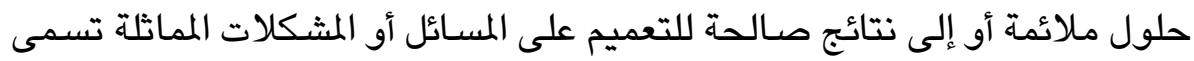
نتائج البحث)(33).

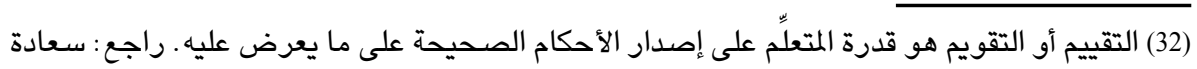

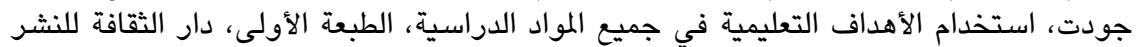

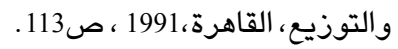
(33) عبد الفتاح خضر ، مرجع سـابق، ص اهرة 15. 


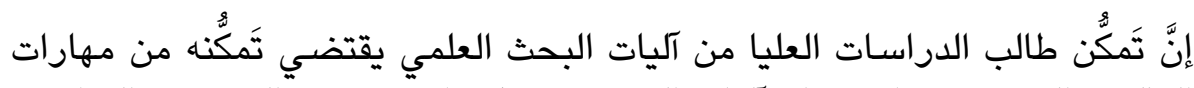

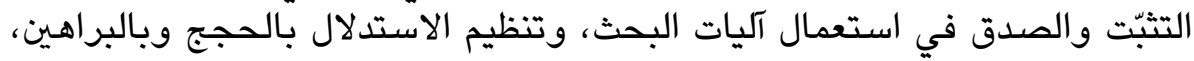

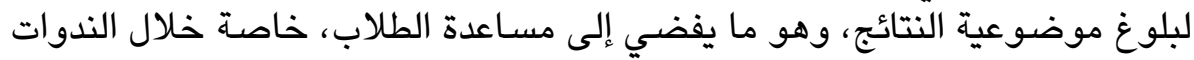

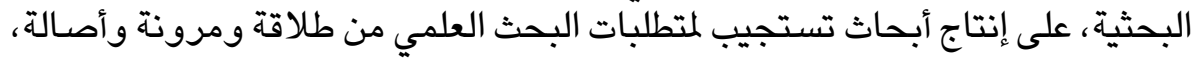

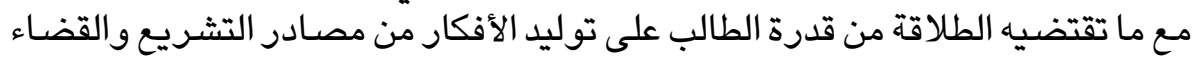

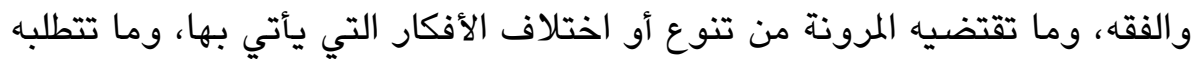
الأصالة من التجديد والانفراد والعمق في الأفكار.

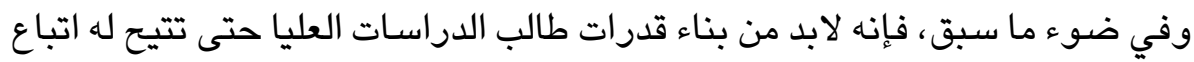

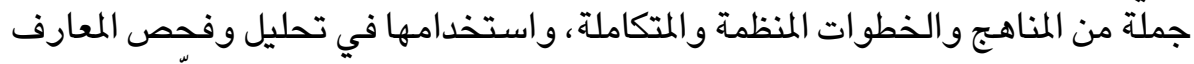

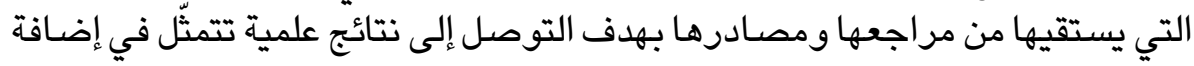

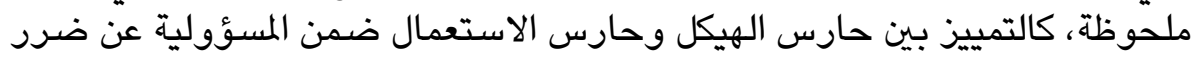

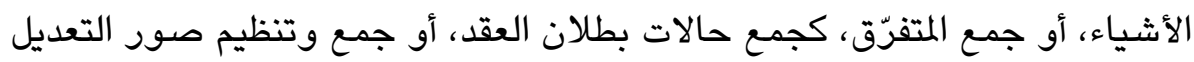

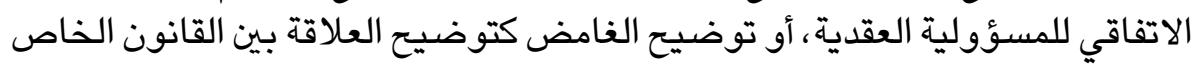
وحقوق الإنسان.

\section{الغرع الثاني \\ الآليات المتعلقة بالتدريب على النزاهة العلمية

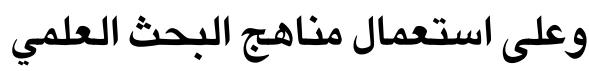

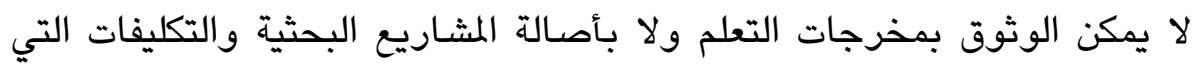

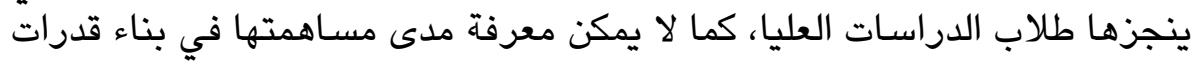

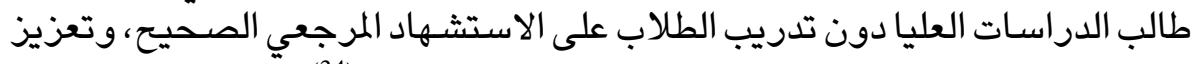

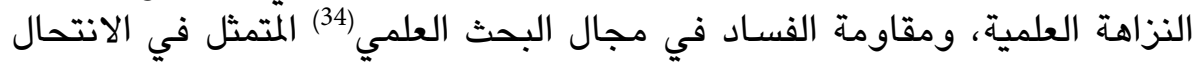

(34) يرجى مراجعة نسب الانتحال بالنسبة إلى عِينات من البحوث المنشورة ضمن الجدول التالي:

\begin{tabular}{|c|c|c|c|c|c|c|c|c|}
\hline للسرقات العلمئة المئوية & الدولة ل & & للسرقات العلميةية & الدولة & & للسرقات العلمية المئية & الدولة الد & \\
\hline$\% 3.68$ & السعودية & 9 & $\% 10.79$ & الصين & 5 & $\% 20.43$ & بلغاريا & 1 \\
\hline$\% 3.22$ & ألمانيا & 10 & $\% 8$ & البرازيل & 6 & $\% 18.91$ & مصر & 2 \\
\hline$\% 2.41$ & نيوزيلندا & 11 & $\% 5.89$ & أستراليا & 7 & $\% 15.55$ & إيران & 3 \\
\hline$\% 1.82$ & الولايات المتحدة & 12 & $\% 5.65$ & اليابان & 8 & $\% 10.99$ & الهند & 4 \\
\hline
\end{tabular}

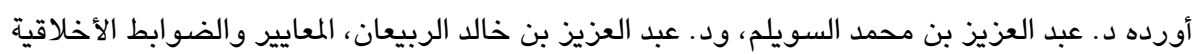

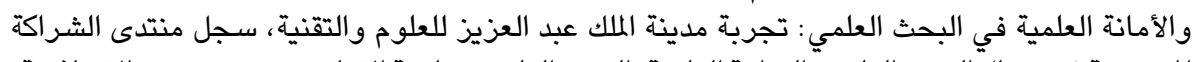

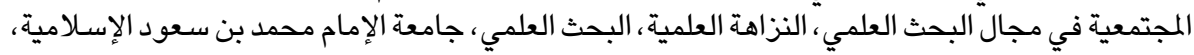

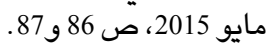




\section{والتلفيق واختلاق النتائج والبيانات(35).}

ولذلك فإنه لا بد من توجيه أستاذ المقرر جهوده منذ الحصص الأولى إلى بناء بيئة

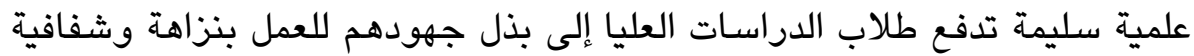

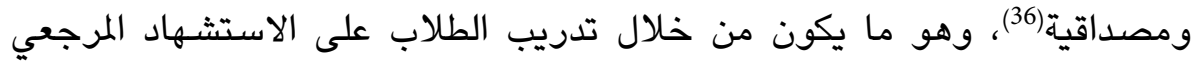

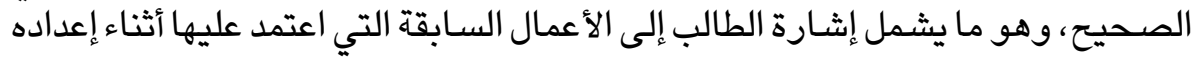

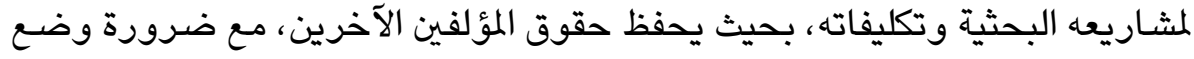
الكلمات بين علامتي اقتباس لو قام الطالب باستخدام كلمات المؤلف ذاتها، إذ يمكن

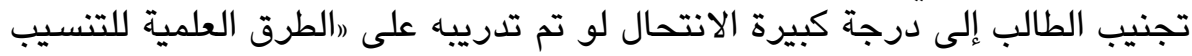

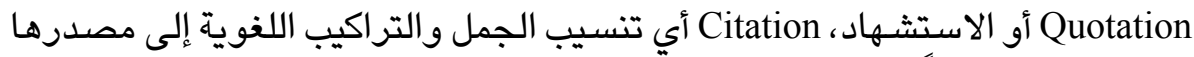

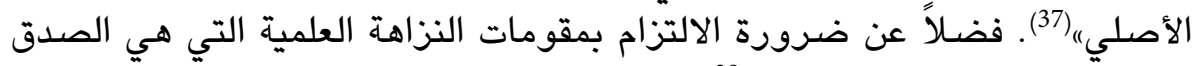

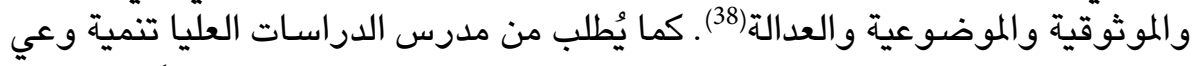

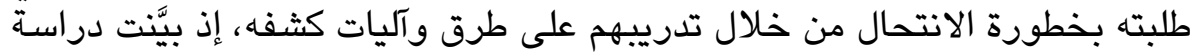

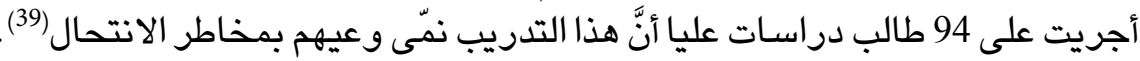
كما يجب على مدرس الدراسـات العليا عدم قبول أي مشروع بحثي أو تكليف أي

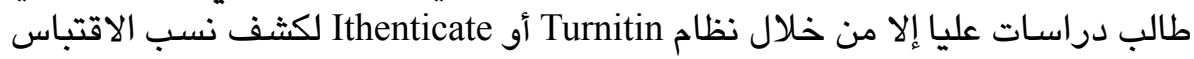
similarity

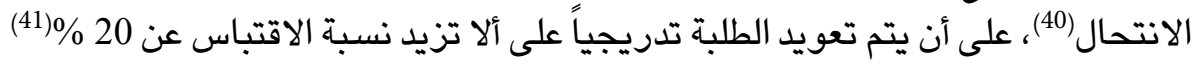

(35) Otto, C.M., Bradley, S.M. and Newby, D.E., Research integrity: we are all accountable, Heart Online First published on January 30, 2015 as 10.1136/ heartjnl 2015307458.

(36) Wolpe, P.R., Scientific work in changing environment, Office Research Integrity, News, 22 (1) 2013. Available from: http://ori.hhs.gov/images/ddblock/dec_vo122-no1.pdf.

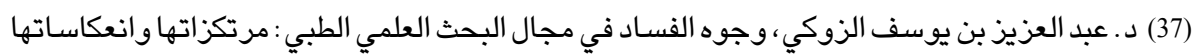

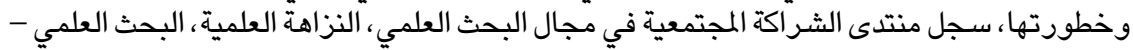

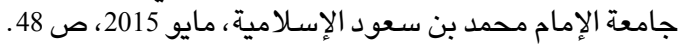

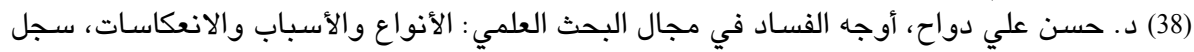

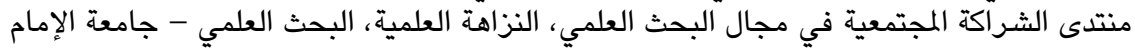

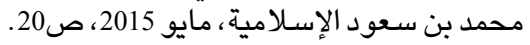

(39) Landau, Joshua D.; Druen, Perri B., Arcuri, Jennifer A. (2002). Methods for Helping Students Avoid Plagiarism. Teaching of Psychology, 29 (2). 112-115. Available at: http://www.tandfonline.com/doi/ abs/10.1207/S15328023TOP2902_06.

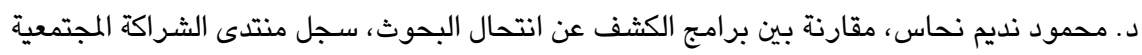

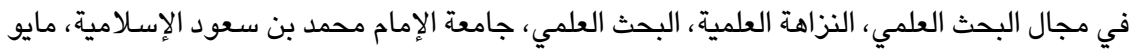
2015، ص ص 164.

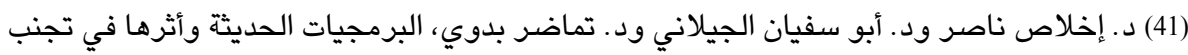

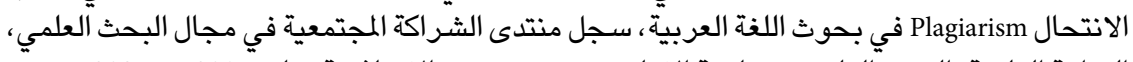

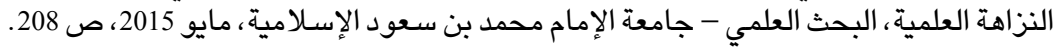


أو 25 \% في المشـاريع البحثية والتكليفات المقدمة للتقييم حسب النسبة التي تعتمدها الجامعة(42)."وكلا البرنامجين نظام إلكتروني يدعم عدة لغات منها المات اللغة العربية

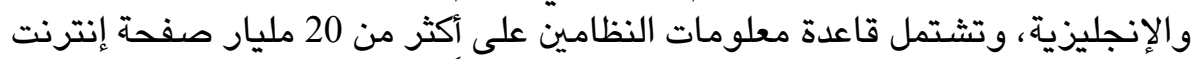

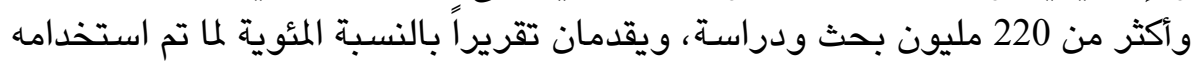

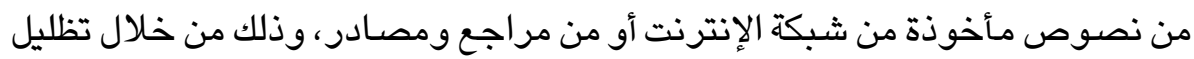

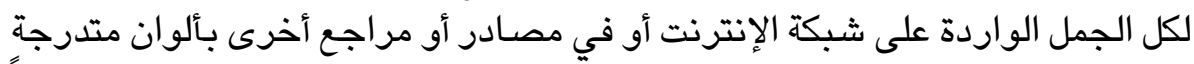

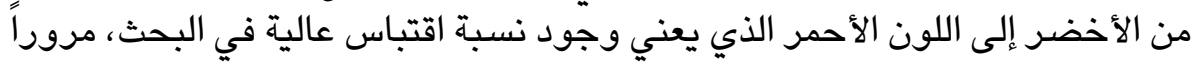

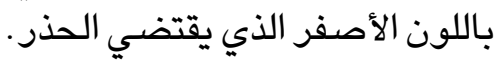

ويتم استخدام iThenticate من قبل كل من المفوضية الأوروبية والبرلمان الأوروبي

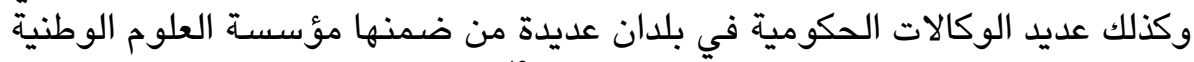
السويسرية والصندوق القطري للبحث العلمي(43). وفي المقابل يعمل فني نظام

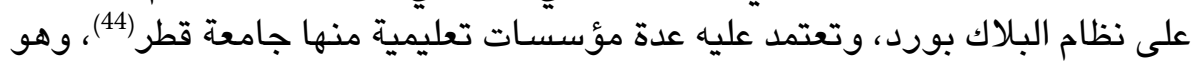

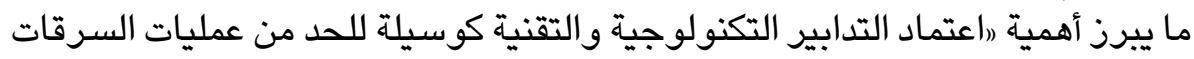
العلمية والانتحال خاصـة تلك التي تتم باستخدام شبكات الإنترنت أو بواسطتها،

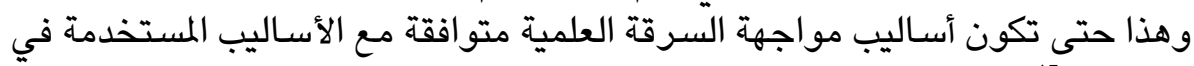

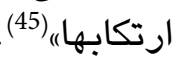

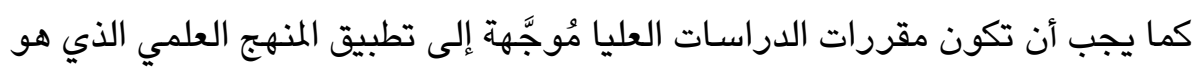

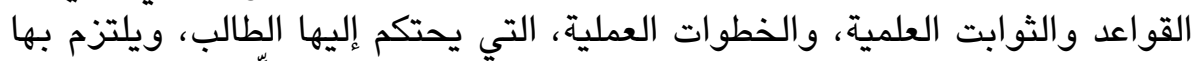

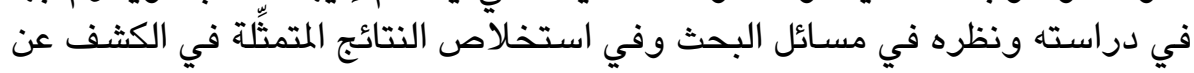

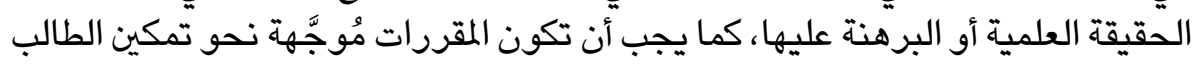

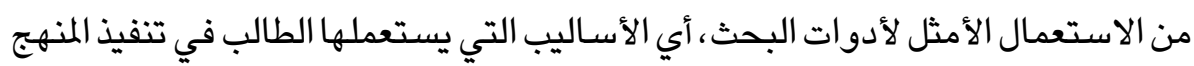
الذي يسير عليه في بحثه، وهي مجموعة وسـائل ينفذ بها الباحث منهج البحث لاتئ ويرتبط

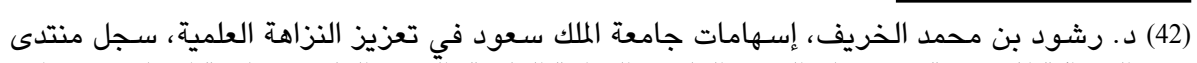

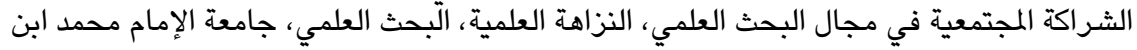

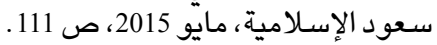

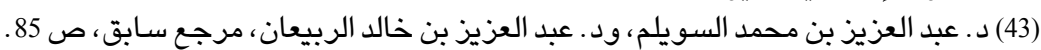

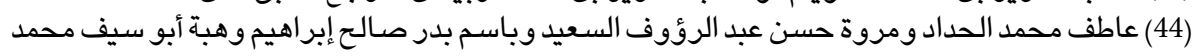

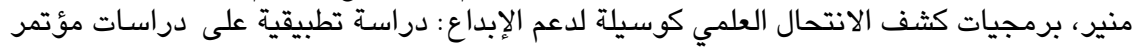

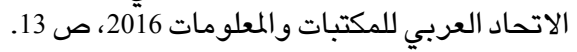

https://www.researchgate.net/profile/Atef_Hadad/publication/328412627_brmjyat_ kshf_alanthal_allmy_kwsylt_1dm_alabda_drast_ttbyqyt_ly_drasat_mwtmr_alm_2016/ links/5bcc118892851 cae 21 b6dd25/brmjyat-kshf-alanthal-allmy-kwsylt-ldm-alabda-drast-ttbyqyt-lydrasat-mwtmr-alm-2016

(45) د. طه عيساني، الممارسـات الأكاديمية الصـيحة وأسـاليب تجنب السرقة العلمية، مقال ضمن أعمال

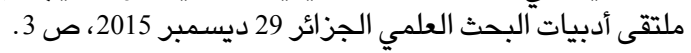


اختيارها بسمات شخصيته ـ وتتقسم أسـاليب البحث، باعتبارها وسائل مميزة لتنفيذ منهج البحث، إلى فئتين هما:

1) الأسلوب الوصفي الذي يقوم على وصف ظاهرة تانونية معينة وتعداد مختلف

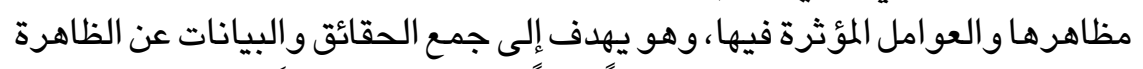

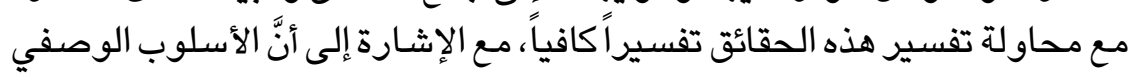

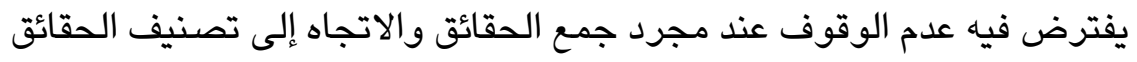

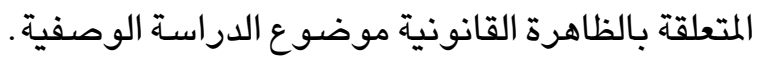

2) الأسلوب التحليلي الذي يطبقه الباحث على ما جمعه من معلومات حتى يستتج

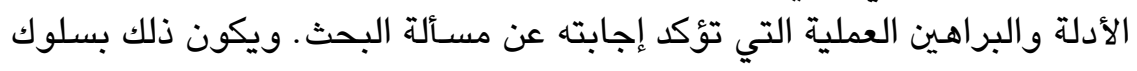

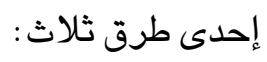

توضيح العلاقة بين ظاهرتين من خلال تحليل ارتباطي على غرار إبراز الارتباط بين

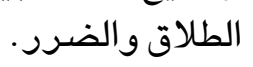

توضيح أسباب الظاهرة القانونية من خلال التحليل السبيب، من قبيل تحليل سبب المسؤولية عن ضرر الأشياء.

بيان مجال تطبيق الظواهر القانونية من خلال التحليل المجالي على غرار الحماية القانونية للحائز.

كما لا بد من تدريب الطالب على استعمال مناهـج البحث القانوني الأربعة(46)، وهي : 1) المنهج الاستدلالي أو الاستنباطي الذي يربط بين المقدمات والنتائج، أو بين الأشياء

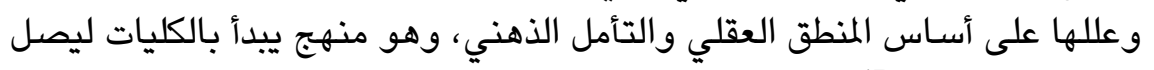
منها إلى الجزئيات(47).

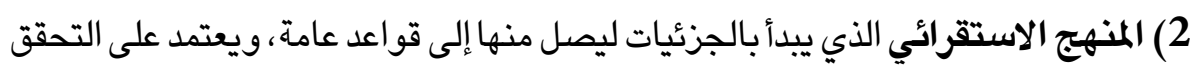
بالملاحظة المنظمة للعناصر المشتركة بين عدة حالات خاصة لاستخلاص تلك القواعد (48). 3) المنهج الاستردادي أو التاريخي الذي يتبعه الباحث في جمع المعلومات عن الأحداث

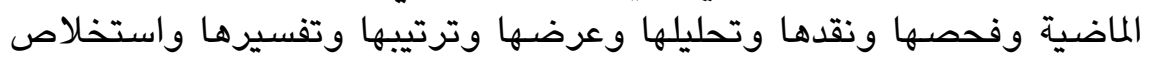

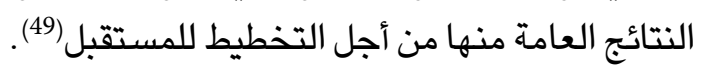

(46) د. إبراهيم محمد تركي، البحث العلمي أسسه ومناهجه، دار الكتب القانونية، القاهرة، 2010، ص ص 139 - 159.

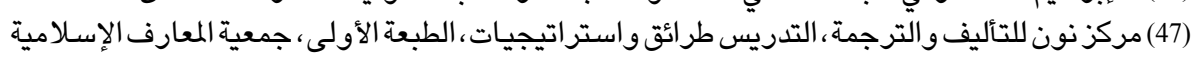

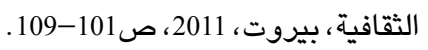

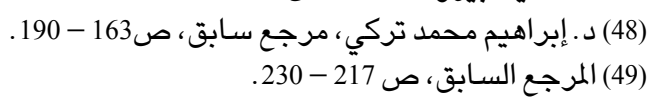


4) المنهج المقارن الذي يستهدف دراسـة النظم القانونية المختلفة لاستخلاص أوجه الشبه والاختلاف وتحديد جوهرهـا الاجتماعي وشكلها ووظائفها بغية إظهار

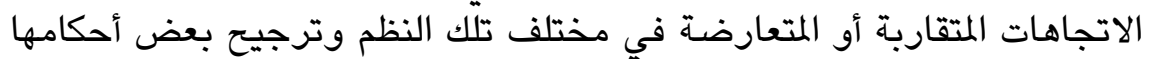

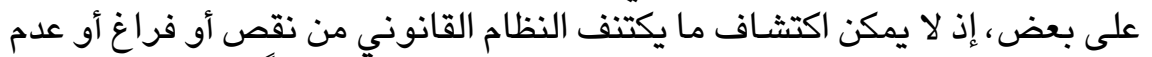

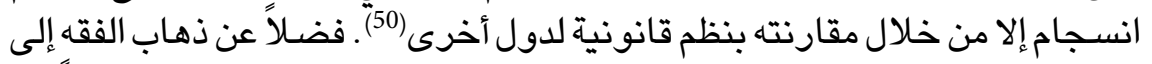
أنّ : (معظم طلبة القانون اليوم، سيقضون حياتهم المهنية في عالم لن يكون كافياً فيه

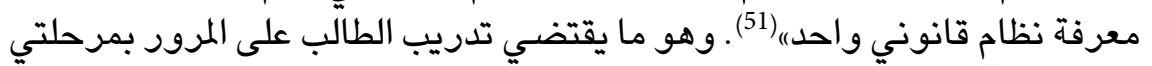

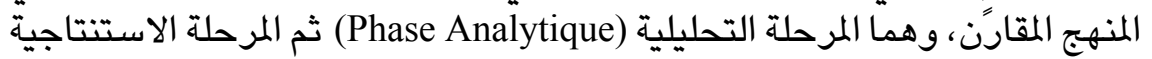
${ }^{(52)}$ (Macro Comparison)

كما يقتضي بناء قدرات طالب الدراسـات العليا في المنهج المقارن وتدريبه على استعمال

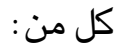
أ- المقاربة المصطلحية (Approche Conceptuelle) من خلال البحث عن مصطلحات تضاهي المصطلحات التي يراد مقارنتها (مثلاً مقارنة مصطلح السبب (مثن بمصطلح . ${ }^{(53)}$ (Consideration

ب- المقاربة الوظيفية (Approche Fonctionnelle) من خلال مقارنة وظائف المؤسسات القانونية (مثلاً مقارنة وظائف مؤسسة الإنة Promissory Estoppel التي نشأت في النظام الأنجلوسكسوني بوظائف مؤسسة القانون الطبيعي التي نشأت في النظام اللاتيني)(54).

ج- المقاربة السياقيتة أو الثقافية (Approche Contextualiste ou Culturaliste) التي تقوم على أخذ السياقات الاقتصـادية والاجتماعية والثقافية الخاصـة بكل قانون عند

(50) Leon Aucoc, Les études de législation comparée en France, Paris, Alphonse Picard, Kditeur 1889. Site Gallica. Bibliothèque numérique de la bibliothèque nationale, $\mathrm{p}$ 9. https://gallica.bnf.fr/ark:/12148/ bpt6k840655.texteImage.

(51) «Most of today's law students will spend their professional life in a world in which knowledge of only one jurisdiction is not enough». Smits, Jan M., Contract Law: A Comparative Introduction, Chapter 1 (2014). Contract Law: A Comparative Introduction, Chapter 1 (pp. 3-15), Edward Elgar Publishing 2014. Available at SSRN: https://ssrn.com/abstract=2669692 or http://dx.doi.org/10.2139/ ssrn.2669692; Rudolf B. Schlesinger: Formation of Contracts: A Study of the Common Core of Legal Systems. (GEN. ED.). Dobbs Ferry, N. Y.:

Oceana Publications, Inc., and London: Stevens \& Sons. 1968. Vol. I, p. 6.

(52) Béatrice Jaluzot, Méthodologie Du Droit Comparé Bilan Et Prospective, In Revue internationale de droit comparé. Vol. 57 N¹,2005. pp. 29-48.

(53) Linda Hantrais et Marie-Thérèse Letablier, La démarche comparative et les comparaisons francobritanniques, Revue de l'IRES n_28 - automne 1998, pp 157 et 158. http://www.ires.fr/publicationsde-1-ires/item/download/1172 067c7a515f1a0c12659cca56bd8ae641.

(54) Ruth Sefton-Green, Compare And Contrast Monstre A Deux Têtes, Revue Internationale De Droit Compare, 2002, 1, pp 91 et 92. https://www.persee.fr/doc/ridc_0035-3337_2002_num_54_1_17849. 


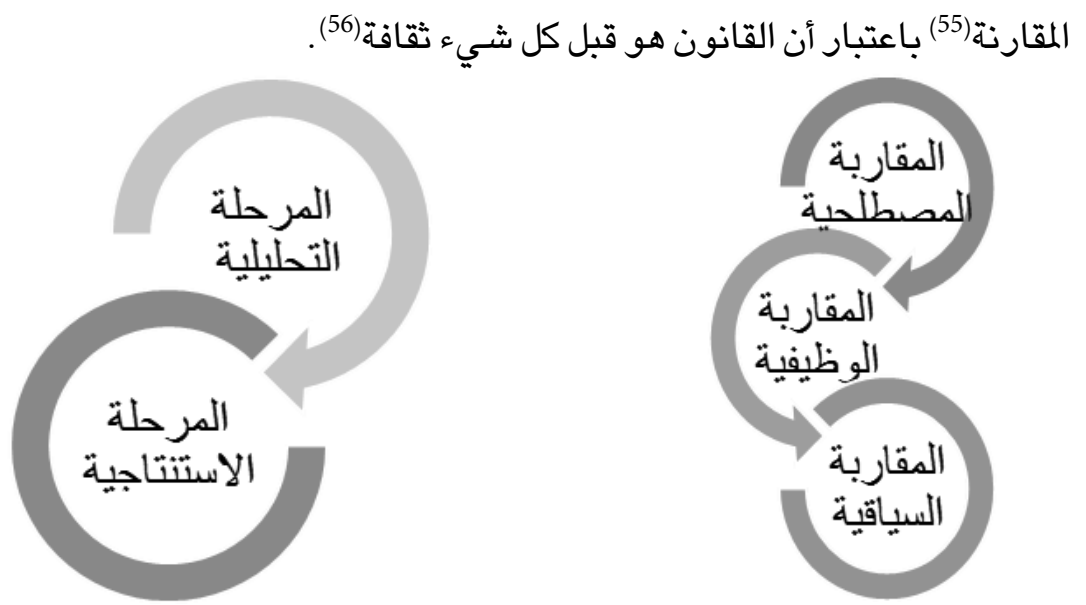

ورغم ما سبقت الإشـارة إليه من مناهـج، فإنه يجب توجيه طالب الدراسـات العليا إلى مدئ

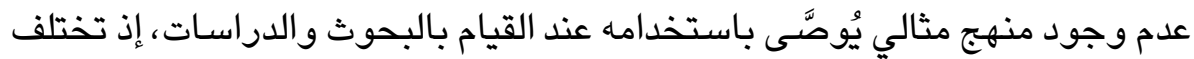

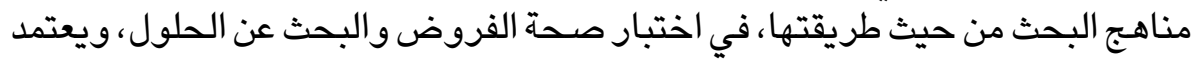

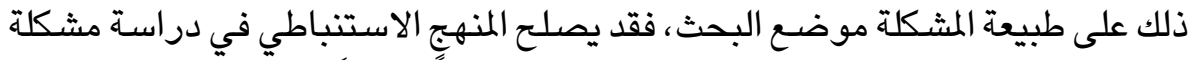

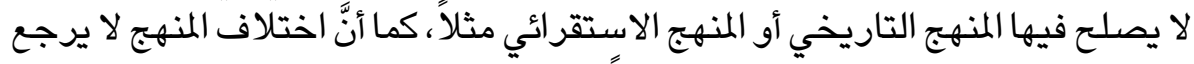

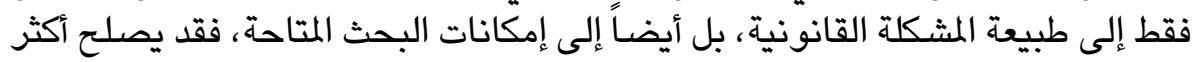

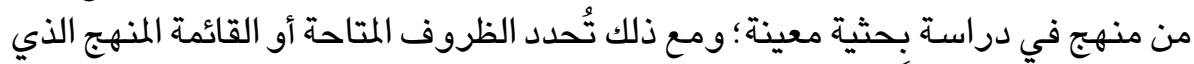

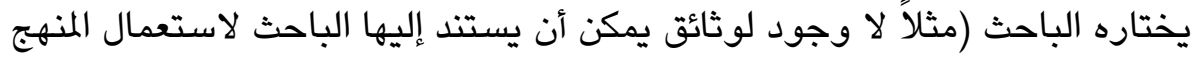

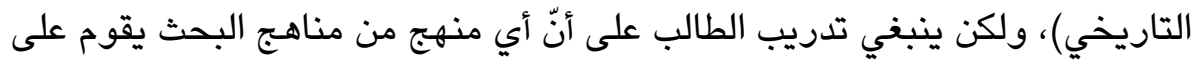

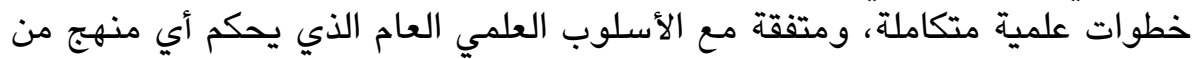

\section{الفرع الثالث}

\section{تدريب الطلاب على إنجاز مشاريع بحثية وعرضها}

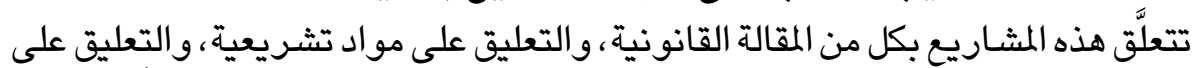

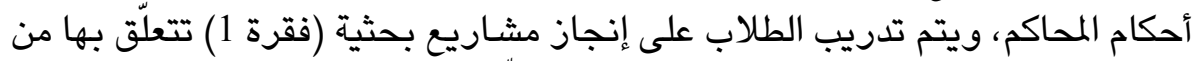

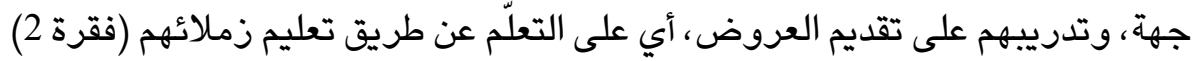

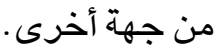

(55) Vernon Valentine Palmer: From Lerotholi to Lando: Some Examples of Comparative Law Methodology, Global Jurist Frontiers, Vol. 4 [2004], Iss. 2, Pp. 1-29. https://www.uio.no/studier/ emner/jus/jus/JUS5240/h12/undervisningsmateriale/palmer.pdf.

(56) Naomi Mezey, Law as Culture, Yale Journal of Law \& the Humanities, Vol.13, Pp. 45-67, http:// scholarship.law.georgetown.edu/facpub/317/. 


\section{ققرة 1 ـ تدريب الطلاب على إنجاز مشاريع بحثية: \\ يهذف المشروع البحثي إلى بناء:}

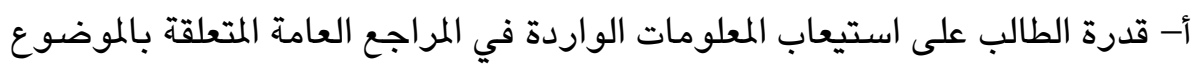

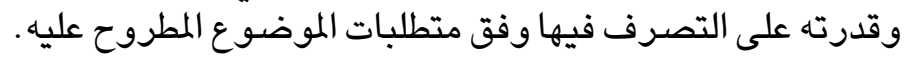

ب- تَعوُّد الطالب على ترتيب وتنسيق أفكاره وتقديمها بشكل سلس وبتسلسل منطقي مبوب.

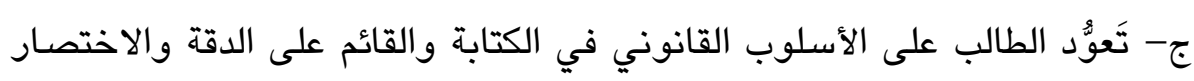

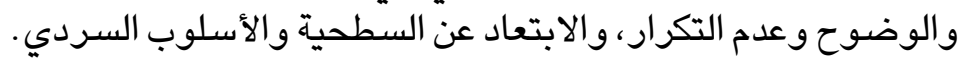

وهو ما يقتضي:

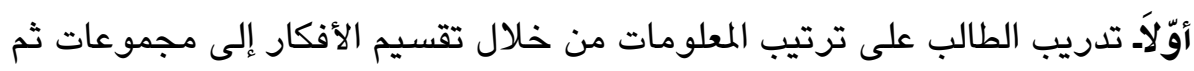

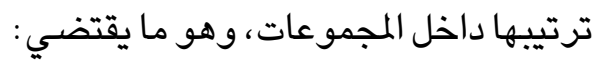

أ. أن يتم تدريب الطالب على تقسيم الأفكار إلى مجموعات من خلال ثلاث آليات هي :

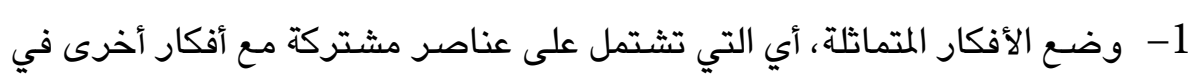
مجموعة رئيسية واحدة.

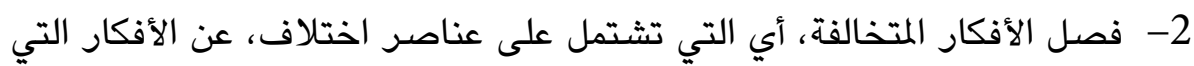

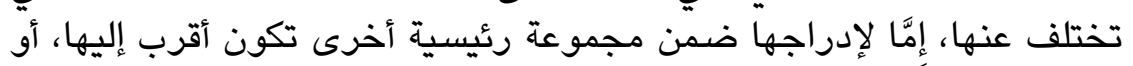

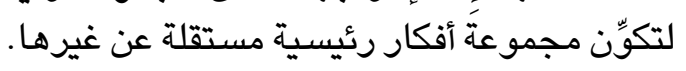

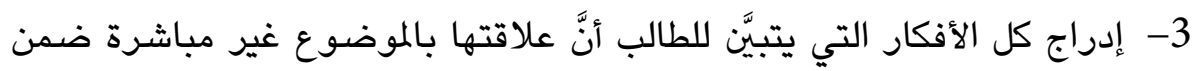

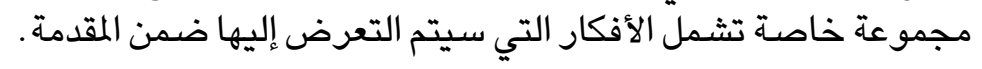
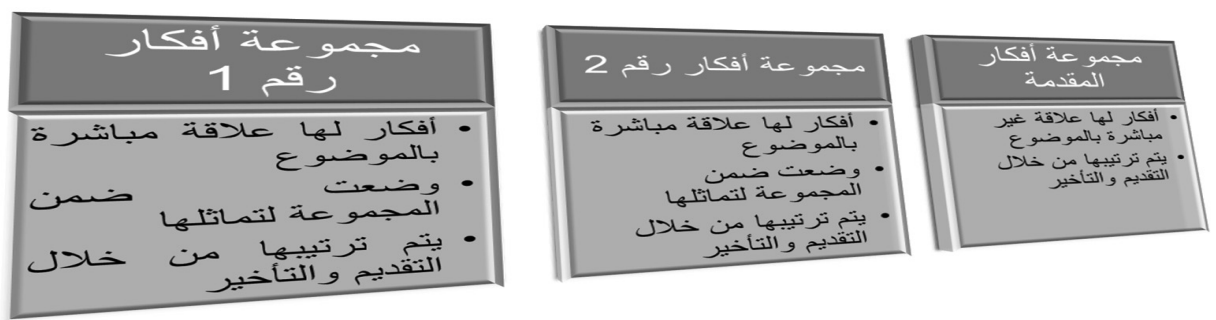

ب. يتم تدريب الطالب على تنظيم الأفكار ضمن تلك المجموعات من خلال تقسيم كل

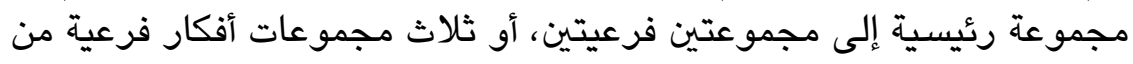

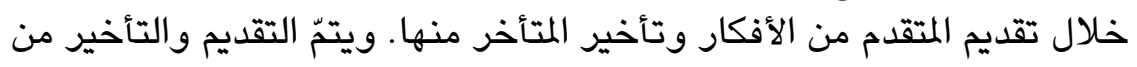
خلال اعتماد ثلاثة معايير هي مي الأكار 


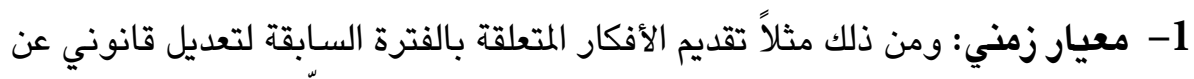

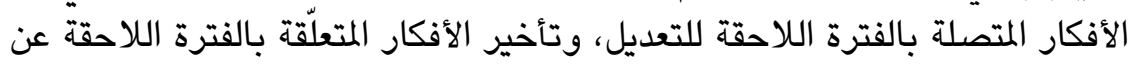

الأفكار المتعلقة بالفترة السابقة لها.

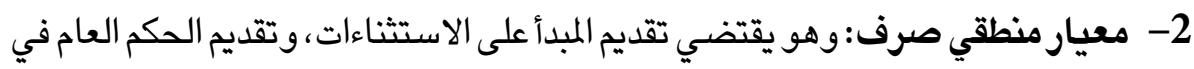

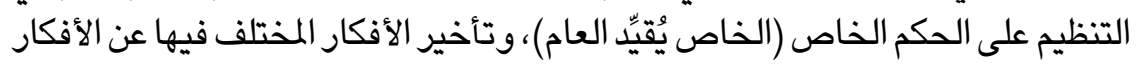
المتفق حولها أو المجمع عليها.

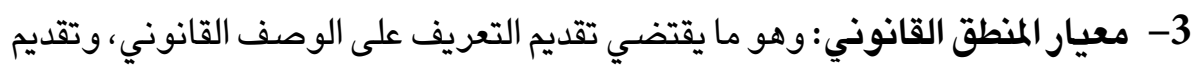

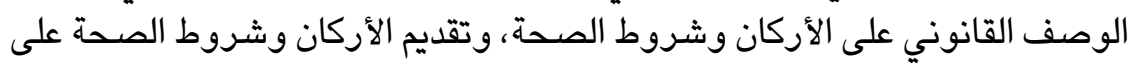

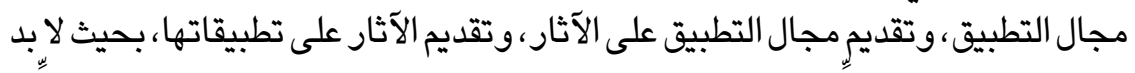

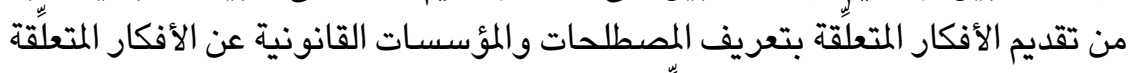

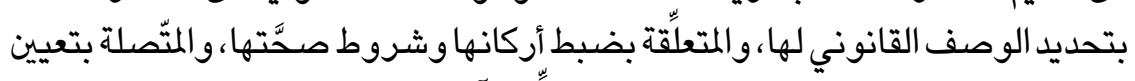

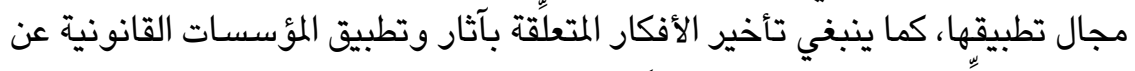

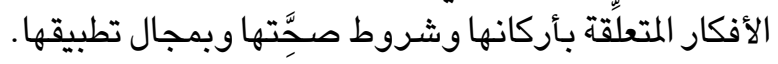
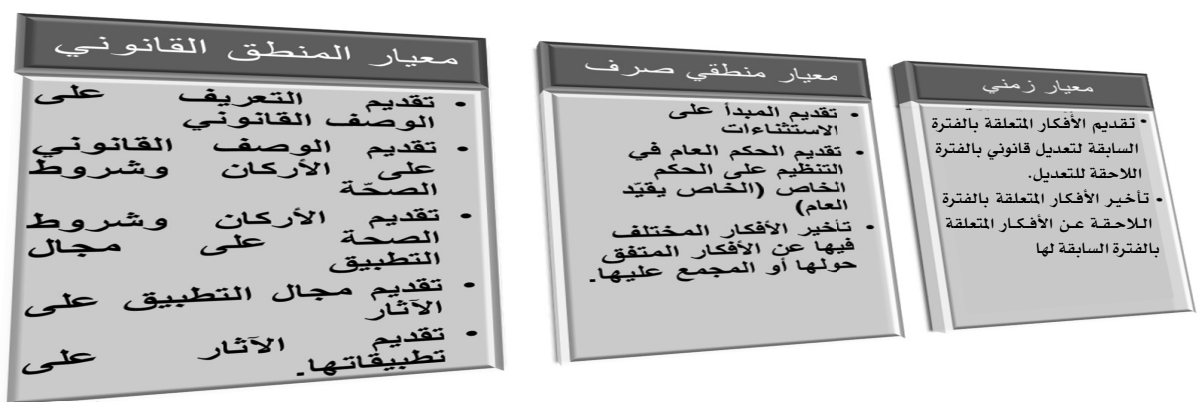

ثانياً. تدريب الطلاب على استخراج المشكل القانوني أو المسألة القانونية التي يتعلَّق بها المها

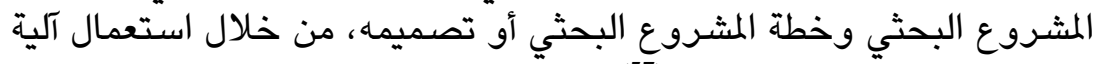

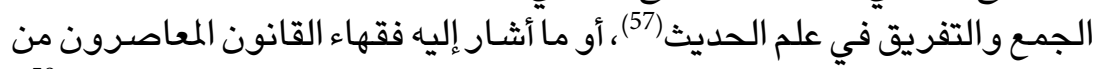

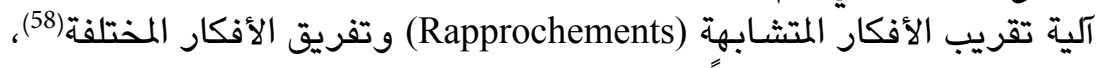

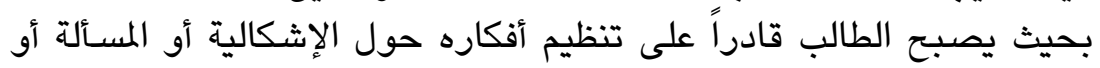

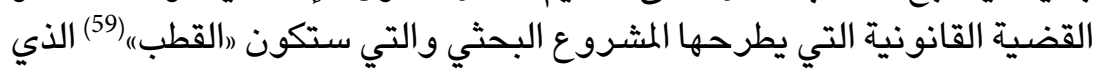
يحوم حوله كل المشروع البحثي ـ وهو ما يتم منّ خلالٍ:

(57) أحمد علي ثابت الخطيب البغدادي أبو بكر، كتاب الموضح لأوهام الجمع و التفريق، تحقيق عبد الرحمن

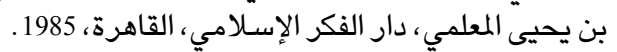

(58) Ch. Atias, Savoirs et pouvoirs juridiques: des ombres portées, RRJ 2001-1, p.59-75.

(59) د. عبد المجيد الزروقي، المنهجية أو البلاغة القانونية - التعبير عن التفير، مجمع الأطرش للكتاب

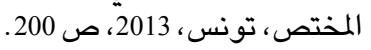


أ. فصل المعلومات التي تجيب عن الإشكالية التي طرحها الطالب، والتي ستشكِّ

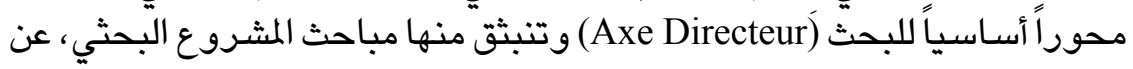
تلك الأفكار التي لا علاقة لها بالإشكالية والتي ستستبعد من التحليل. ب. فصل المعلومات الهامة عن المعلومات الأقل أهمية أو الجزئية التي سيتم تناولها ضمن المطالب.

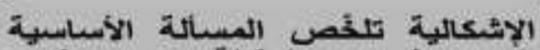

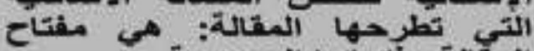

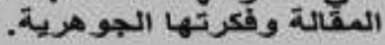

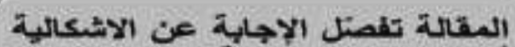

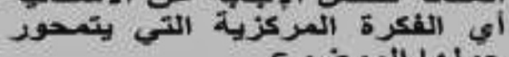
هوبها الموضون

ثالثاً. تدريب الطلاب على بناء الخطة البحثية أو التصميم بحيث تكون كافة المباحث

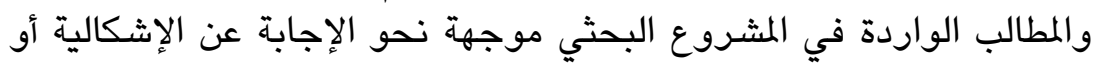

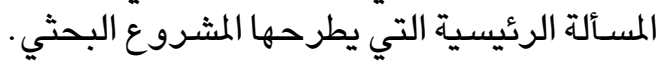
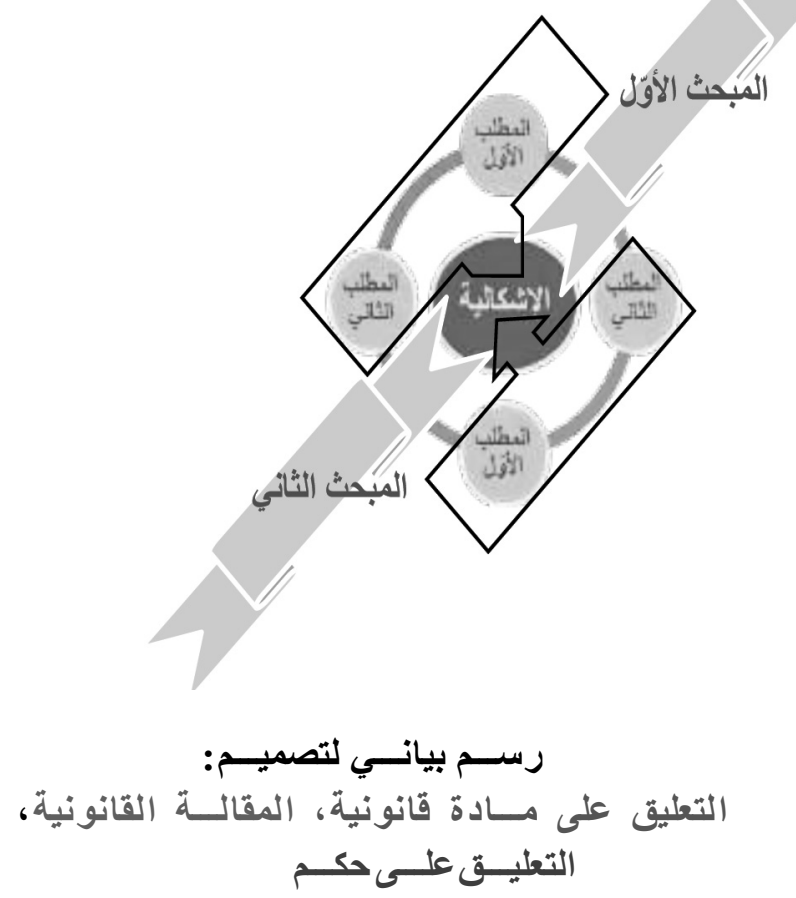


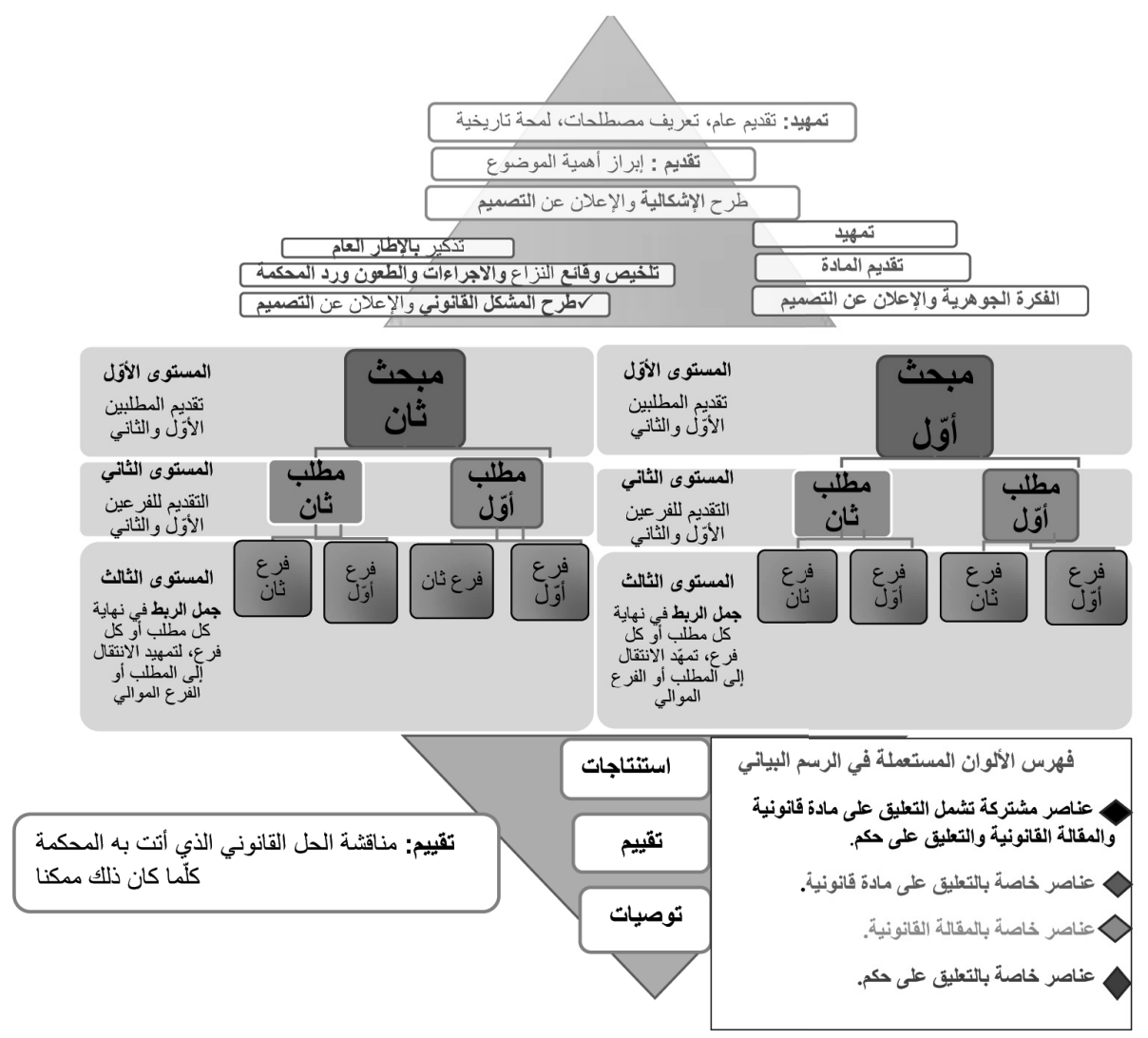

فقرة 2 ـ تدريب الطلاب على تقديم العروض: التعلم عن طريق تعليم زملائهم: يتم تدريب الطلاب على نوعين من العروض هما عروض الإثبات من جهة، وعروض

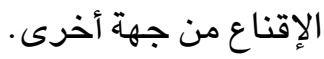

1. تنقسم عروض الإثبات إلى أنواع ثلاثة : أ- إثبات حقيقة وضعية قانونية (الرضائية في العقود). ب- إثبات أفضلية (شركات الأشخاص وشركات وفية الأموال).

ج- إثبات وجود وحدود سياسة شرعية معيّّة (حماية الطرف الضعيف في العقود).

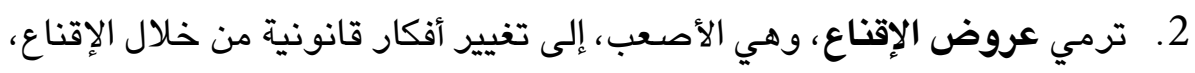

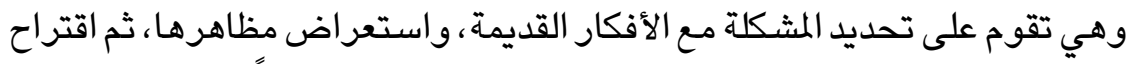

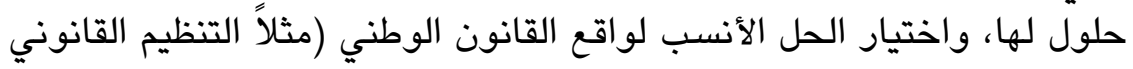
للعمل التطوعي). 


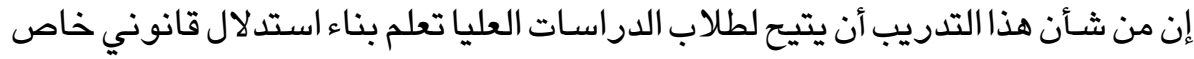

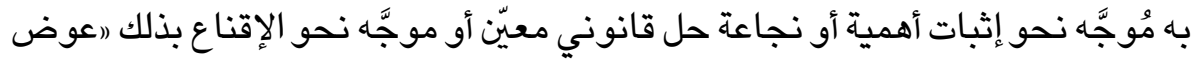

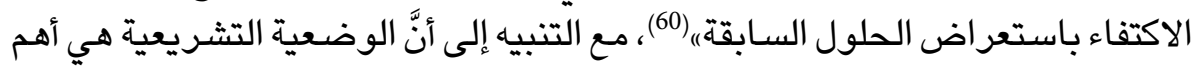
المخاطر التي تهدد هذا التوجه في التدريس؛ لكونه يجعل النقاش القانوني ينحصر في

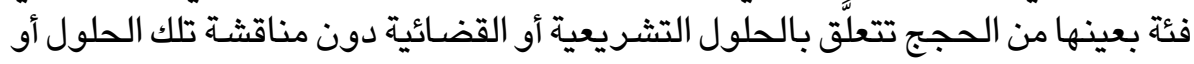

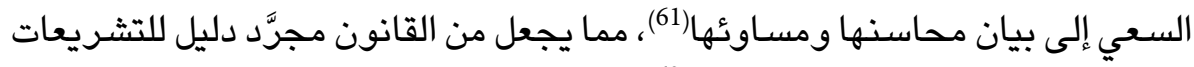

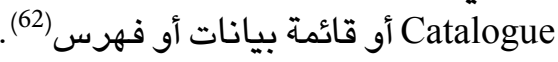

ولكنَّ هذا التدريب يتيح خاصة استعمال طريقة تعلم ناجعة توصلت إليها أبحاث التربية

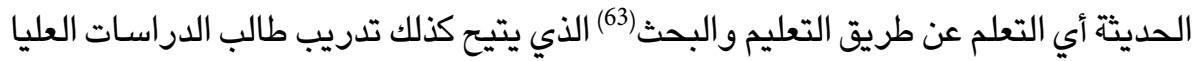

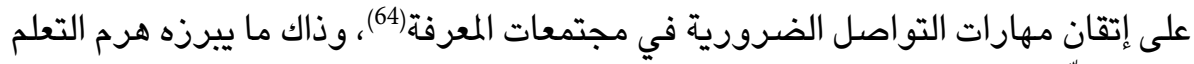
الذي يوضِّح متوسط نسبة تعلم الطالب حسب وسـائل التدريس التي يعتمدها المدرِّس (65).

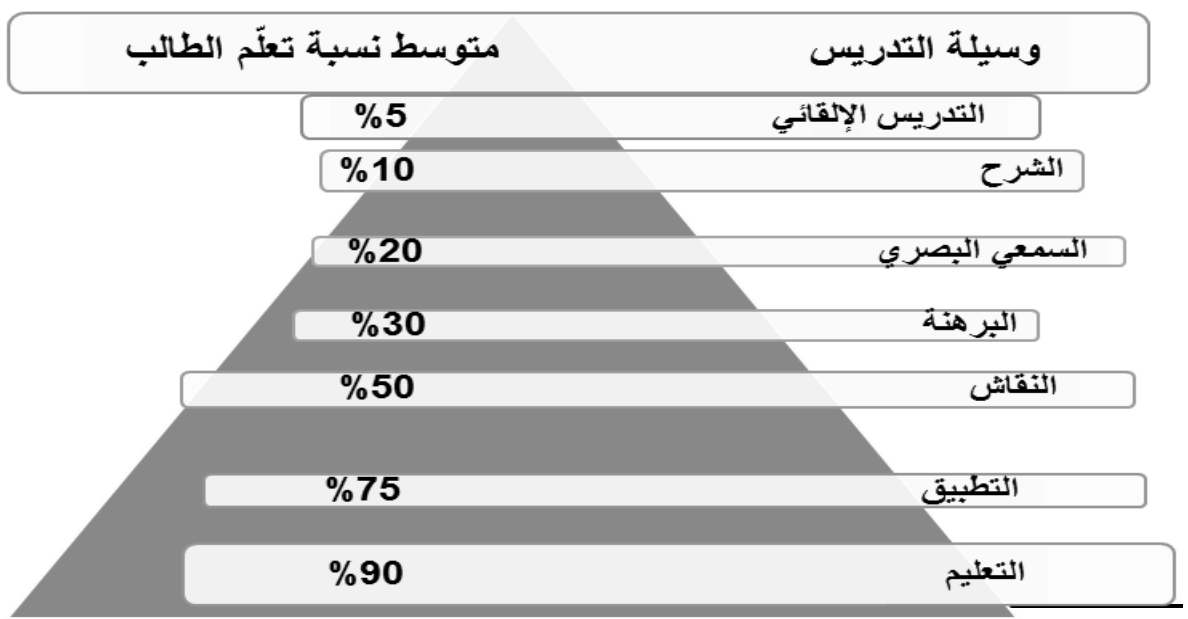

(60) E. Thaller, Traité élémentaire de droit commercial, Paris, 1898, Rousseau, préface, p. IV.

(61) Christian Atias, La Controverse Et L'enseignement du Droit, Annales D'histoire des Facultés de Droit, 1985, 2, p 120. L.L. Fuller, The Law in Quest of Itself, Chicago, Foundation Press, 1940 aux pp. 138-140.

(62) Christian Atias, La mort de la littérature juridique? Le droit et le savoir : Mémoire en défense, Mc Gill Law Journal Revue De Droit De Mcgill, Volume 32, 1987, No 4, p.754.

(63) Joachim Grzega Learning by Teaching: The Didactic Model LdL in University Classes, p. 5. http:// www.joachim-grzega.de/ldl-engl.pdf.

(64) J. Grezga, J. Schaner, The didactic model L dL (lemen durch lehren) as a way of preparing students for communication in a knowledge society, Journal of Education and teaching, 34 (3), Pp. (175-176) (2008).

(65) Benjamin C.Storm, Genna Angello §Dorothy R.Buchli, Rebecca H.Koppel, Jeri L.Little and John F.Nestojko, Psychology of Learning and Motivation, Chapter Five: A Review of Retrieval-Induced Forgetting in the Contexts of Learning, Eyewitness Memory, Social Cognition, Autobiographical Memory, and Creative Cognition, science direct, Elsevier, Volume 62, 2015, Pp. 141-194. 


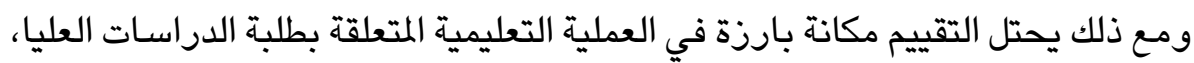

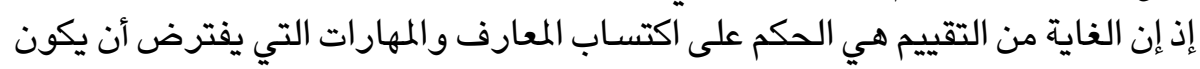

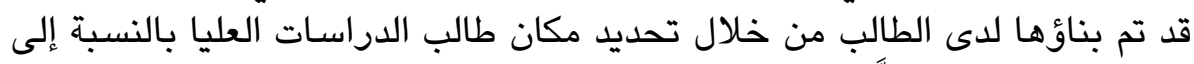

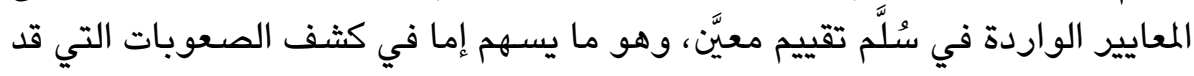

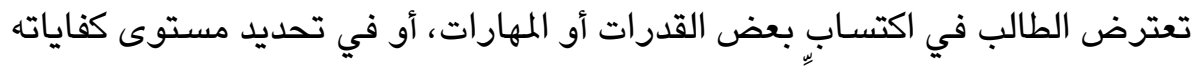

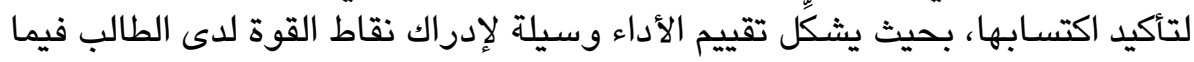

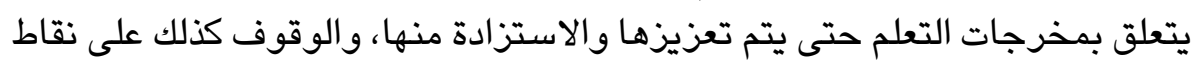

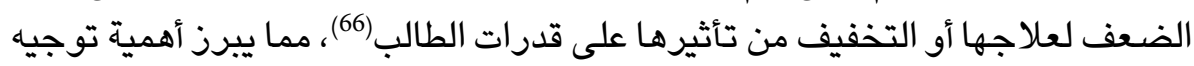

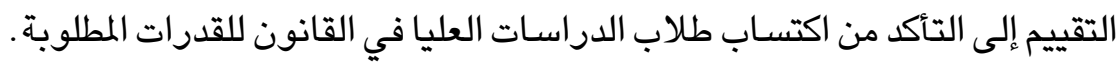

(66) أحمد حسين اللقاني وعلي أحمد الجميل، معجم المصطلحات التربوية المعرفة في المناهج وطرق التدريس،

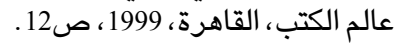




\section{المبحث الثاني}

\section{توجيه التقيـم إلى التأكد من اكتسـاب طلاب الدراسات العليا في القانون للقدرات المطلوبتة}

يُوظِّف الطلاب الجهد في تلقي المعرفة ضمن أي مقرر من خلال تصسورهم لعاملين

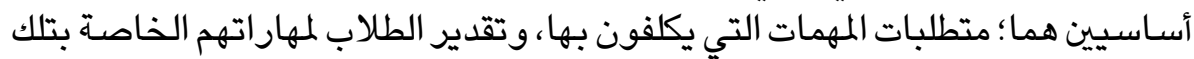

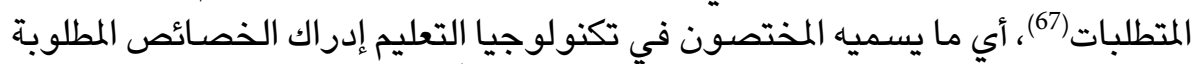

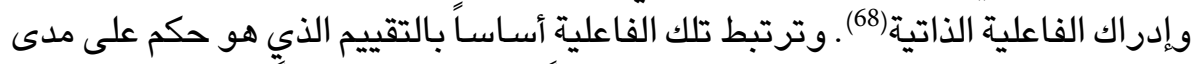

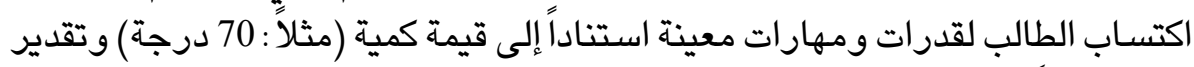
نوعي (مثلاً: ضعيف، مقبول، جيد، ممتاز)(69)، حيث يجب على الملدرِّ أن يضبط معايير

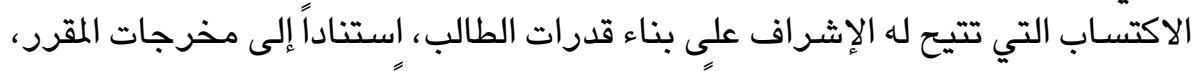

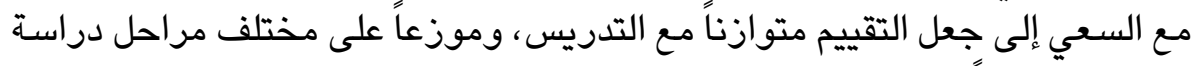

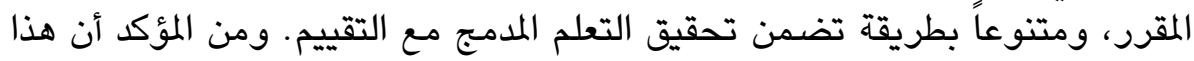

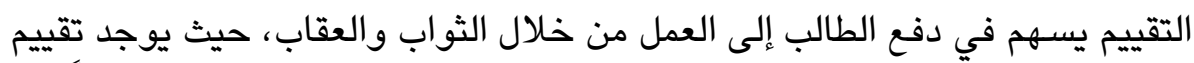

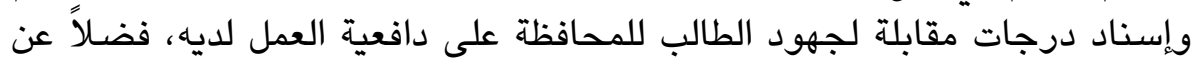

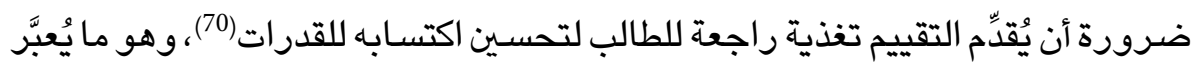

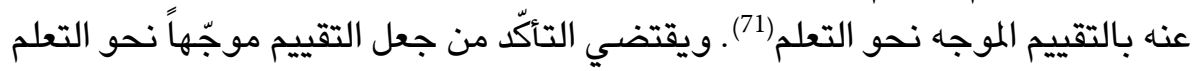

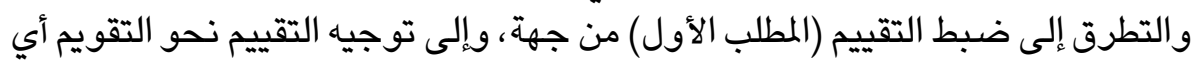
التقييم من أجل التعلم (المطلب الثاني) من جهة أخرى .

(67) Michael R. Solomon and Sarah Drenan and Chester A. Insko, When is consensus information informative?, Journal of Personality, 1981, Volume 49, Issue 2, pp 212-224, https://doi.org/10.1111/ j.1467-6494.1981.tb00738.x

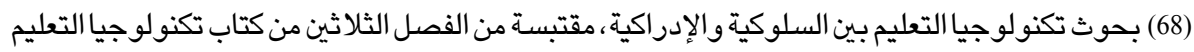

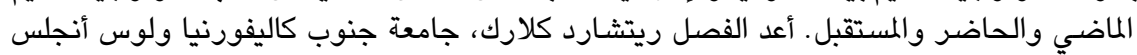

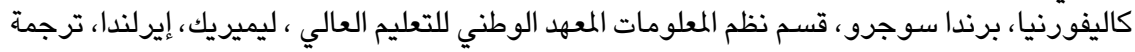

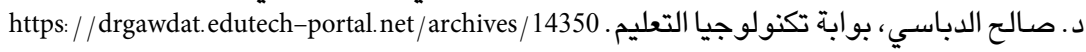

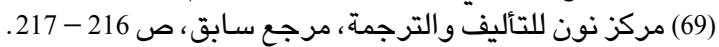

(70) A. Astin, Assessment for excellence: The Philosophy and Practice of Assessment and Evaluation in Higher education, New York: MacMillan Publishing Company.

(71) إقبال زين العابدين درنديري، نحو تقييم موجه للتعلم : أفضل الممارسات وأهم التحديات، منشور على : لمالى

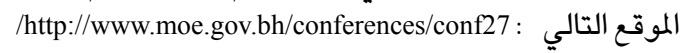




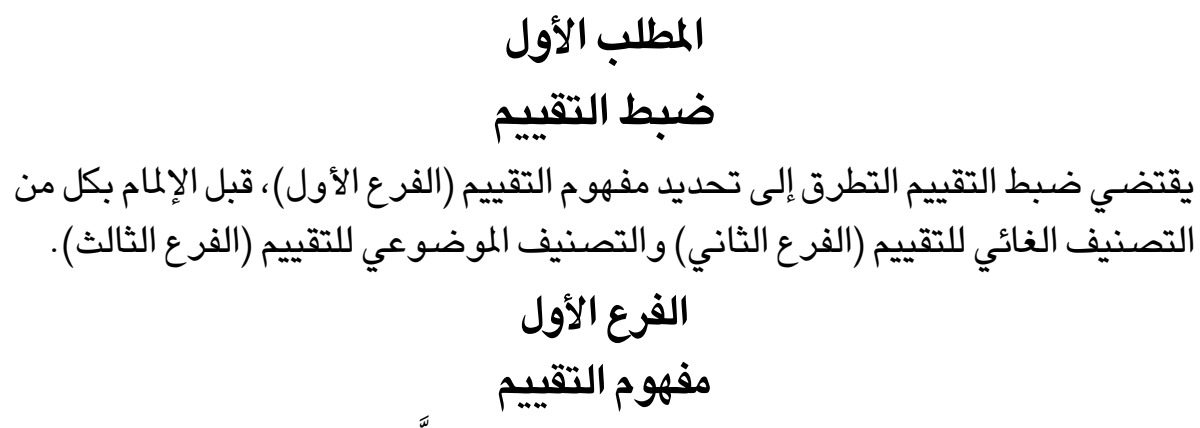

لقد كان لتقييم طلبة الدراسـات العليا أهداف تقليدية تتمثلّ في انتقاء النخبة الأكاديمية

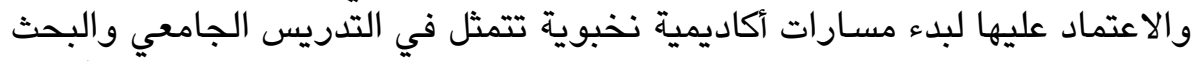

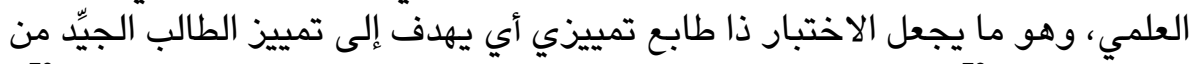

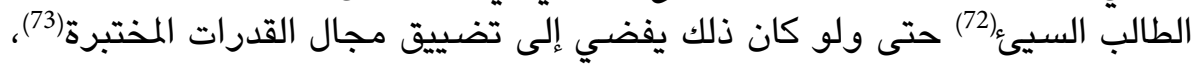

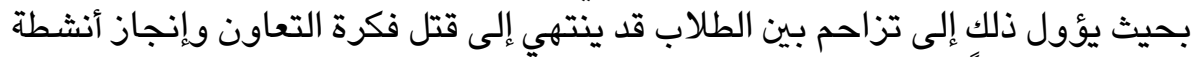

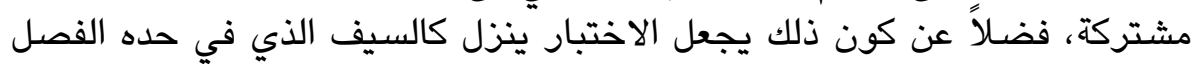
بين الطالب الجيد والطالب السيئ، وهو ما يخرج عن الأهداف المعاصرة لتقييم طلبية

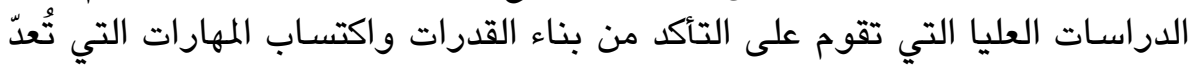
مخرجات لمقررات الدراسـات العليا.

وقد أخذت بذلك السياسـة الأكاديمية لجامعة شـربروك بكندا التي ورد فيها أنّه : (ريتجاوز التقييم مجرد الجزاء، وإنما هو مكوِّن لا يمكن فصله عن عملية التدريب وإكسـاب

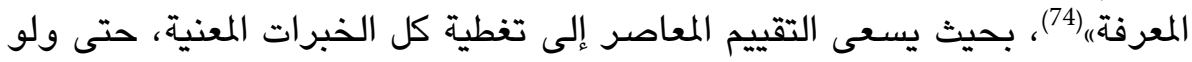

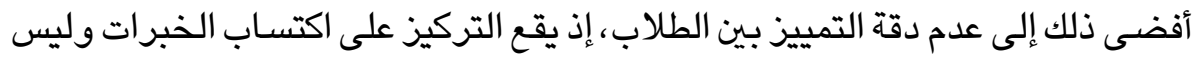

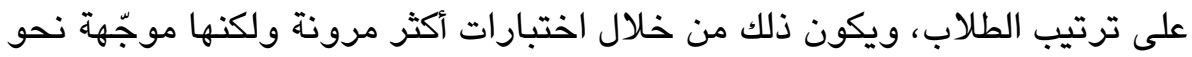

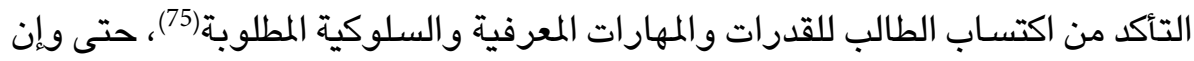

(72) Felouzis Georges, Les étudiants et la sélection universitaire, Revue française de pédagogie, volume 119, 1997, L'éducation préscolaire, pp. 91-106; doi: https://doi.org/10.3406/rfp.1997, 1170. https:// www.persee.fr/doc/rfp_0556-7807_1997_num_119_1_1170.

(73) Marc Romainville, L'évaluation des acquis des étudiants dans l'enseignement universitaire, Décembre 2002, page 21, Rapport établi à la demande du Haut Conseil de l'évaluation de l'école. Directeur de la publication: Christian Forestier, Secrétariat général: 3-5, bd Pasteur 75015 - PARIS; http://ifgu.auf.org/media/document/L\%C3\%A9valuation_des_acquis_des_\%C3\%A9tudiants_dans_ lenseignement_universitairer.pdf.

(74) Politique 2500-008 Évaluation des apprentissages, Université de Sherbrooke, page 2, l'évaluation dépasse le simple geste «sanctionnel»: elle est une composante indissociable de la dynamique même de l'apprentissage» https:/www.usherbrooke.ca/accueil/fileadmin/sites/a-propos/documents/ direction/politiques/2500-008.pdf.

(75) Martin A. O’Neill, Adrian Palmer: Importance performance analysis, useful tool for directing continuous quality improvement in higher education, Journal of Quality Assurance in Education, Volume: 12, Issue: 1; 2004, Pp.39- 52 . 
كانت إحدى الدراسـات قد بَيَّت أنَّ 16 \% فقط من الطلبة يعتبرون التقييم فرصـة لإعادة النظر فيما تعلموه(76)، مما يبرز ضرورة وضـع نظام للتقييم يضمن تحقق عدم سطحية مخرجات التعلم(77).

ويجوز الاستناد عموماً إلى تصنيفين رئيسيين للتقييم، يتمثّل أحدهما في التصنيف

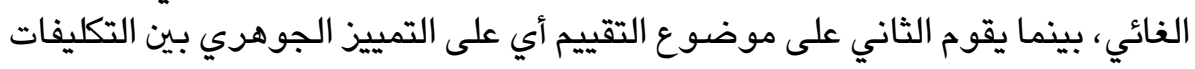

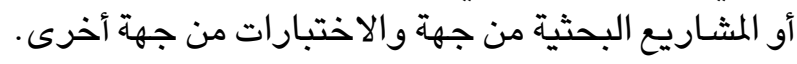

\section{الغرع الثاني}

\section{التصنيف الغائي للتقيبم}

ينقسـم التقييم، استناداً إلى المعيار الغائي، إلى فئات ثلاث من التقييمات :

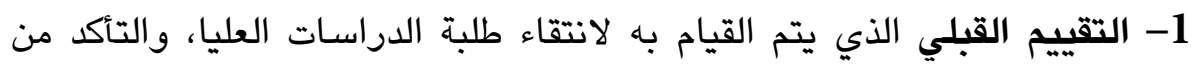

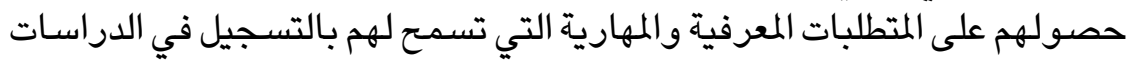

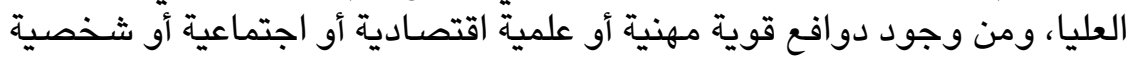

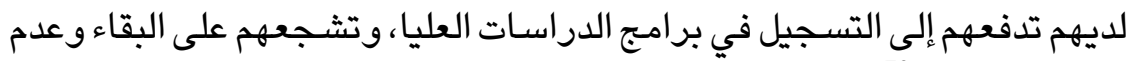

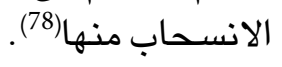

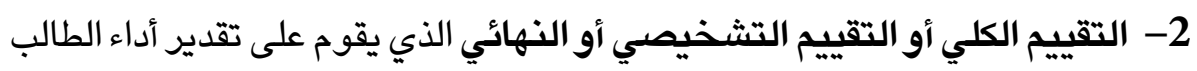

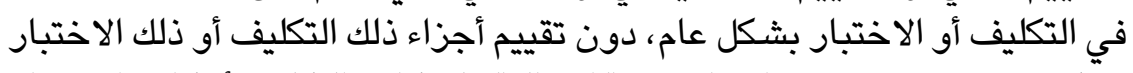

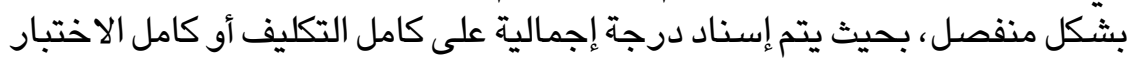
دون أن تكون هنالك أية درجة جزئية تتعلق بالتكليف أو الاختبار.

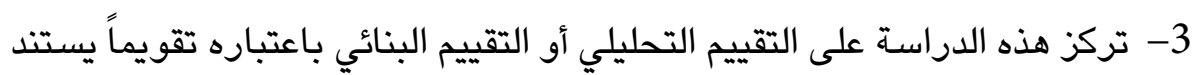

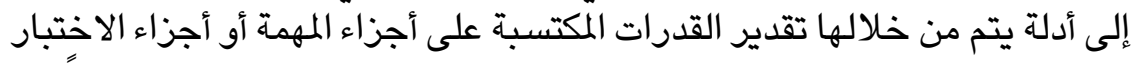

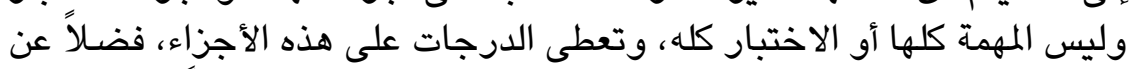

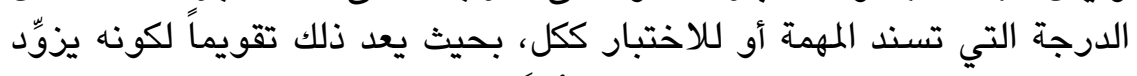

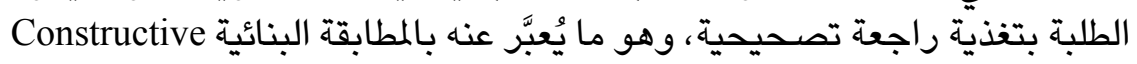
Alignment

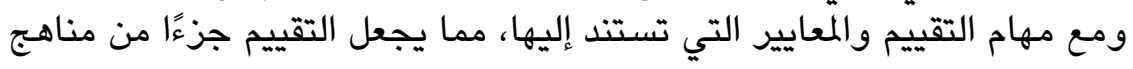

(76) Gabriela Ibeth Navarro : L'évaluation des étudiants à l'université. Communication à la 6e Biennale de l'éducation et de la formation, Paris (2-5 juillet 2002). http://www.inrp.fr/biennale/7biennale/Contrib/ longue/7037.pdf.

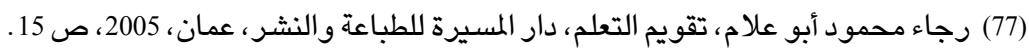

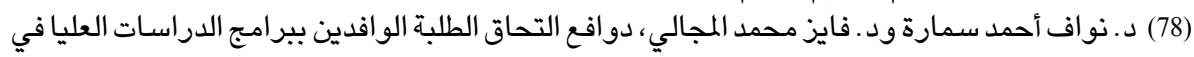

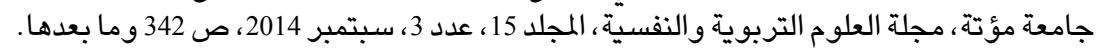


التدريس ومخرجات التعلم (79). كما أنَّ من شـأن ذلك أن ينقل التقييم (من كونه أحداثاً منفصلة ترتبط بنهاية التدريس إلى كونه سلاسل متصلة من الأحداث المرتبطة

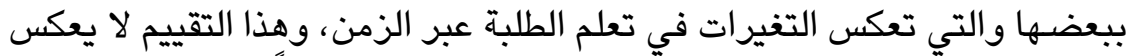

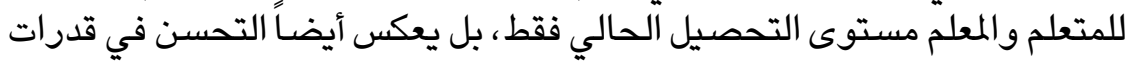

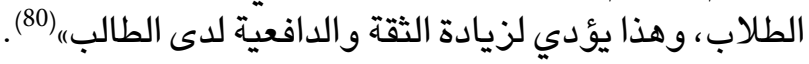

\section{الثرع الثالث}

\section{التصنيف الموضوعي للتقيـم: الاختبارات والتكليفات والمشاريح البحثية}

لا يتم تقييم ذات القدرات بواسطة اختبار يجري في الفصل ضمن حيز زمني مُحدَّد،

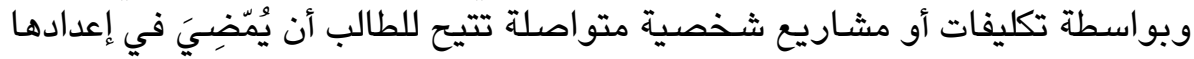

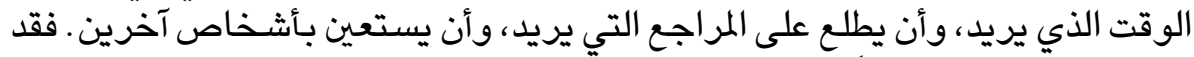

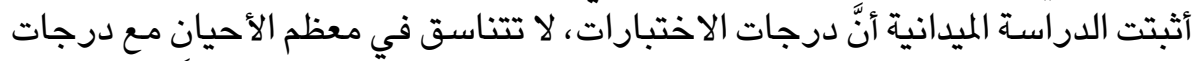

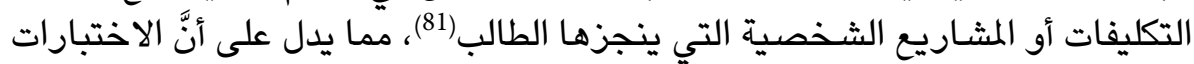

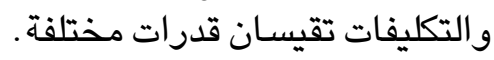

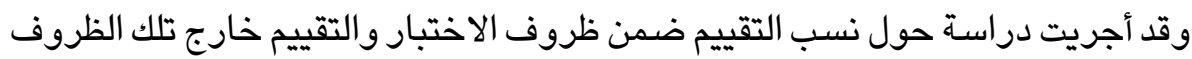

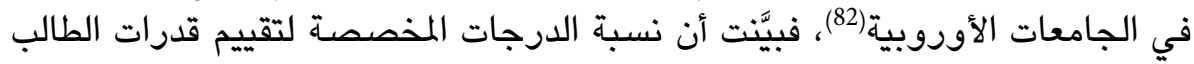

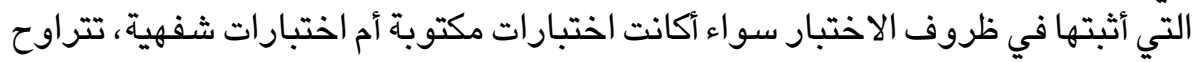
بين 40 \% و70 \% من مجموع درجات الطالب، بينما تراوحت نسبة الدرجات المخصدية

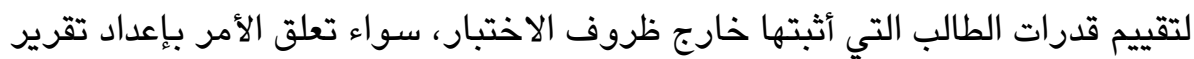

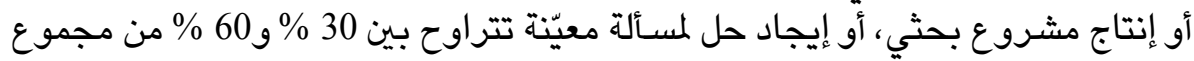

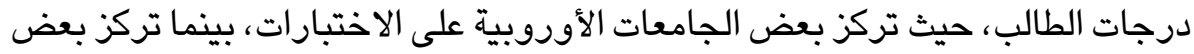

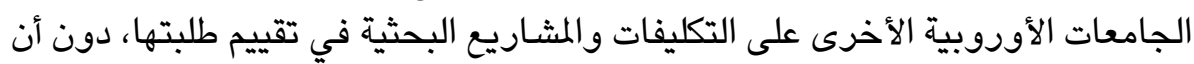

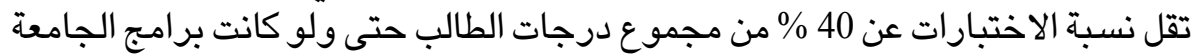

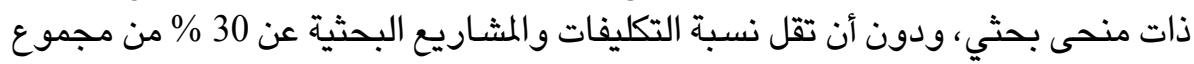

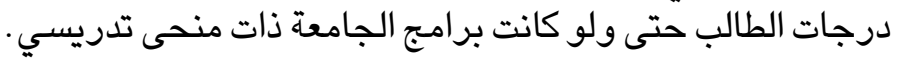

(79) John Biggs and Catherine Tang, Teaching for quality learning at university, what the student does, 4th edition, (London, Society for Research into Higher Education and the Open University Press) 2011, pp 95-110.

(80) Richard John Stiggins, Student-involved assessment for learning (5th ed.), Upper Saddle River, NJ: Pearson Merrill Prentice Hall 2008, p. 27; Richard John Stiggins: Assessment Crisis: The Absence of Assessment FOR Learning, Phi Delta Kappan, June 2002, pp.758-765.

(81) York M., Bridges P. \& Woolf H., Mark distributions and marking practices in UK higher education, Active learning in higher education, 1 (1), pp.7-27.

(82) Warren Piper D., Are professors professional? The Organization of University Examinations, London, Jessica Kingsley Publishers; Heywood J.: Assessment in Higher Education, London, Jessica Kingsley Publishers. 


\section{المطلب الثاني}

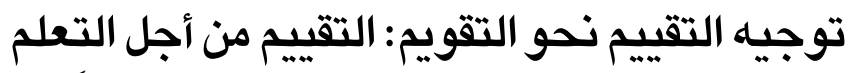

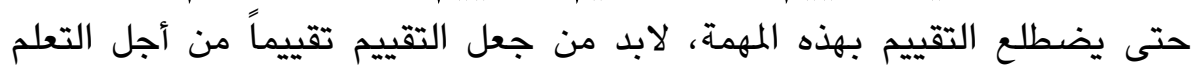
Assessment for Learning

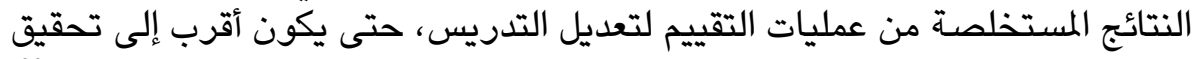

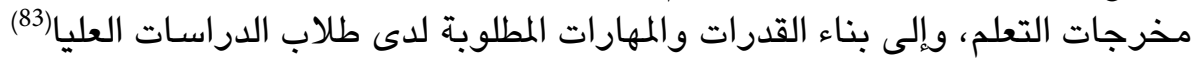

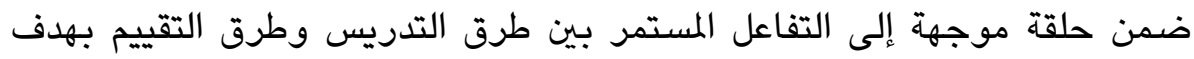

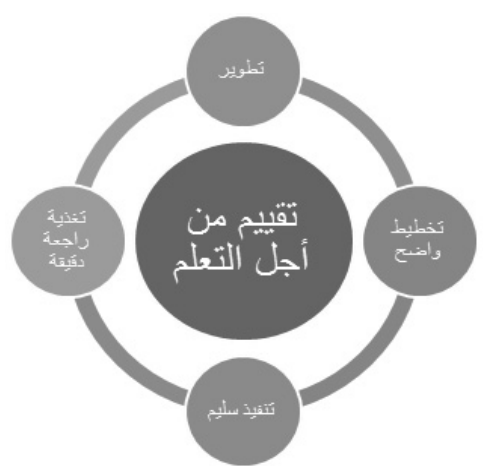

التحسين المستمر (84) فئه

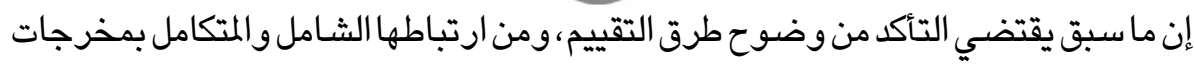

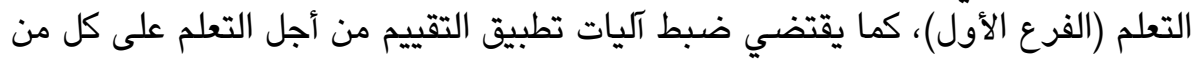

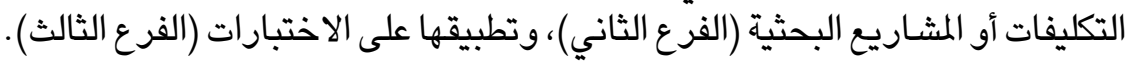

\section{الفرع الأول}

\section{وضوح طرق التقييم وارتباطها بمخرجات التعلم}

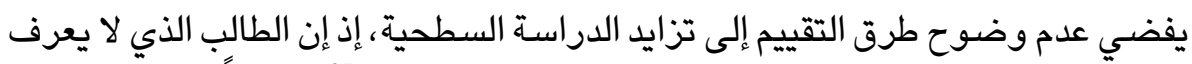

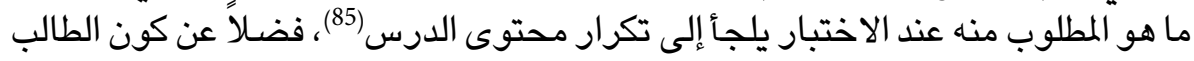

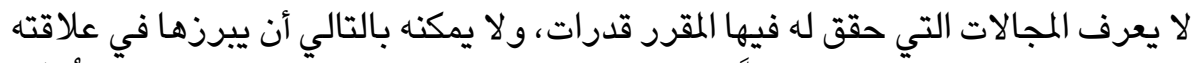

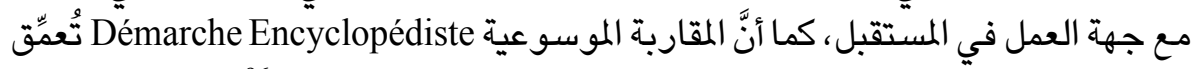
لدى الطالب الميل إلى الاعتماد على الذاكرة وحفظ معلى المقاربة المعات دون تعمق (86).

(83) أخذت بذلك صراحة سياسة التقييم والامتحانات لمعهد الدوحة للدراسات العليا ضمن مقدمة

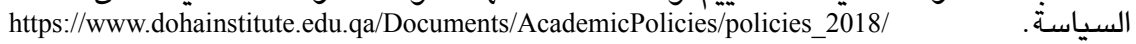
DIAcademicPolicies_Assessment_AR_2018_10_15.pdf

(84) P. Black \& D. William, Inside the black box: Raising standards through classroom assessment, Phi Delta Kappan, 1980, 2, pp.139-148.

(85) Edwards A. \& Knight P., Assessing competence in higher education,. London: Kogan Page.

Elton L., Are UK degree standards going up, down or sideways? Studies in Higher Education, 23 (1), pp. 35-42.

(86) Comité national d'évaluation, La formation des pharmaciens en France, Volume 1: les études, Paris: 


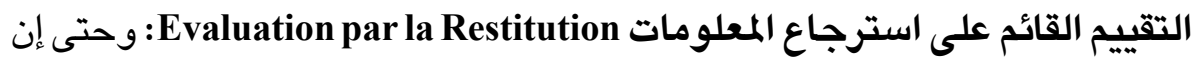

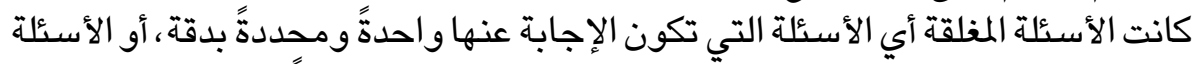

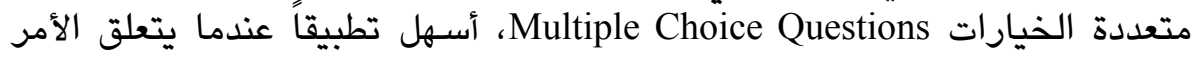

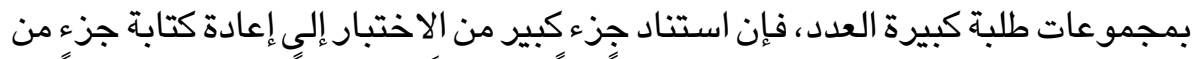

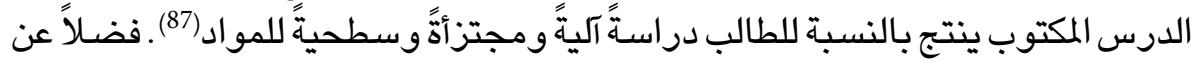

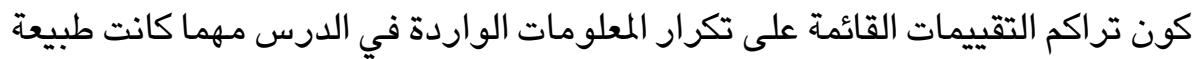

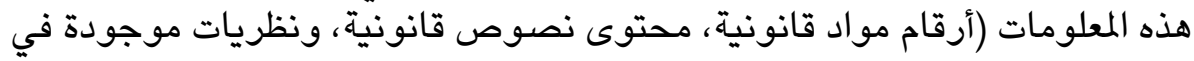

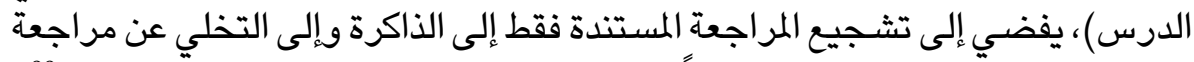

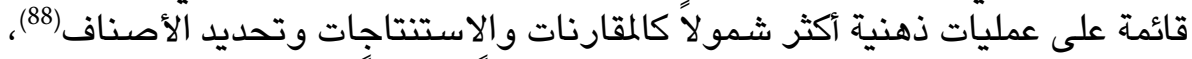

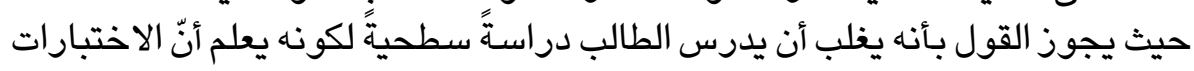

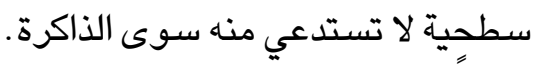

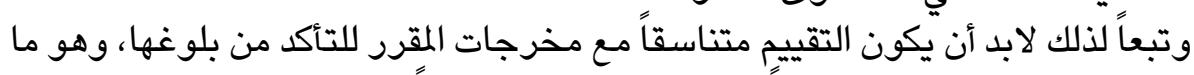

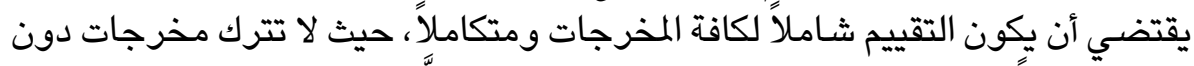

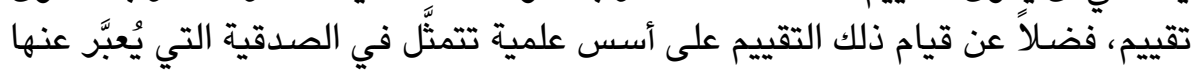

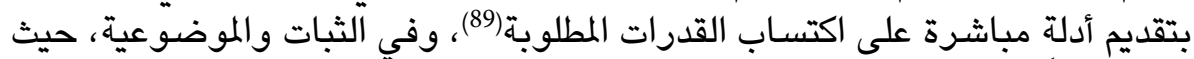

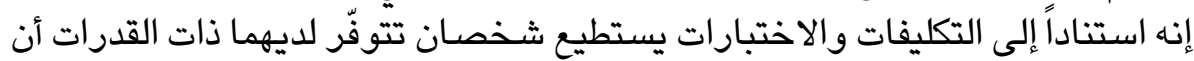

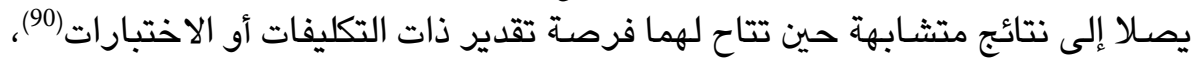

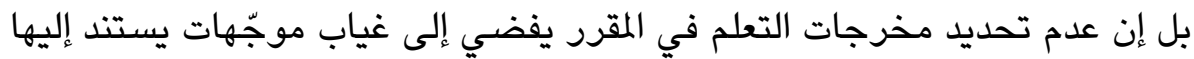

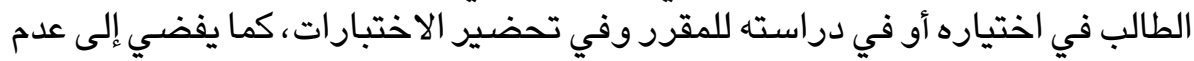

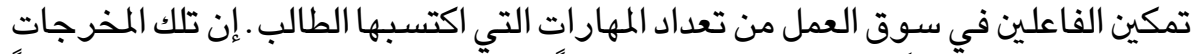

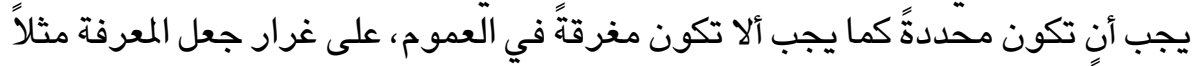

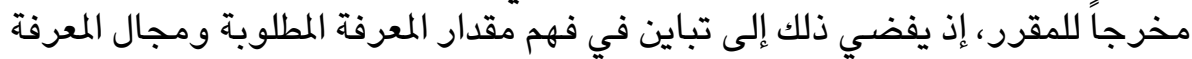

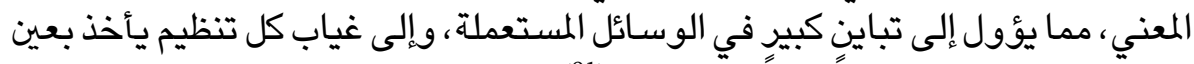

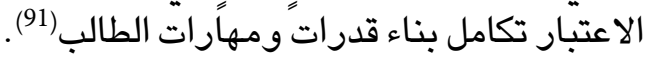

La Documentation Française, p 39.

(87) Montgomery D., Critical theory and practice in evaluation and assessment, G. Gibbs (ed). Improving student learning through assessment and evaluation, Oxford Brookes University, pp 88-105.

(88) Scouller K., The influence of assessment method on students' learning approaches. Higher Education, 35 (4), pp 453-472.

(89) Irving A Taylor: A theory of creative trans-actualization: op. cit., p.146.

(90) Irving A Taylor: A theory of creative trans-actualization: op. cit. p.144.

(91) Comité national d'évaluation, La formation des pharmaciens en France - Volume 1: les études, Paris: La Documentation française, p. 37 ; Dejean J. : L'évaluation de l'enseignement dans les universités françaises. Rapport établi à la demande du Haut Conseil pour l'évaluation de l'école. Paris: Haut Conseil pour l'évaluation de l'école. 


\section{الفرع الثاني}

\section{تطبيق التقييم من أجل التعلم على التكليفات والمشاريع البحثية}

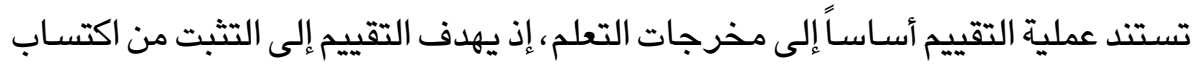

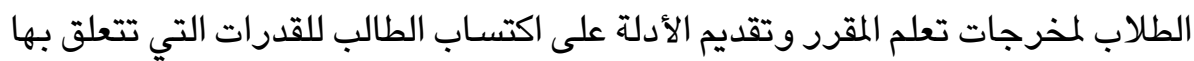
تلك المخرجات(92).

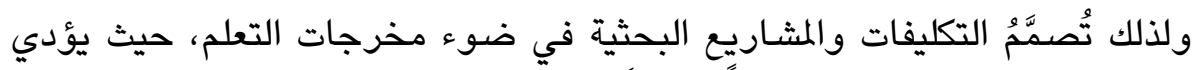

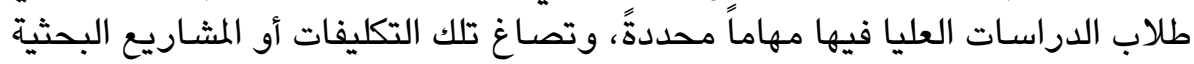

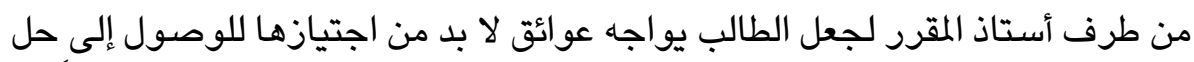

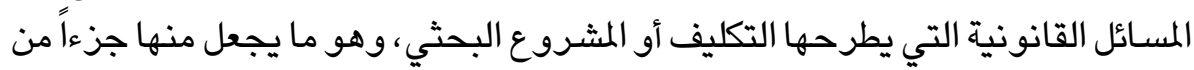

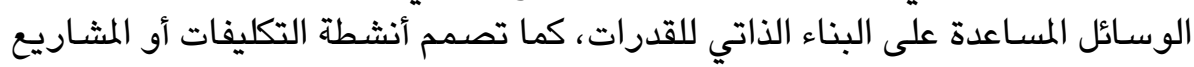

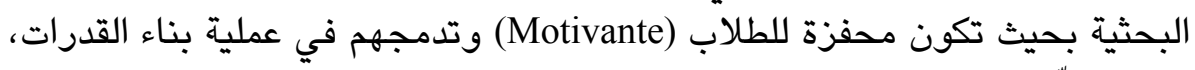

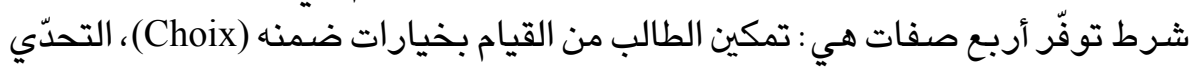

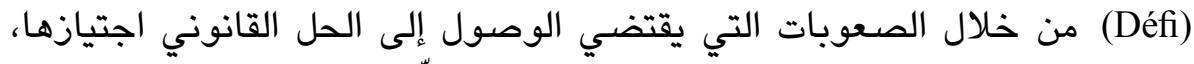

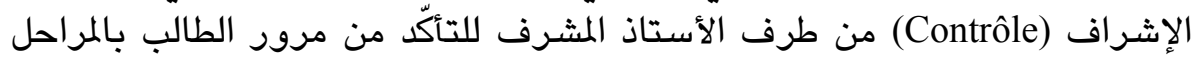

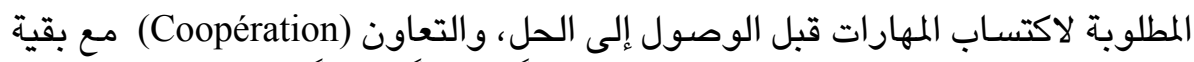

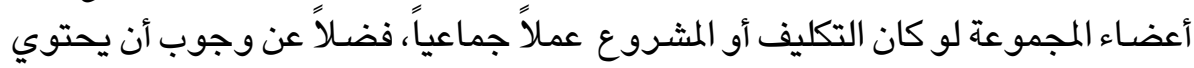

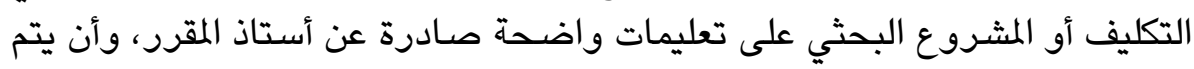
إنجازه في مدة زمنية كافية. وتأسيساً على ذلك ترتبط نجاعة تصميم التكليف أو المشروع البحثي بتوفُّر الصفات التالية : و

1 ـ الارتباط القوي والمباشر بمخرجات تعلم المقرر، أو بأهداف جزئية ذات صلة

$$
\text { قوية بمخرجات التعلم. }
$$

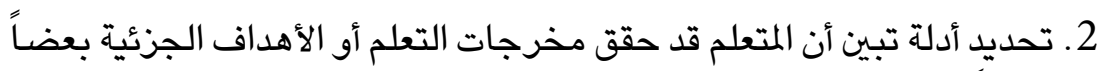

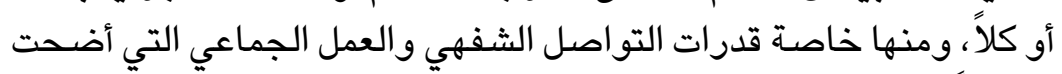
مطلوبةً بشدة في سوق العمل، وتحتاج إلى دعم مكانتها في التقييم (93).

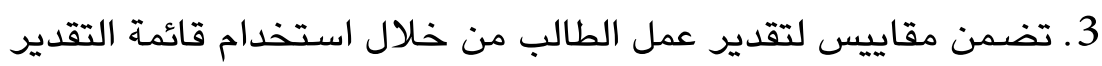

.(Les Rubriques)

(92) Irving A Taylor, A theory of creative trans-actualization : op. cit., p.138.

(93) Montgomery D., Critical theory and practice in evaluation and assessment. In G. Gibbs (ed). Improving student learning through assessment and evaluation, Oxford Brookes University, pp.88-105. 


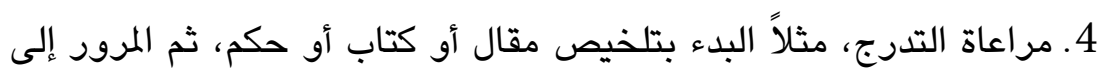

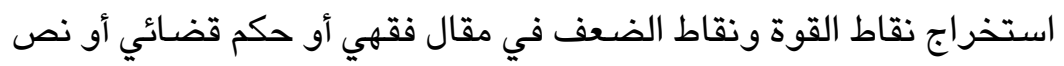

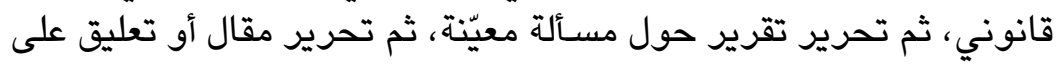
حكم أو على نص قانوني تصني.

5. تضمن تقويم وتفكر : تزويد الطلبة بتغذية راجعة تصحيحية.
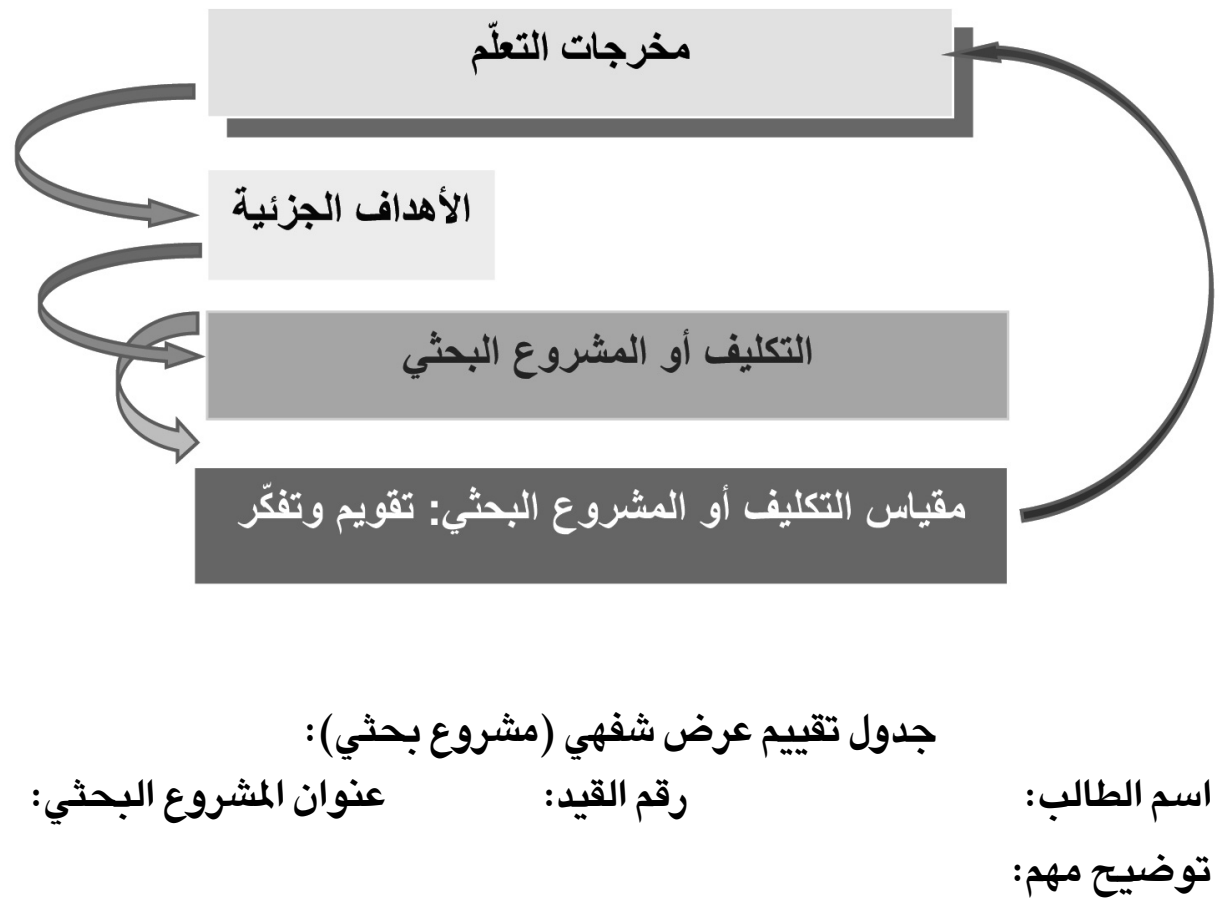

1 - لا يتم ملء الجدول إلا بعد الاستماع إلى عرض الطالب كاملاً وبعد الاستماع إلى إجاباته على كل الأسئلة

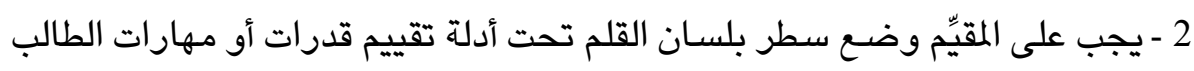
التي يراها موجودة في العرضي وضع.

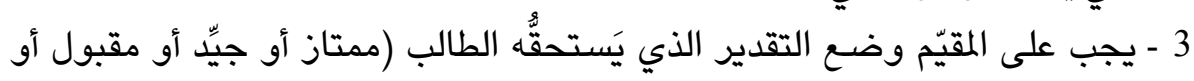
ضعيف)، ضمن دائرة يرسمها بالقلم.

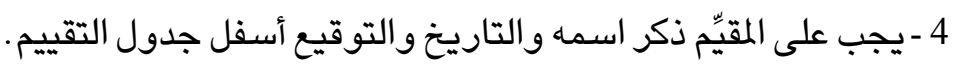




\begin{tabular}{|c|c|c|c|c|c|}
\hline موضيوع التقيبم & ضعيف & مقبول & جيّد & ممتاز & الدرجات \\
\hline \multicolumn{6}{|c|}{1 ـ محتوى العرض } \\
\hline 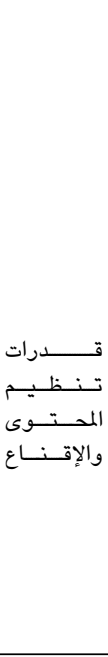 & 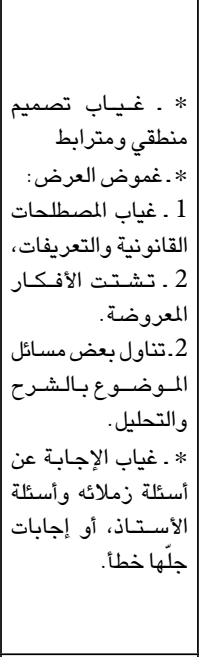 & 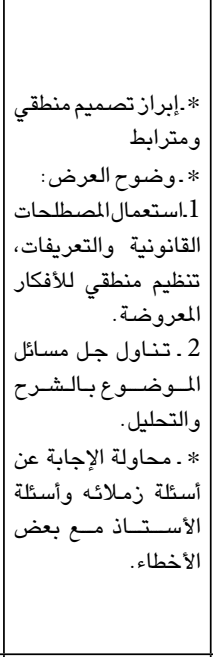 & 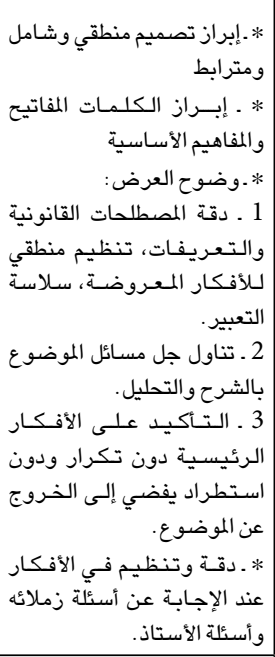 & 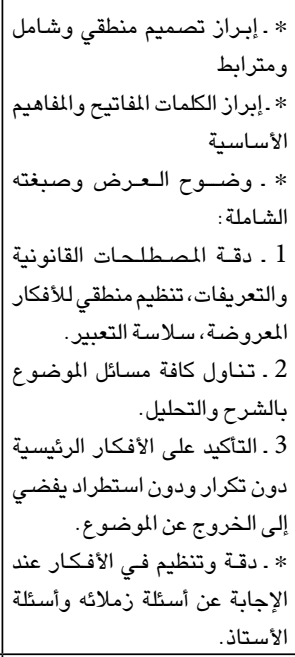 & \\
\hline المتاحة الدات & من 0 إلى 1.5 & من 2 إلى 3 & من 3 إلى 4 & من 4 إلى 5 & \\
\hline \multicolumn{5}{|c|}{ الدرجة المسندة للطالب } & $/ 5$ \\
\hline \multicolumn{6}{|c|}{ 2 ـ شكل العرض } \\
\hline والتـــــــــــل & 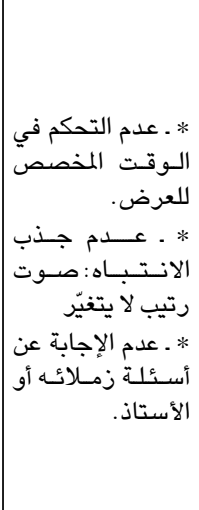 & 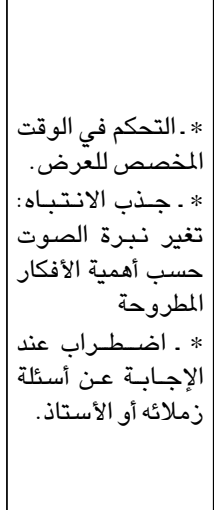 & 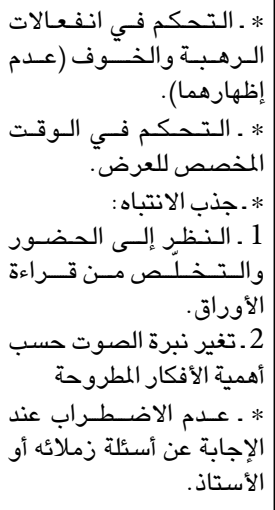 & 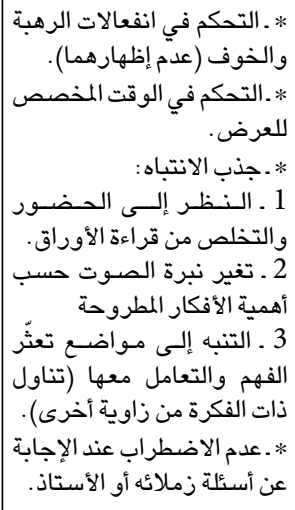 & \\
\hline المتاحة الدات & من 0 إلى 1.5 & من 2 إلى 3 & من 3 إلى 4 & من 4 إلى 5 & \\
\hline \multicolumn{5}{|c|}{ الدرجة المسندة للطالب } & $/ 5$ \\
\hline \multicolumn{5}{|c|}{ مجموع الدرجات } & $/ 10$ \\
\hline
\end{tabular}

التتوقيع:

التاريخ:

اسهم المقيَهَ: 


\section{الغرع الثالث \\ تطبيق التقييم من أجل التعلم على الاختبارات}

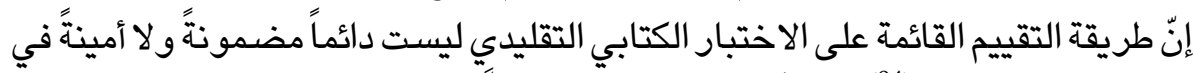

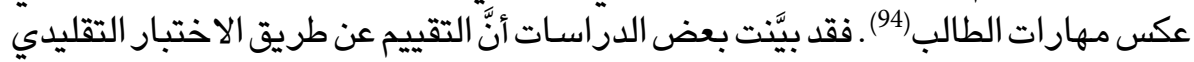

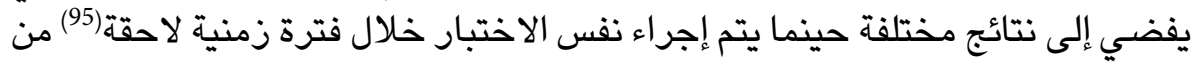

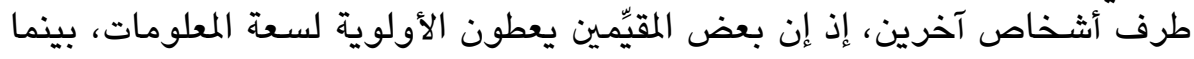

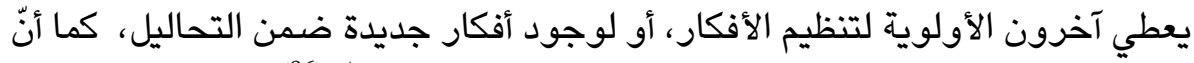

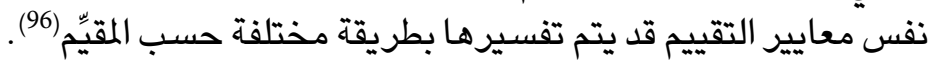
فضـلاً عن كون نتائج الاختبارات التقليدية ليست دائماً مضمونةً نظراً لتضـافر عدة عوامل أهمها: 1. التنامي المضطرد لسلوكيات الغش المتنوِّعة أثناء الاختبار الذي يعتمد على

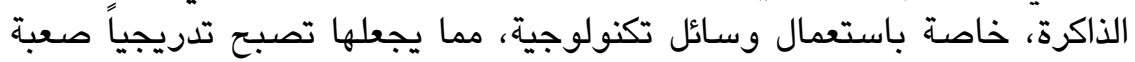
الاكتشاف (97).

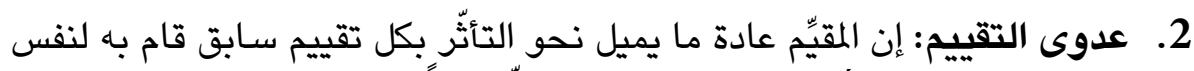

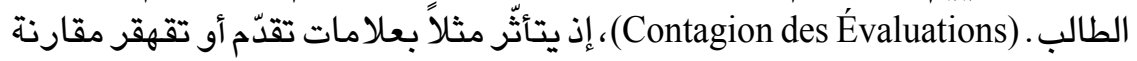
بيداية الدرس.

3. اعتماد الطريقة المعيارية (Méthode Normative) لإسناد الدرجات ضمن الاختبار

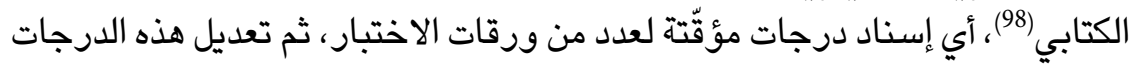

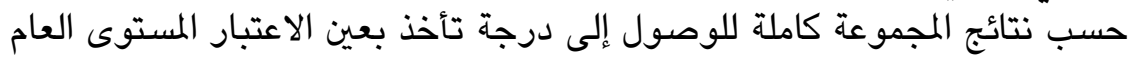

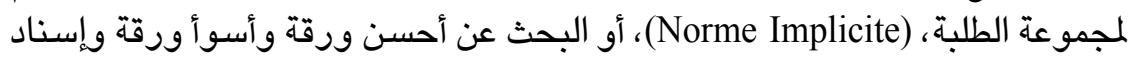

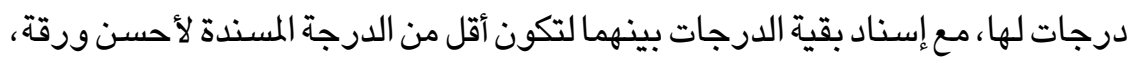
وأحسن من الدرجة المسندة لأسوأورقة (Les Deux Extrêmes).

$$
\text { وهي طريقة لا تخلو من مأخذين جوهريين هما: }
$$

(94) Noizet G. \& Caverni J.-P., Psychologie de l'évaluation scolaire., Presses Universitaires de France, Paris.

(95) Warren Piper D., Are professors professional?, The Organisation of University Examinations; De Landsheere G. : Évaluation continue et examens, Précis de docimologie, Bruxelles, Éditions Labor, London: Jessica Kingsley Publishers.

(96) Webster F., Pepper D. \& Jenkins A. Assessing the undergraduate dissertation. Assessment and evaluation in Higher education, 200, 25 (1), Pp. 71-80.

(97) Phillip C. Wankat, Richard M. Felder, Karl A. Smith, Frank S. Oreovicz, The Scholarship of Teaching and Learning In Engineering, Chapter 11 of M.T. Huber and S. Morreale, eds., Disciplinary Styles in the Scholarship of Teaching and Learning: Exploring Common Ground. AAHE/ Carnegie Foundation for the Advancement of Teaching, Washington, 2002.

(98) Blais J.-G., Laurier M., Van der Maren J.-M., Gervais C., Lévesque M., Pelletier G.: L'évaluation des apprentissages à l'Université de Montréal et dans ses écoles affiliées. Montréal: Groupe de Recherche Interdisciplinaire en Pédagogie Universitaire. 


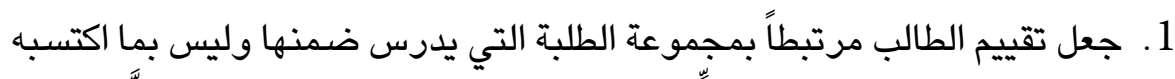

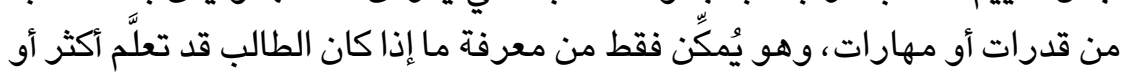

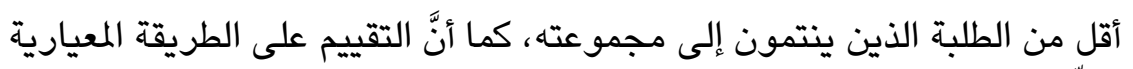
يُركِّز على ترتيب الطلبة ضمن الطبة مجموعاتهم.

2. عدم وضوح القدرات أو المهارات التي اكتسبها الطالب، مما يجعل هذا التقييم مجرَّد

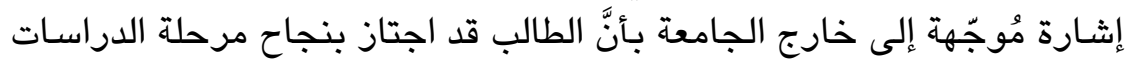
العليا، وهو لا يضمن سوى مستوى أدنى من المعرفة ومن الثقافة الملائمة للفئة

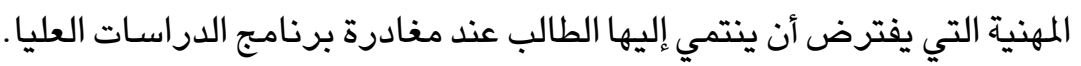
يستند التقييم التقليدي إلى تقييم المعارف الوصفية الشكلية، ولا تذكر الحالات العملية

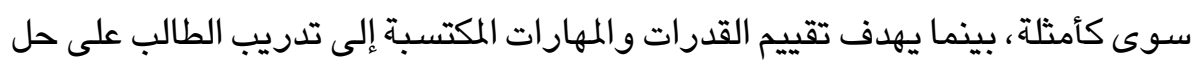

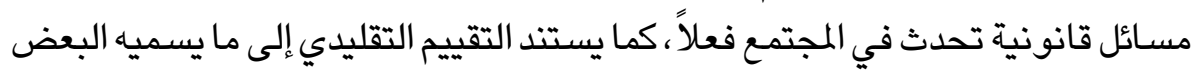

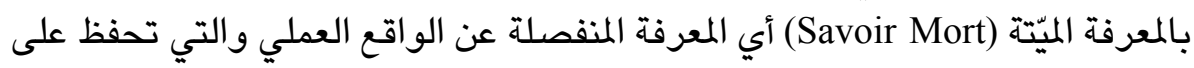

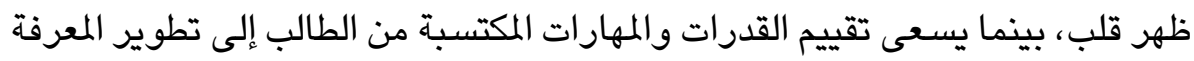
الحية (Savoir Vivant) أي قدرات ومهارات لفهم الواقع العملي والتأثير عليه من خلال التهال

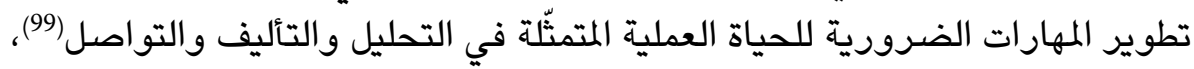

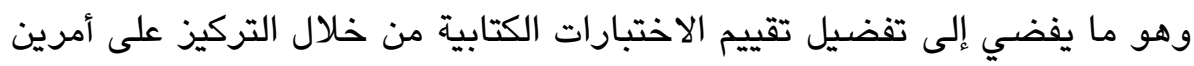

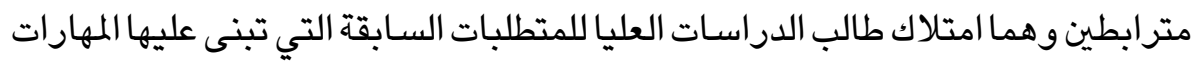

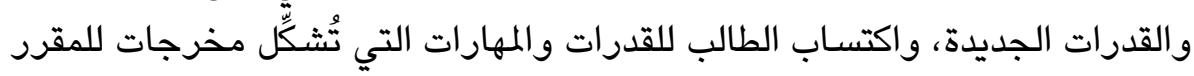
Evaluation par Compétences Acquises

$$
\text { للاختبارات هما: }
$$

1 ـ. جعل الاختبارات قائمة على الأسئلة المفتوحة التي تبرز قدرات الطالب على تحاليل أكثر عمقاً. 2. الأخذ بنظام الثلاث طبقات لتقييم الاختبارات الكتابية(100) حتى يتم التثبُّت من

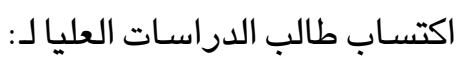

(99) Ramsden, P. Improving learning—New perspectives, London, Kogan Page., Poirier, D. (2001). Le rôle des universitaires dans le développement de la common law en français. Les Cahiers de droit, 42(3), 571-594. https://doi.org/10.7202/043660ar.

(100) Katherine Samuelowicz and John D. Bain, Identifying academics' orientations to assessment practice, Higher education, March 2002, Volume 43, Issue2, pp.173-201. 


\section{أ. القدرة على التأليف Synthèse}

ب. القدرة على إعادة تشكيل المعرفة واستخدامها بطريقة مبتكرة.

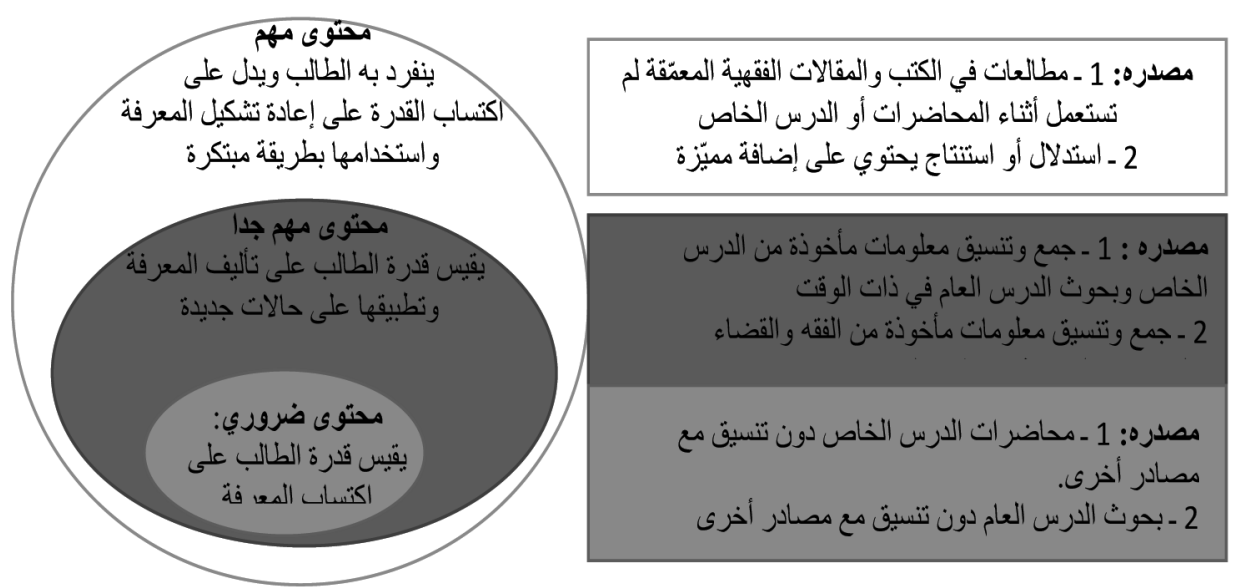

وهو ما يتيح لمدرّس الدراسـات العليا تغذية راجعة حول كل ما توفّره المتطلبات السـابقة

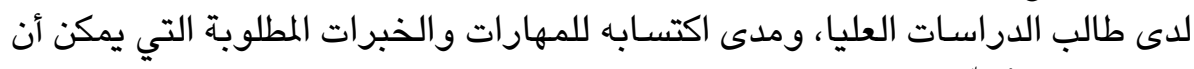

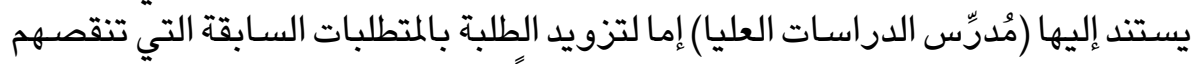

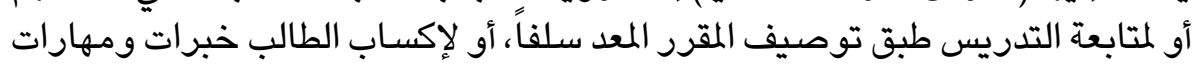

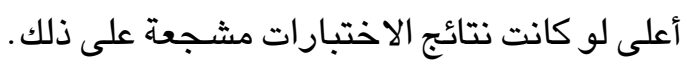

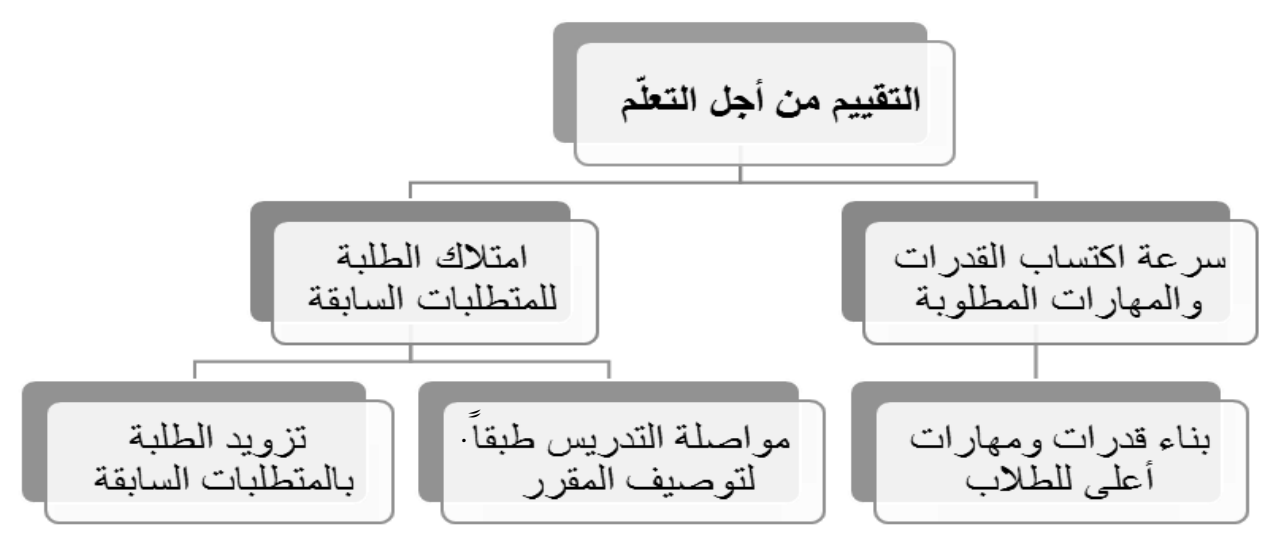

(101) Jim Greer and Gord McCalla and Julita Vassileva and Ralph Deters and Susan Bull and Lori Kettel, Lessons Learned in Deploying a Multi-Agent Learning Support System, The I-Help Experience, Proceedings of AI in Education AIED, 2001, pp.41-42. 


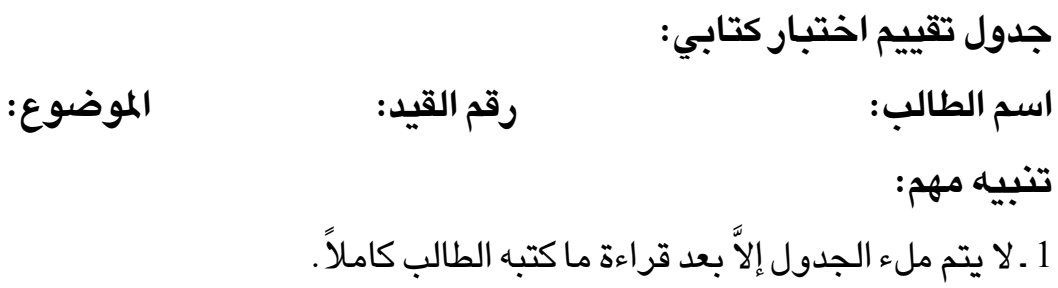

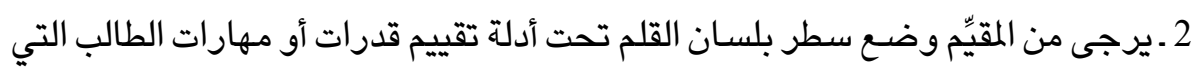

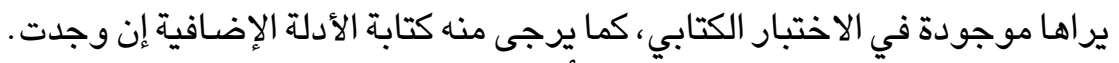

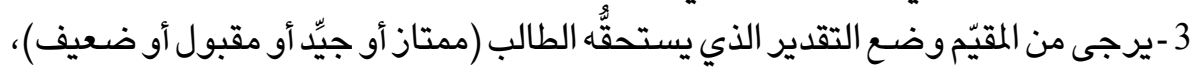
ضمن دائرة يرسمها بالقلم. 4 ـ يرجى من المقيّم ذكر اسمه والتاريخ، ثم التوقيع أسفل جدول التقييم.

\begin{tabular}{|c|c|c|c|c|c|}
\hline \multicolumn{3}{|c|}{ الجزء الأول: تقييم المهارات المتعلقة بالمنهجية القانونية } & \multirow[b]{2}{*}{ 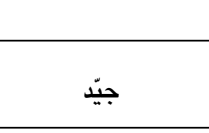 } & \multirow[b]{2}{*}{ 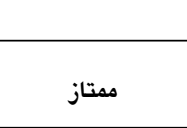 } & \multirow[b]{2}{*}{ الدرجات } \\
\hline موضوع التقييم & ضعيف & 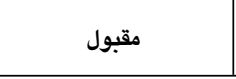 & & & \\
\hline \multicolumn{6}{|c|}{ 1 ـ التقديم } \\
\hline 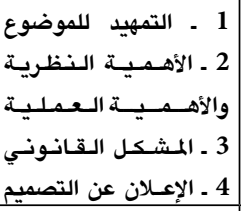 & 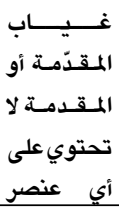 & 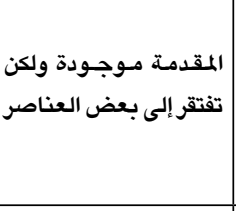 & كل دون ترابط منطق موجودة أو & كل ومنظة العناصرموجودة ومترابطة & \\
\hline 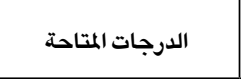 & من 0 إلى 1.5 & 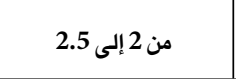 & 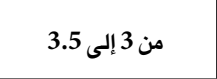 & من 3.5 إلى 4 & \\
\hline \multicolumn{5}{|c|}{ 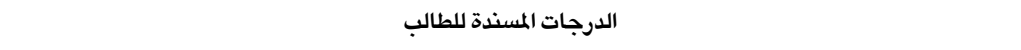 } & $/ 4$ \\
\hline \multicolumn{6}{|c|}{ 2 ـ ـ هيكلة الأفكار وتنظيمها } \\
\hline 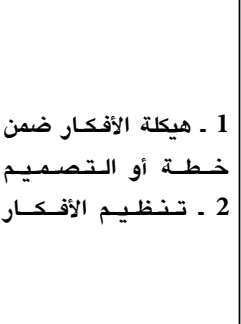 & 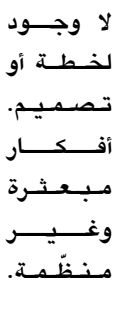 & 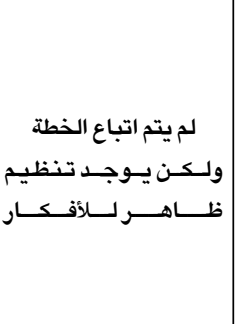 & تنظيم واضــ للأفكار. & 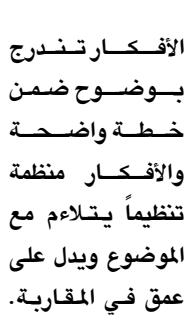 & \\
\hline الدرجات المتاحة & $\begin{array}{c}0 \text { من } 0 \text { إلى } 1.5 \\
0\end{array}$ & من 2 إلى 2.5 & من 3 إلى 3.5 & من 3.5 إلى 4 & \\
\hline \multicolumn{5}{|c|}{ 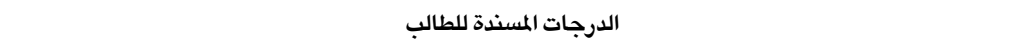 } & $/ 4$ \\
\hline
\end{tabular}




\begin{tabular}{|c|c|c|c|c|c|}
\hline \multicolumn{6}{|c|}{ 3ـ الخاتمة: نتائج البحث والرأي الشخصي } \\
\hline 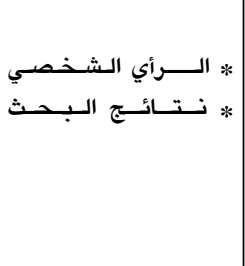 & | غيـاب الرأي & 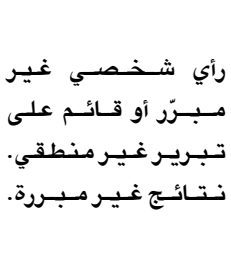 & 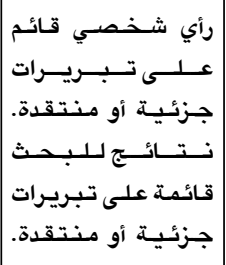 & 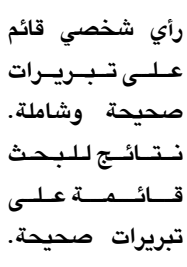 & \\
\hline الدرجات المتاحة & $\begin{array}{c}0 \\
0 \\
\text { إلى } 1.5\end{array}$ & من 2 إلى 2.5 & 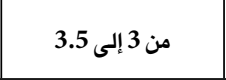 & من 3.5 إلى 4 & \\
\hline \multicolumn{5}{|c|}{ الدرجات المسندة للطالب المالب } & $/ 4$ \\
\hline \multicolumn{6}{|c|}{ الجزء الأول } \\
\hline \multicolumn{2}{|c|}{ من 0 إلى 5.5 } & \multicolumn{3}{|c|}{ من 10.5 إلى 12 من 9 إلى 10.5 من 6 إلى 8.5} & / 12 \\
\hline
\end{tabular}

\begin{tabular}{|c|c|c|c|c|c|}
\hline \multicolumn{3}{|c|}{ الجزء الثاني: تقييم القدرات المتعلقة بمحتوى الاختبار الكتابي } & \multirow[b]{2}{*}{ جيّد } & \multirow[b]{2}{*}{ 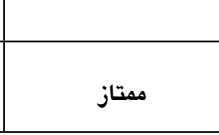 } & \multirow[b]{2}{*}{ الدرجات } \\
\hline التقييم & ضعيف & 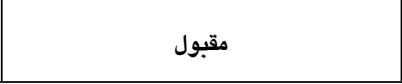 & & & \\
\hline \multicolumn{6}{|c|}{ 1 التحليل } \\
\hline تــــــــــــل & 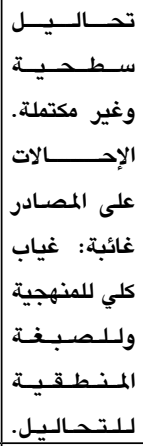 & 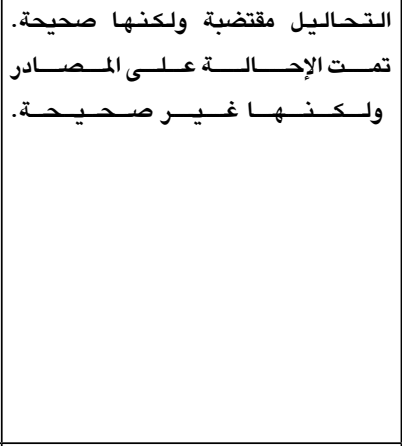 & 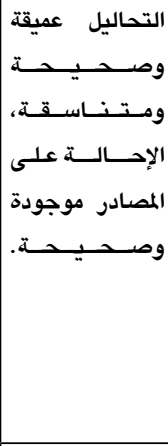 & 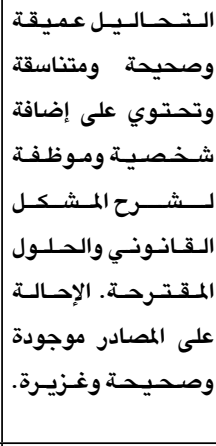 & \\
\hline الداحة المتات & من 0 إلى 1.5 & من 2 إلى 3 & من 3 إلى 4 & من 4 إلى 5 & \\
\hline \multicolumn{5}{|c|}{ الدرجات المسندة للطالب } & $/ 5$ \\
\hline \multicolumn{6}{|c|}{2 ـ استعمال المعلومات وإعادة صياغتها } \\
\hline
\end{tabular}




\begin{tabular}{|c|c|c|c|c|c|}
\hline | المـــــــــــة & 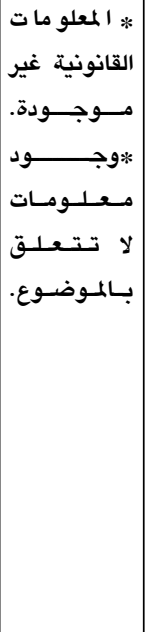 & 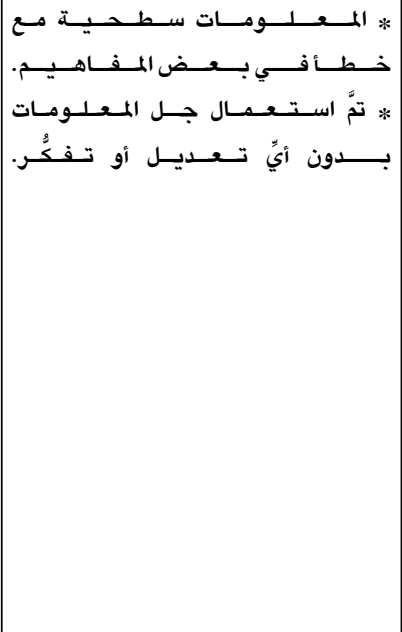 & 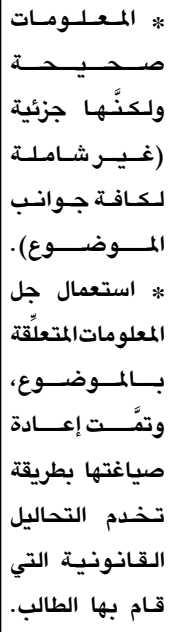 & 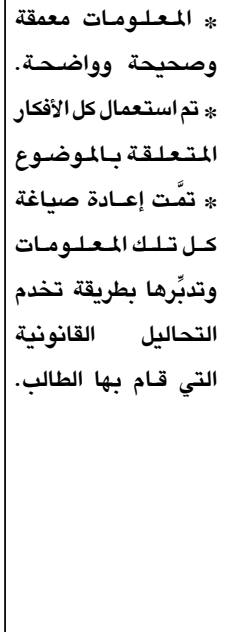 & \\
\hline 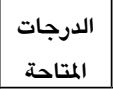 & من 0 إلى 1.5 & من 2 إلى 2.5 & من 3 إلى 3.5 & من 3.5 إلى 4 & \\
\hline \multicolumn{5}{|c|}{ الدرجات المسندة للطالب } & $/ 4$ \\
\hline \multicolumn{6}{|c|}{ 3ـ الكتابة القانونية } \\
\hline 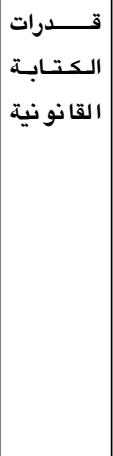 & 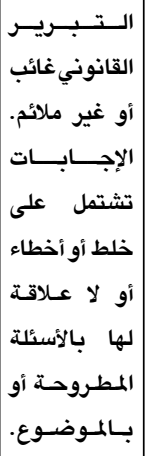 & 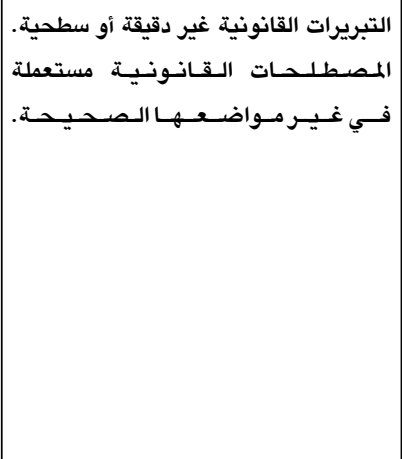 & 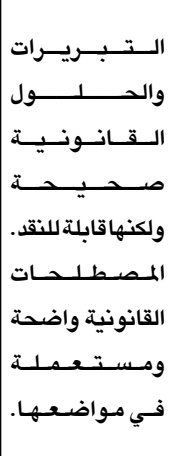 & 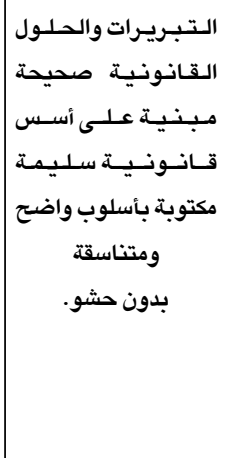 & \\
\hline الدرجات المتاحة & من 0 إلى 1.5 & من 2 إلى 2.5 & من 3 إلى 3.5 & من 3.5 إلى 4 & \\
\hline \multicolumn{5}{|c|}{ الدرجات المسندة للطالب } & $/ 4$ \\
\hline \multicolumn{5}{|c|}{ الجزء الثاني } & $/ 13$ \\
\hline \multicolumn{5}{|c|}{ 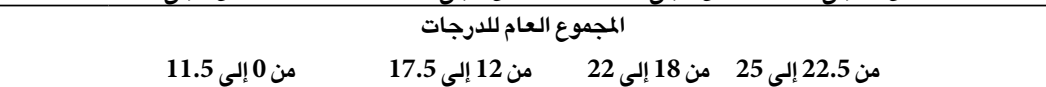 } & $/ 25$ \\
\hline
\end{tabular}


الخاتمة:

يتبيَّن من خلال هذه الورقة البحثية أنَّ السعي إلى جودة التعليم ساهم في تطوير كل

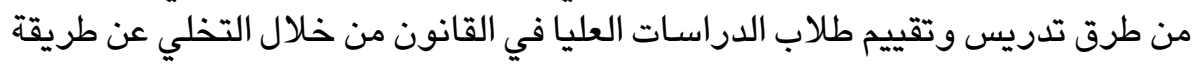

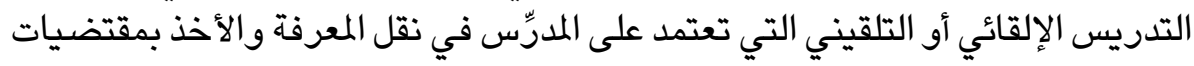

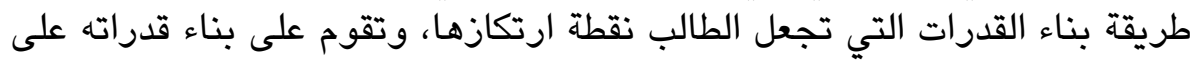
اكتساب المهارات المعرفية والسلوكية المطلوبة المية.

وهو ما يقتضي:

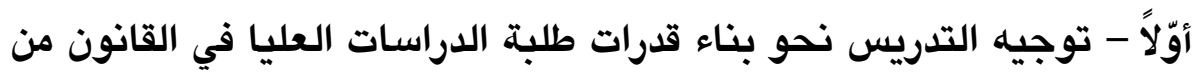
خلال:

أ. جعل التدريس ضمن الدراسات العليا يرتكز على أسس ثلاثة هي:

$$
\begin{aligned}
& \text { 1) التعلم من خلال المسـائل القانونية. } \\
& \text { 2) التعلم التعاوني. } \\
& \text { 3) التعلم من خلال المشاريع البحثية. }
\end{aligned}
$$

ب. الأخذ بآليات توجيه التدريس إلى بناء قدرات طلبة الدراسات العليا في

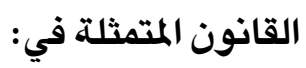

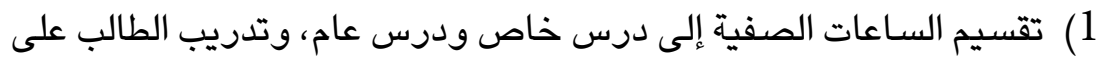

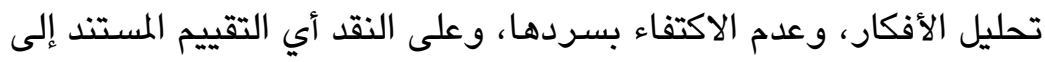

$$
\text { تبريرات قانونية ومنطقية. }
$$

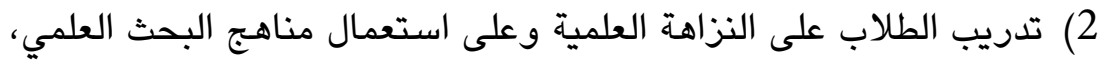

$$
\begin{aligned}
& \text { والالتزام بمناهـج البحث العلمي في مجال القانون. } \\
& \text { 3) تدريب الطلاب على إنجاز مشاريع بحثية وعرضها. }
\end{aligned}
$$

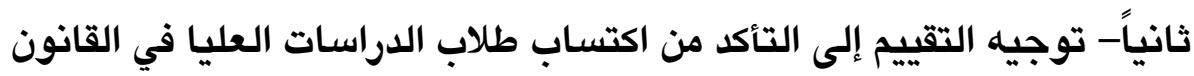

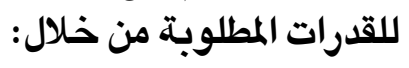

$$
\text { أ. ضبط التقييم استناداً إلى: }
$$

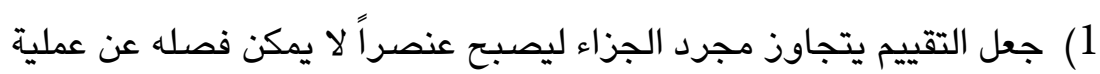

$$
\text { التدريب، وإكساب المهارات المعرفية والسلوكية المطلوية. }
$$

2) الأخذ بالتقييم التحليلي أو التقييم البنائي باعتباره تقويماً يستند إلى أدلة يتم المبات 


\section{من خلالها تقدير القدرات المكتسبة.}

3) جعل التقييم التحليلي أو البنائي يشمل الاختبارات والتكليفات والمشاريع البحثية.

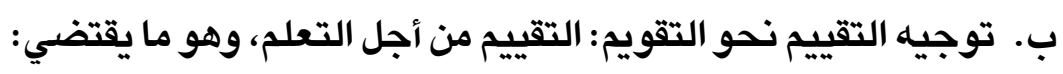

$$
\text { 1) وضوح طرق التقييم وارتباطها بمخرجات التعلم. }
$$

2) تطبيق التقييم من أجل التعلم على التكليفات والمثـاريع البحثية.

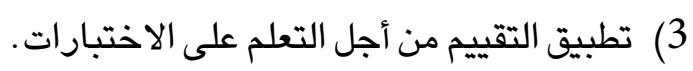

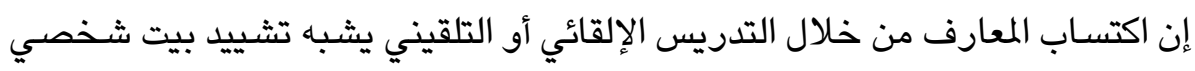

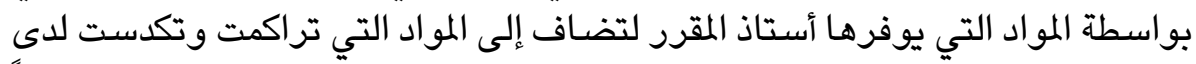

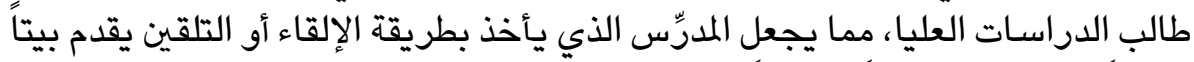

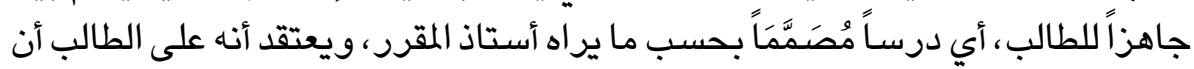

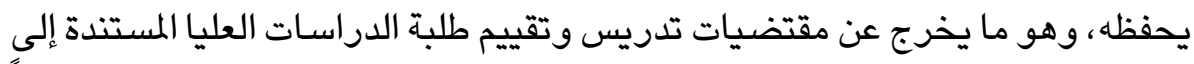

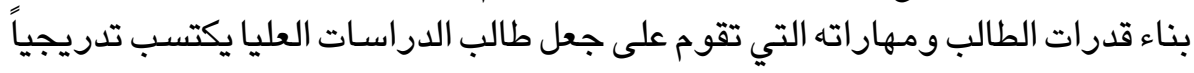

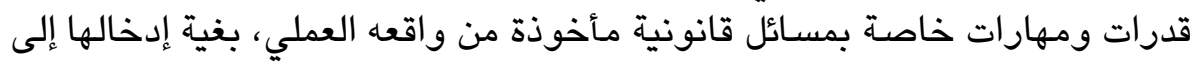

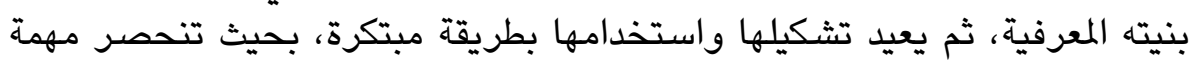

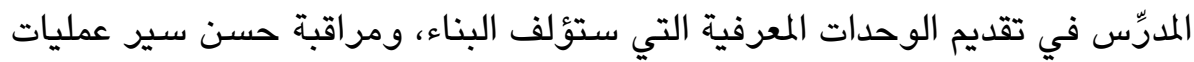

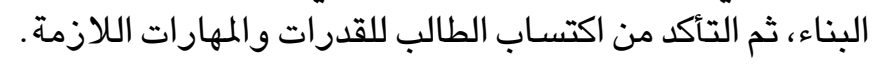

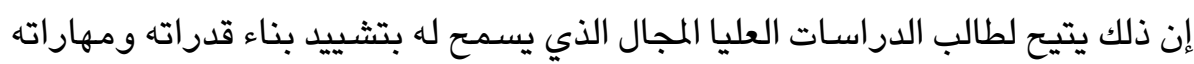

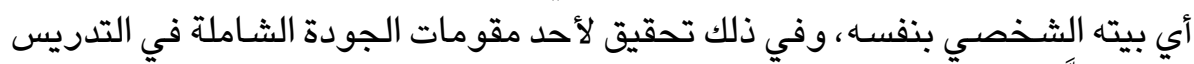

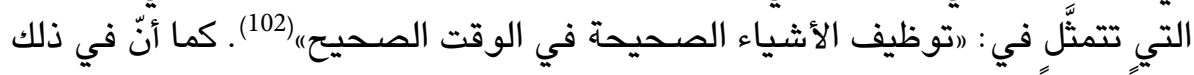

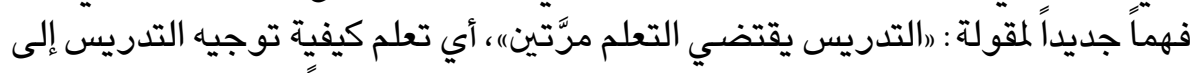

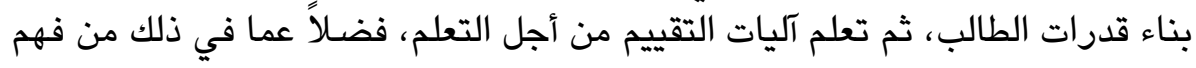

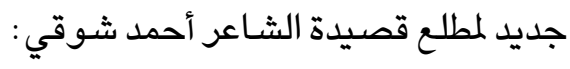

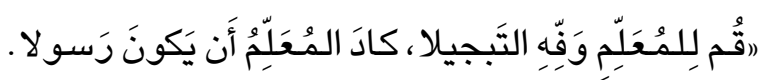

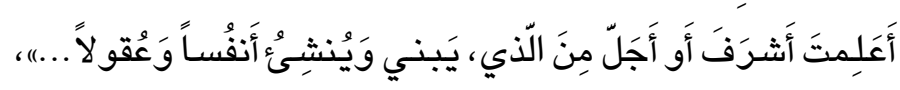
إذاً فتبجيل المدرِّس مرتبط ببناء الأنفس والعقول أي قدرات طلبة الدراسـات العليا.

(102) الهلالي الشربينى الهلالي، إدارة الجودة الشاملة في مؤسسات التعليم الجامعي والعالي، رؤية

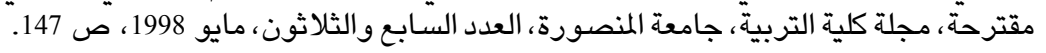




\section{المراجح:

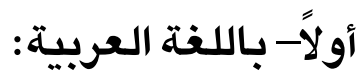 \\ أــ الكتب:}

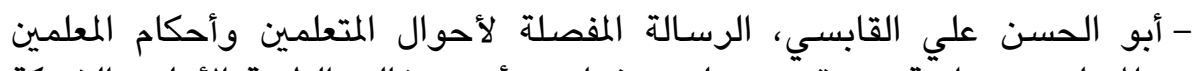

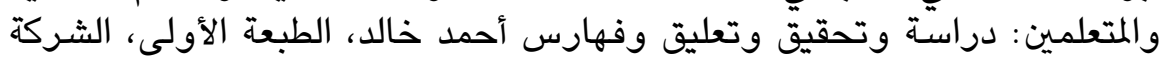

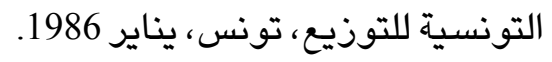

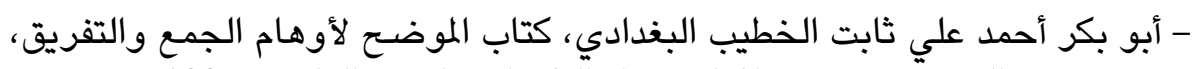

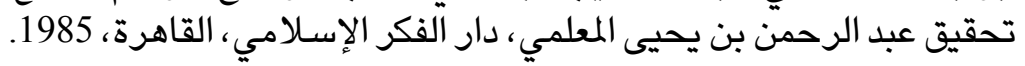

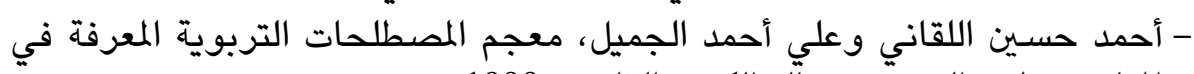

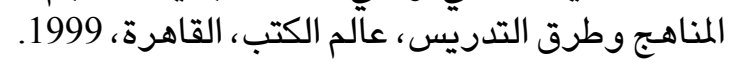

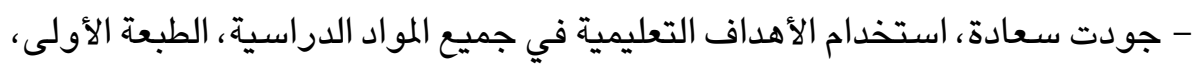

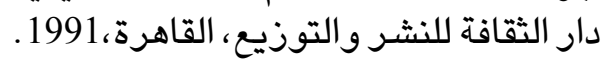

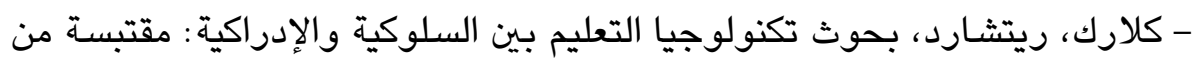

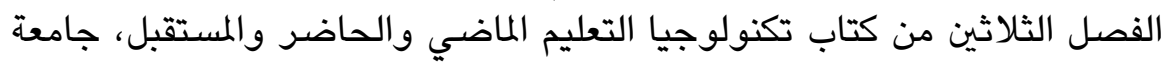

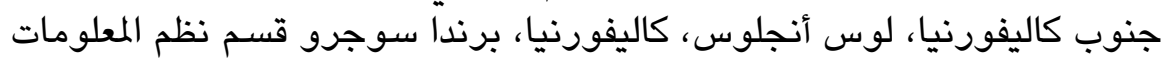

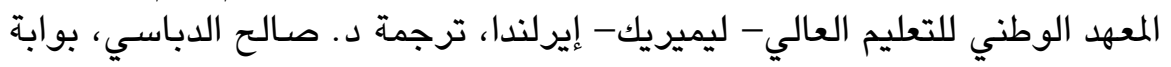

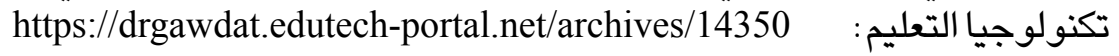

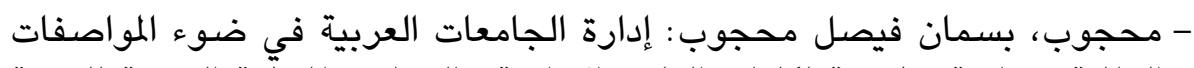

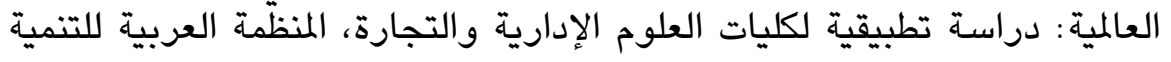

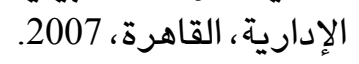

- مركز نون للتأليف والترجمة، التدريس، : طرائق واستراتيجيات، الطبعة الأولى، جمعية

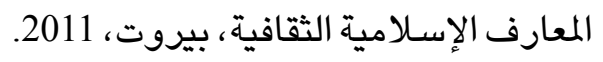

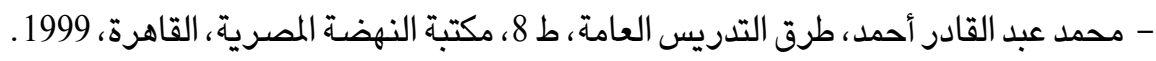

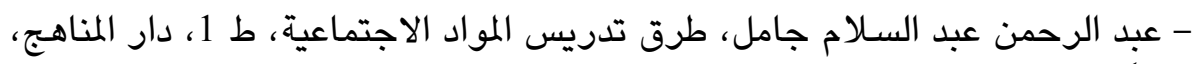

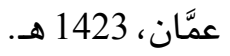

- د.عبد المجيد الزروقي، المنهجية أو البلاغة القانونية، التعبير عن التفكير، مجمع الأطرش للكتاب المختص ، تونس، المنس 2013.

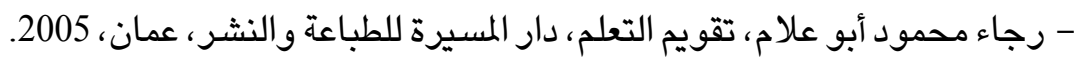

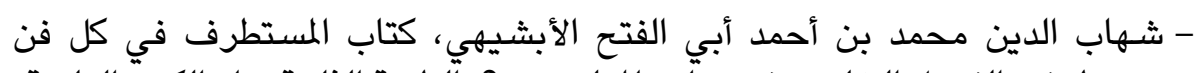
مستظرف، الفصل الخامس في نوآدر المعلمين ج 2، ألطبعة الثانية، دار الكتب المئ العلمية، 


$$
\text { بيروت، } 1986 .
$$

- رشيد التلواتي، نظريات التعلم، المدرسة السلوكية، منشور على الموقع التالي: https://www.new-educ.com/behaviorisme-et-de-sa-relation-a-leducation-dela-technologie

- سياسة التقييم والامتحانات لمعهد الدوحة للدراسات العليا ضمن مقدمة السياسة https://www.dohainstitute.edu.qa/Documents/AcademicPolicies/

policies_2018/DIAcademicPolicies_Assessment_AR_2018_10_15.pdf - عبد الفتاح خضر، أزمة البحث العلمي في العالم العربي، الناشر الإلكتروني كتب عربية، ، بدون تاريخ. - د. تركي إبراهيم محمد، البحث العلمي أسسه ومناهجه، ، دار الكتب القانونية، القاهرة، 2010

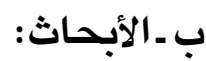

- - إقبال زين العابدين درنديري، نحو تقييم موجه للتعلم: أفضل الممارسات وأهم

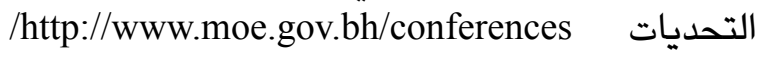

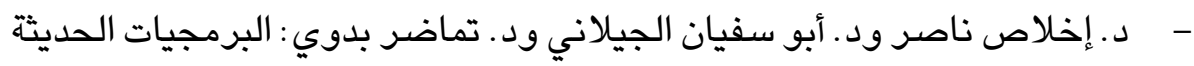

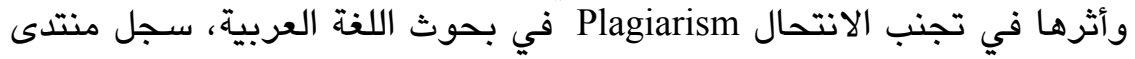

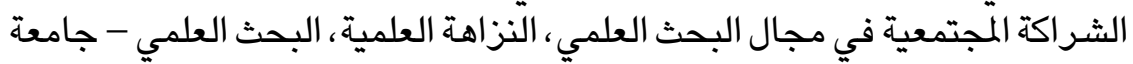

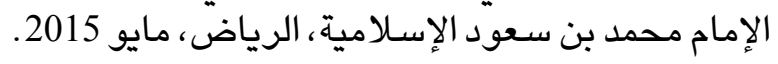

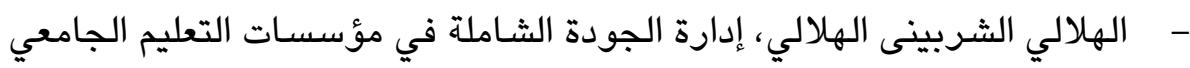

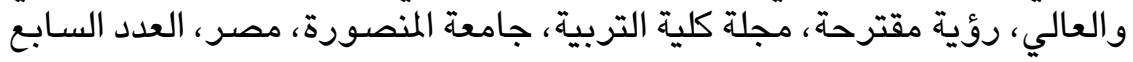

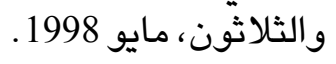

- - د. حسن علي دواح، أوجه الفساد في مجال البحث العلمي، الأنواع والأسباب

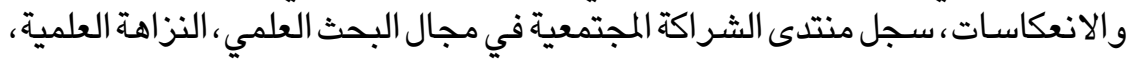

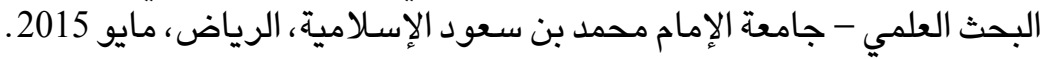

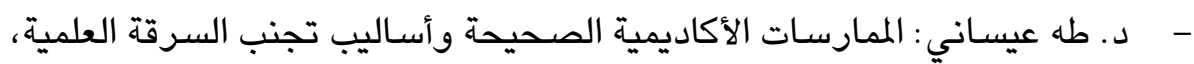
مقال ضمن أعمال ملتقى أدبيات البحث العلمي الجزائز 29 ديسمبر 2015.

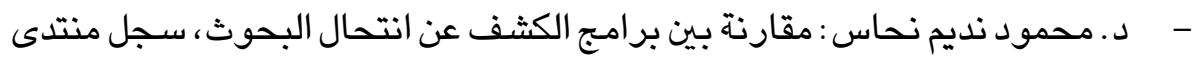

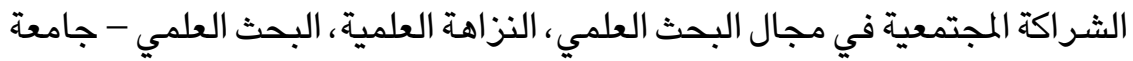

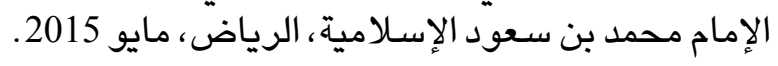

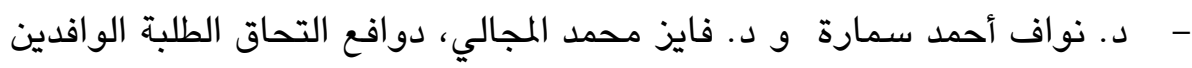


ببرامج الدراسات العليا في جامعة مؤتة، الأردن، مجلة العلوم التربوية والنفسية، المجلد 15، عدد 3، سبتمبر الدراست السيا في 2014.

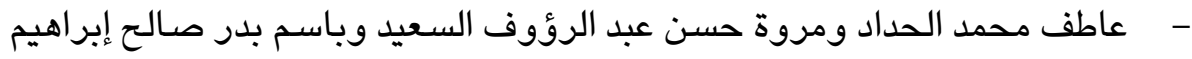
وهبة أبو سيف محمد منير، برمجيات كثف الانتحال العلمي كوسيلة لدعم الإبداع: دراسة تطبيقية على دراسات مؤتمر الاتحاد العربي للمكتبات والمعلومات 2016. https://www.researchgate.net/profile/Atef_Hadad/publication/328412627_ brmjyat_kshf_alanthal_allmy_kwsylt_ldm_alabda_drast_ttbyqyt_ly_drasat_ mwtmr_alm_2016/links/5bcc118892851cae21b6dd25/brmjyat-kshf-alanthalallmy-kwsylt-ldm-alabda-drast-ttbyqyt-ly-drasat-mwtmr-alm-2016

- د. عبد العزيز بن يوسف الزوكي، وجوه الفساد في مجال البحث العلمي الطبي:

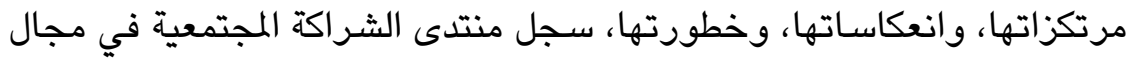

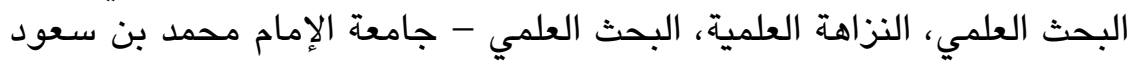
الإسلامية، مأيو 2015.

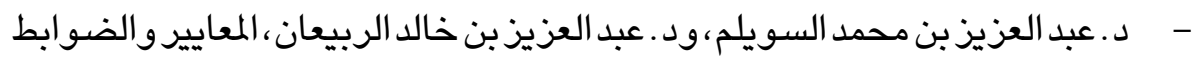

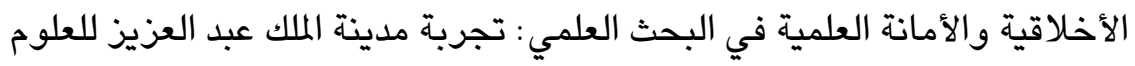

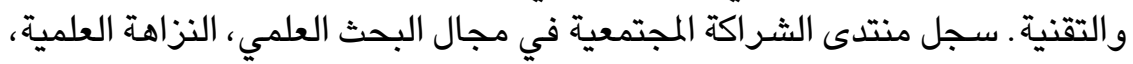

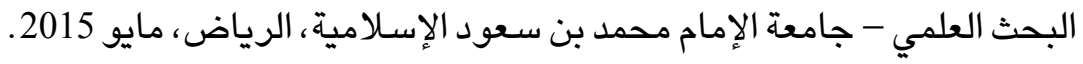

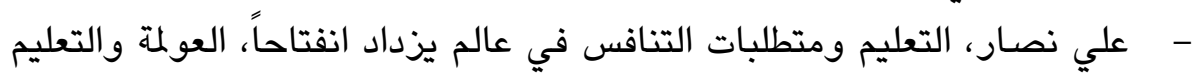

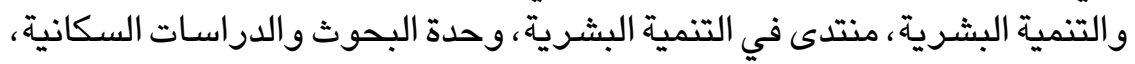

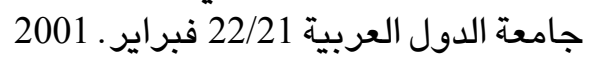

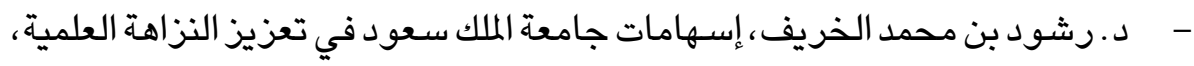

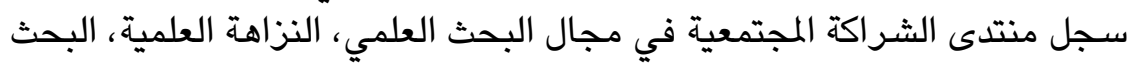

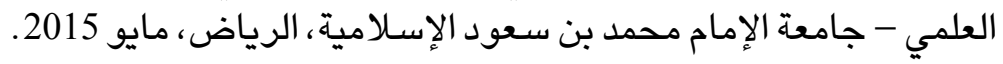

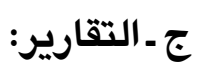
- - - تقرير الأمم المتحدة للتنمية البشرية 2003 http://hdr.undp.org/en/media/hdr03_complete.pdf.

$$
\text { - تقرير التنمية البشرية } 2015 \text { التنمية في كل عمل، لمحة عامة }
$$
https://www.un.org/ar/esa/hdr/pdf/hdr15.pdf. 


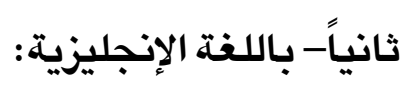

\section{A- Books:}

- Astin A., Assessment for excellence: the philosophy and practice of assessment and evaluation in higher education, New York, MacMillan Publishing Company, USA.

- Benjamin C.Storm, Genna Angello §Dorothy R.Buchli, Rebecca H.Koppel, Jeri L.Little and John F.Nestojko, Psychology of Learning and Motivation, Chapter Five - A Review of Retrieval-Induced Forgetting in the Contexts of Learning, Eyewitness Memory, Social Cognition, Autobiographical Memory, and Creative Cognition, science direct, Elsevier, Volume 62, 2015.

- Dale H. Biesterfield \&others, Total Quality management, Columbus, Ohio, upper sadder River, USA, 1999.

- Herbert spencer; Education, Intellectual, Moral, and Physical, New York, D. Appleton and company, USA, 1981.

- Jahm Radford \& Others, Quantity and Quality in higher Education, Athenaeum press, Cambridge, Massachuseth, USA, 1997.

- James R. Evens. \& William Lindsay, The Management and Control of Quality, South Western College Publishing, Tennessee, USA,1999.

- John Biggs and Catherine Tang, Teaching for quality learning at university, what the student does, 4th edition, (London, Society for Research into Higher Education and the Open University Press), UK, 2011.

- Juan Campechano Covarrubias, The Globalization Effects on the Quality of Higher Education, the Mexican case, national executive committee, national teachers trade union, Mexico, 2004.

- Padly-al-Patani, Introduction of Psychology, Behaviorism , May 2014,

- https://www.academia.edu/9426444/Behaviorism

- Peter Jackson \& David Asheton, Achieving Besom I so 9000, India, Kagan 1996.

- Schlesinger Rudolf B., Formation of Contracts: A Study of the Common Core of Legal Systems. (GEN. ED.). Dobbs Ferry, N. Y.: Oceana 
Publications, Inc., and London: Stevens \& Sons. 1968. Vol. I.

- Smits, Jan M., Contract Law: A Comparative Introduction, Chapter 1 (2014). Contract Law: A Comparative Introduction, Edward Elgar Publishing 2014. Available at SSRN: https://ssrn.com/abstract=2669692 or http://dx.doi.org/10.2139/ssrn.2669692

- Warren Piper D. Are professors professional? The Organization of University Examinations. London: Jessica Kingsley Publishers; Heywood J. Assessment in Higher Education. London: Jessica Kingsley Publishers, UK.

\section{B- . Articles:}

- Edwards A. \& Knight P., Assessing competence in higher education, London, Kogan.

- Elton L., Are UK degree standards going up, down or sideways? Studies in Higher Education, 23 (1).

- Irving A Taylor, A theory of creative trans-actualization: A systematic approach to creativity with implications for creative leadership (Creative Education Foundation, occasional paper, 1972, 8.

- J. Grezga, J. Schaner, The didactic model L dL (lemen durch lehren) as a way of preparing students for communication in a knowledge society, Journal of Education and teaching, 34 (3), (2008).

- Jim Greer, Gord McCalla, Julita Vassileva, Ralph Deters, Susan Bull, Lori Kettel: Lessons Learned in Deploying a Multi-Agent Learning Support System: The I-Help Experience, Proceedings of AI in Education AIED, 2001.

- Joachim Grzega Learning By Teaching The Didactic Model LdL in University Classes, http://www.joachim-grzega.de/ldl-engl.pdf

- Katherine Samuelowicz, John D. Bain: Identifying academics' orientations to assessment practice, Higher education, March 2002, Volume 43, Issue2.

- Landau, Joshua D.; Druen, Perri B., Arcuri, Jennifer A. (2002), Methods for Helping Students Avoid Plagiarism, Teaching of Psychology, 29 (2). Available at: http://www.tandfonline.com/doi/abs/10.1207/ S15328023TOP2902_06 
- L.L. Fuller, The Law in Quest of Itself, Chicago, Foundation Press, 1940.

- Martin A. O'Neill, Adrian Palmer: Importance performance analysis, useful tool for directing continuous quality improvement in higher education, Journal of Quality Assurance in Education, Volume: 12, Issue: 1, 2004.

- Mezey Naomi: Law as Culture, Yale Journal of Law \& the Humanities, Vol.13, Pp. 45-67, http://scholarship.law.georgetown.edu/facpub/317/,

- Michael R. Solomon, Sarah Drenan, Chester A. Insko: When is consensus information informative?, Journal of Personality, 1981, Volume 49, Issue 2. https://doi.org/10.1111/j.1467-6494.1981.tb00738.x.

- Montgomery D. Critical theory and practice in evaluation and assessment. In G. Gibbs (ed). Improving student learning through assessment and evaluation: Oxford Brookes University.

- Nina Becket \& Maureen, Analyzing Quality Audits in Higher Education, Brookes journal of Learning and Teaching, Volume 1, Issue 2,2005.

- Otto, C.M., Bradley, S.M. and Newby, D.E., Research integrity: we are all accountable, Heart Online First published on January 30, 2015.

- P. Black \& D. William, Inside the black box: Raising standards through classroom assessment, Phi Delta Kappan, 1980, 2.

- Palmer Vernon Valentine, From Lerotholi to Lando: Some Examples of Comparative Law Methodology, Global Jurist Frontiers, Vol. 4 [2004], Iss 2. https://www.uio.no/studier/emner/jus/jus/JUS5240/h12/ undervisningsmateriale/palmer.pdf.

- Phillip C. Wankat, Richard M. Felder, Karl A. Smith, Frank S. Oreovicz, The scholarship of Teaching and Learning in Engineering, Chapter 11 of M.T. Huber and S. Morreale, eds., Disciplinary Styles in the Scholarship of Teaching and Learning: Exploring Common Ground. AAHE/Carnegie Foundation for the Advancement of Teaching, Washington, 2002.

- Ramsden, P., Improving learning-New perspectives, London : Kogan Page., Poirier, D. Le rôle des universitaires dans le développement de la common law en français. Les Cahiers de droit, 42(3).

- https://doi.org/10.7202/043660ar 
- Richard John Stiggins, Student-involved assessment FOR learning (5th ed.). Upper Saddle River, NJ: Pearson Merrill Prentice Hall 2008.

- Richard John Stiggins, Assessment Crisis: The Absence of Assessment FOR Learning, Phi Delta Kappan, June 2002.

- Scouller K., The influence of assessment method on students' learning approaches, Higher Education, 35 (4).

- York M., Bridges P. \& WoolfH. Mark, Distributions and Marking practices in UK higher education, Active learning in higher education, 1 (1).

- Webster F., Pepper D. \& Jenkins A., Assessing the undergraduate dissertation: Assessment and evaluation in Higher education, 25 (1).

- Wolpe, P.R., Scientific Work in Changing Environment, Office Research Integrity News,22(1). 2013.

- Available from: http://ori.hhs.gov/images/ddblock/dec_vo122-no1.pd

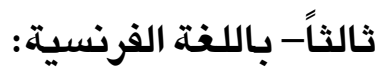

\section{A. Livres:}

- Aucoc Léon, Les études de législation comparée en France, Paris, Alphonse Picard,Editeur1889, Site Gallica, Bibliothèque numérique de la bibliothèque nationale. https://gallica. bnf. fr/ark:/12148/bpt6k840655.texteImage.

- Blais J.-G., Laurier M., Van der Maren J.-M., Gervais C., Lévesque M., Pelletier G. L'évaluation des apprentissages à l'Université de Montréal, et dans ses écoles affiliées, Montréal: Groupe de Recherche Interdisciplinaire en Pédagogie Universitaire.

- Brien, Robert, Science cognitive et formation، 3ème éd., Presses de 1'Université du Québec - et sur le Web: http://www. fse. ulaval.ca/fac/ten/ reveduc/html/voll/nol/scco.html.

- De Landsheere Gilbert, Évaluation continue et examens, Précis de docimologie, Bruxelles, Éditions Labor, London، Jessica Kingsley Publishers, UK.

- Joseph Joubert, De l'éducation, LXVIII (1866), Enseigner, c'est apprendre deux fois. 
- Philippe Meirieu, Apprendre... oui, mais comment, ESF Éditeur, Paris, 5 eme édition augmentée d'un guide méthodologique et d'un nouveau glossaire, février 1990.

- Thaller (Edmond-Eugène), Traité élémentaire de droit commercial, Paris, 1898, Rousseau.

B. Articles :

- Atias Christian, Savoirs et pouvoirs juridiques: des ombres portées, RRJ 2001-1.

- Atias Christian, La controverse et l'enseignement du droit, Annales d'histoire des Facultés de droit, nº 2, 1985.

- Blanquet Estelle Picholle Éric, Démarche d'investigation, pédagogie transmissive et principe d'autorité: l'exemple du système héliocentrique, Revue recherches en éducation, $\mathrm{N}^{\circ} 34$ - Novembre 2018.

- Bideaud Jacqueline, Constructivismes, développement cognitif et apprentissages numériques, Revue Perspectives revue trimestrielle d'éducation comparée, no 118, Vol. XxX1, no 2, juin 2001.

- Ducret Jean-Jacques, Constructivismes: usages et perspectives en éducation, Revue Perspectives revue trimestrielle d'éducation comparée, no 118, Vol. XXXI, no 2, juin 2001.

- Georges Felouzis, Les étudiants et la sélection universitaire, Revue française de pédagogie, volume 119, 1997. L'éducation préscolaire; doi : https://doi.org/10.3406/rfp.1997.1170

- $\quad$ https://www.persee.fr/doc/rfp_0556-7807_1997_num_119_1_1170.

- Hantrais Linda et Letablier Marie-Thérèse, La démarche comparative et les comparaisons franco-britanniques, Revue de l'IRES n_ 28 - automne 1998. http://www.ires.fr/publications-de-1-ires/item/download/1172_067 c7a515f1a0c12659cca56bd8ae641.

- Jaluzot Béatrice, Méthodologie du droit comparé bilan et prospective, Revue internationale de droit comparé, Vol. 57, $\mathrm{N}^{\circ} 1,2005$.

- Ost François, Questions méthodologiques: A propos de la recherche 
interdisciplinaire en droit, Revue Interdisciplinaire d'études juridiques, 1981.

- La controverse et l'enseignement du droit, Annales d'histoire des Facultés de droit, $\mathrm{n}^{\circ} 2,1985$.

- Noizet Georges. Caverni Jean-Paul, Psychologie de l'évaluation scolaire, Presses Universitaires de France, Paris.

- Perrenoud Philippe, L'université entre transmission de savoirs et développement de compétences, Texte d'une conférence au Congrès de l'enseignement universitaire et de l'innovation, Girona, Espagne, juin 2004.

- Sefton Green Ruth, compare and contrast monstre a deux têtes, revue internationale de droit comparé, , 2002, 1. https://www.persee.fr/doc/ ridc_0035-3337_2002_num_54_1_17849.

- Villey Michel, De la dialectique comme art de dialogue et sur ses relations au droit, Archives de philosophie de droit, 1982, 27.

\section{Reports :}

- Association canadienne des professeurs de droit, Bulletin (octobre 1986) (Document conjoint prépare par le Comité des doyens des Facultés de droit canadiennes et par l'exécutif de l'Association).

- Comité national d'évaluation, La formation des pharmaciens en France Volume 1 : les études. Paris : La Documentation française.

- Dejean J. : L'évaluation de l'enseignement dans les universités françaises. Rapport établi à la demande du Haut Conseil pour l'évaluation de l'école. Paris : Haut Conseil pour l'évaluation de l'école.

- Marc Romainville, L'évaluation des acquis des étudiants dans l'enseignement universitaire, Décembre 2002, Rapport établi à la demande du Haut Conseil de l'évaluation de l'école. Directeur de la publication : Christian Forestier, Secrétariat général, PARIS http://ifgu.auf.org/media/ document $/ \mathrm{L} \% \mathrm{C} 3 \% \mathrm{~A} 9$ valuation_des_acquis_des_\%C3\%A9tudiants_ dans_lenseignement_universitairer.pdf.

- Politique 2500-008 Évaluation des apprentissages, Université de 
Sherbrooke, l'évaluation dépasse le simple geste «sanctionnel»: elle est une composante indissociable de la dynamique même de l'apprentissage» https://www.usherbrooke.ca/accueil/fileadmin/sites/a-propos/documents/ direction/politiques/2500-008.pdf. 


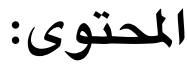

\begin{tabular}{|c|c|}
\hline الصفحة & 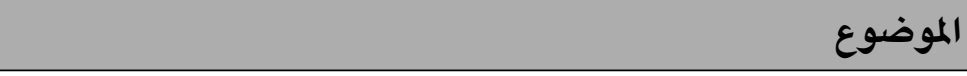 \\
\hline 361 & الملخص - ان \\
\hline 363 & 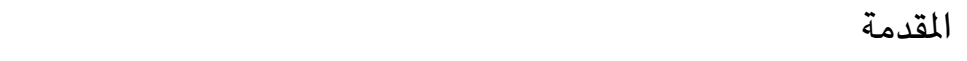 \\
\hline 366 & مبحث تمهيدي - تطوّر طرق التدريس \\
\hline 366 & المطلب الأول- طريقة التدريس الإلقائي أو الإخباري أو التلقيني \\
\hline 367 & المطلب الثاني - الطريقة السلوكية للتدريس \\
\hline 369 & المطلب الثالث- طريقة بناء القدرات \\
\hline 371 & في القانون الأول - توجيه التدريس إلى بناء قدرات طلبة الدراسـات العليا \\
\hline 371 & المطلب الأول- أسس توجيه التدريس إلى بناء القدرات \\
\hline 371 & الفرع الأول - التعلّم من خلال المسـائل القانونية \\
\hline 373 & الفرع الثاني - التعلّم التعاوني \\
\hline 374 & الفرع الثالث- التعلّم من خلال المشـاريع البحثية \\
\hline 375 & المليا في القأنون - آليات توجيه التدريس إلى بناء قدرات طلبة الدراسـات \\
\hline 376 & الفرع الأول- الآليات المتعلّقة بتنظيم التدريس الصفي \\
\hline 378 & استعمال مناهيج البحث الآليات المتعلّة بالتدريب على النزاهة العلمية وعلى \\
\hline 383 & الفرع الثالث- تدريب الطلاب على إنجاز مشـاريع بحثية وعرضـها \\
\hline 390 & 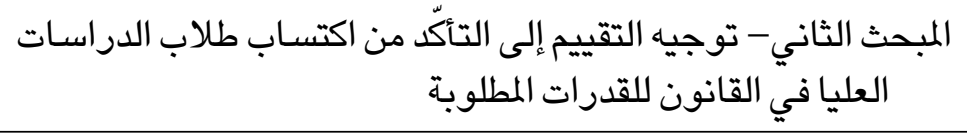 \\
\hline 391 & المطلب الأول- ضبط التقييم \\
\hline
\end{tabular}




\begin{tabular}{|c|c|}
\hline 391 & الفرع الأول- مفهوم التقييم \\
\hline 392 & الفرع الثاني - التصنيف الغائي للتقييم \\
\hline 393 & والتكليفات والمشاريع البحثيفة الموضوعي للتقييم : الاختبارات \\
\hline 394 & المطلب الثاني - توجيه التقييم نحو التقويم : التقييم من أجل التعلّم \\
\hline 394 & الفرع الأول - وضوح طرق التقييم وارتباطها بمخرجات التعلم \\
\hline 396 & البحثية الثاني - تطبيق التقييم من أجل التعلمّ على التكليفات والمشـاريع \\
\hline 399 & الفرع الثالث- تطبيق التقييم من أجل التعلّم على الاختبارات \\
\hline 405 & 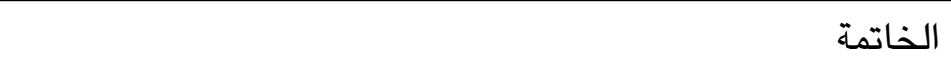 \\
\hline 407 & المراجع \\
\hline
\end{tabular}

